San Jose State University

SJSU ScholarWorks

Spring 2020

\title{
The Impact of the Language of Instruction on Second-Grade Latinx Emergent Bilinguals' Understanding of Place Value in Two Spanish-English Transitional Bilingual Classrooms: An Exploratory Study
}

Angela Maria Rengifo

San Jose State University

Follow this and additional works at: https://scholarworks.sjsu.edu/etd_dissertations

\section{Recommended Citation}

Rengifo, Angela Maria, "The Impact of the Language of Instruction on Second-Grade Latinx Emergent Bilinguals' Understanding of Place Value in Two Spanish-English Transitional Bilingual Classrooms: An Exploratory Study" (2020). Dissertations. 38. DOI: https://doi.org/10.31979/etd.9dbp-jd52

https://scholarworks.sjsu.edu/etd_dissertations/38

This Dissertation is brought to you for free and open access by the Master's Theses and Graduate Research at SJSU ScholarWorks. It has been accepted for inclusion in Dissertations by an authorized administrator of SJSU ScholarWorks. For more information, please contact scholarworks@sjsu.edu. 
The Impact of the Language of Instruction on Second-Grade Latinx Emergent Bilinguals' Understanding of Place Value in Two Spanish-English Transitional Bilingual Classrooms:

An Exploratory Study

\begin{abstract}
A Dissertation
Presented to

The Faculty of the Educational Doctoral Program in Educational Leadership

San José State University
\end{abstract}

\author{
In Partial Fulfillment \\ of the Requirements for the Degree
}

Doctor of Education

by

Angela Maria Rengifo

May 2020 
(C) 2020

Angela M. Rengifo

ALL RIGHTS RESERVED 
The Designated Dissertation Committee Approves the Dissertation Titled

The Impact of the Language of Instruction on Second-Grade Latinx Emergent Bilinguals' Understanding of Place Value in Two Spanish-English Transitional Bilingual Classrooms:

An Exploratory Study

by

Angela Maria Rengifo

APPROVED FOR THE DEPARTMENT OF EDUCATIONAL LEADERSHIP

SAN JOSÉ STATE UNIVERSITY

May 2020

Cheryl Roddick, Ph.D.

Department of Mathematics

Allison Briceño, Ed.D.

Department of Teacher Education

Delnaz Hosseini, Ed.D.

Teacher, Castro Valley Unified School District 


\begin{abstract}
The Impact of the Language of Instruction on Second-Grade Latinx Emergent Bilinguals' Understanding of Place Value in Two Spanish-English Transitional Bilingual Classrooms:

An Exploratory Study

by Angela Maria Rengifo

The relationship between mathematics learning and the language of instruction in bilingual settings has been observed and analyzed widely in educational research. As Latinx Emergent Bilingual students start developing their mathematics knowledge and skills in elementary classrooms, the role that language plays in the process has been studied as a key aspect of classroom practice. A convergent parallel mixed-method approach was used to examine fourteen second-grade Latinx Emergent Bilingual students' understanding of the concept of place value and whether this process was related to the language of instruction chosen in each of the two Spanish-English transitional bilingual classrooms. Findings from the quantitative analysis suggest that the language of instruction did not impact the students' understanding of place value, as measured by the increase in percentage points from pre- to post-test. In contrast, the qualitative analysis of the communication patterns used by participants in three smallgroup collaborative sessions revealed differences across the two classrooms.

Additionally, strategies and classroom practices reported by the two classroom teachers seemed to play an important role in the participants' understanding of place value. In the concluding chapter, the researcher presents implications and suggestions for future research.
\end{abstract}




\section{ACKNOWLEDGMENTS}

This accomplishment means a lot to me. I dedicate it to the loving memory of my mother, Ana Julia, who always encouraged me to persevere and overcome obstacles. I want to thank everyone who has contributed to this accomplishment in one way or another. First, Sarah and Julian, my daughter and son. Thank you for your supporting words when I was about to give up this dream. I also want to thank all Cohort 4 members for making me feel part of such a great and diverse group. I learned different skills from each of you throughout these three years. Special thanks to the faculty of the Ed. D program at San Jose State University. Every single one of you taught me something new, and most importantly, modeled for me high academic standards. I want to thank Dr. Emily Slusser for her support with statistics. I am also very grateful for the support and guidance of my Dissertation Committee members. Dr. Roddick, thank you for your patience, insights, and encouragement when I needed them most. Dr. Briceño and Dr. Hosseini. I highly appreciate your thoughtful suggestions throughout this process. Finally, I want to thank the two classroom teachers and the fourteen students who participated in the study. Their openness and commitment to the field inspired me. I wish to extend my heartfelt gratitude to every one of you! 


\section{TABLE OF CONTENTS}

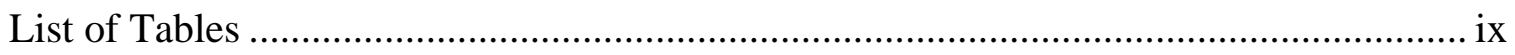

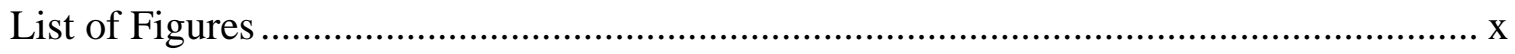

List of Abbreviations ……………….................................................................... xi

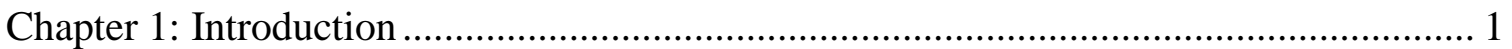

The Unresolved Issue in Education ..................................................................... 1

Statement of the Problem................................................................................ 3

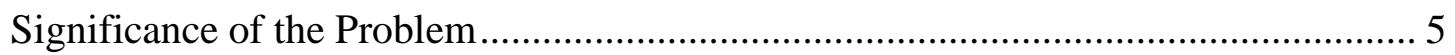

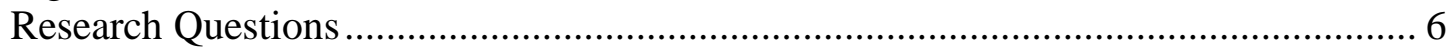

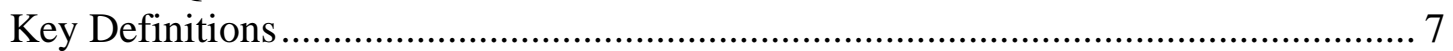

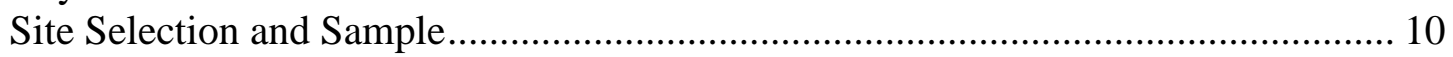

Scope and Limitations of the Study ........................................................................ 11

Assumptions, Background, and Role of the Researcher in the Study ......................... 11

Chapter Two: Review of the Literature ………………….............................................. 14

Importance of Mathematics in Elementary Education Settings................................... 17

Mathematical proficiency ............................................................................... 18

Teaching for understanding in mathematics .......................................................... 19

Learning place value with understanding ........................................................ 20

Language and Mathematics Cognition .................................................................. 24

Language and mathematics learning for bilingual students in SEI classrooms.... 26

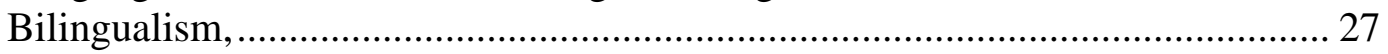

The language of instruction and mathematics learning ...................................... 30

Latinx-Emergent Bilinguals in the Mathematics Classrooms ..................................... 31

Research Gaps and Opportunities ........................................................................ 33

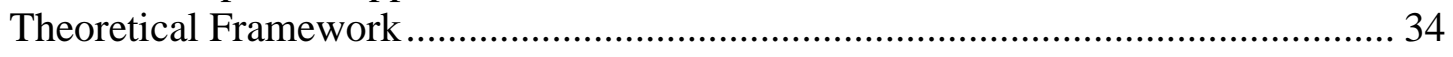

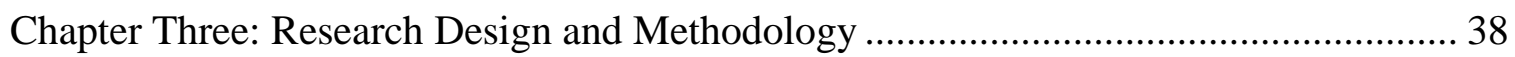

Research Methodology and Study Design .............................................................. 40

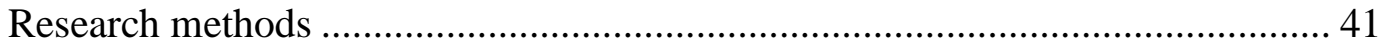

Study population

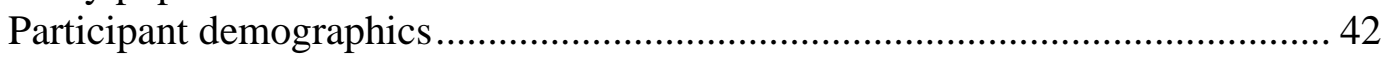

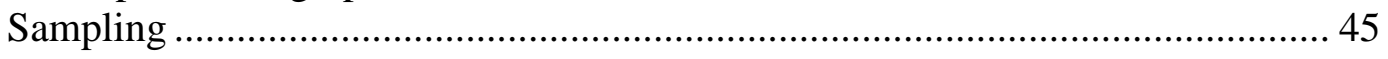

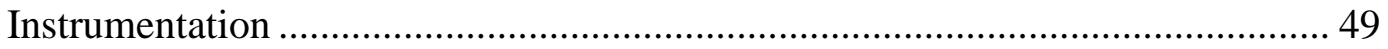

Pre- and post-test design ............................................................................ 49

Small-group collaborative sessions and place-value tasks ............................. 50

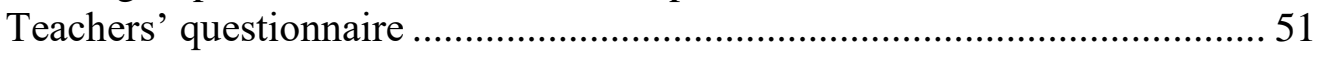

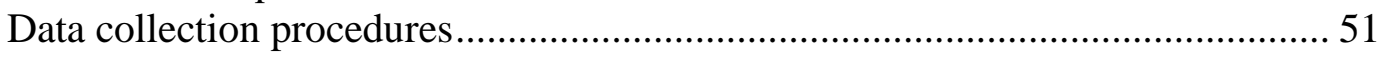

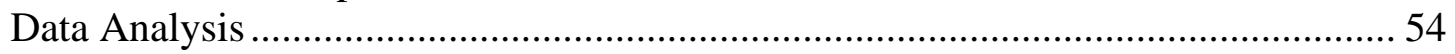

Quantitative data analysis ............................................................................ 54

Quantitative data analysis: The end of unit assessment (pre- and post-test) ........ 54 


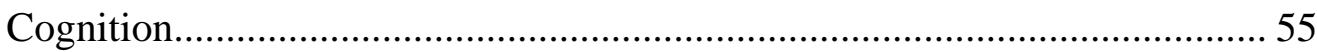

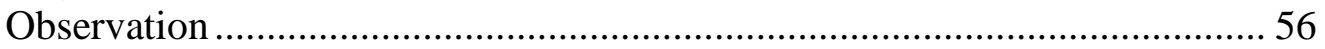

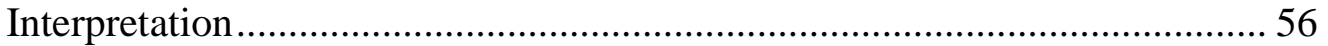

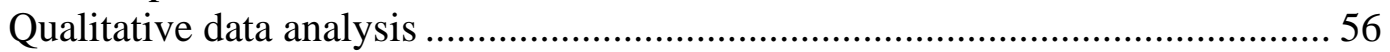

Qualitative data analysis: Small-group collaborative sessions ............................. 57

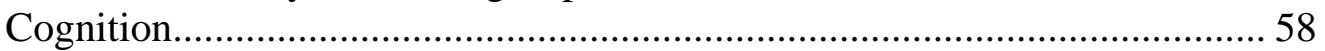

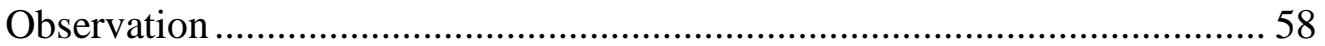

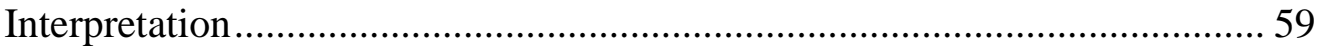

Qualitative data analysis: Teachers questionnaire ……………………................ 59

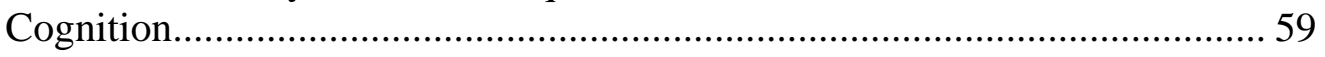

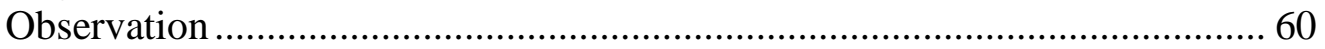

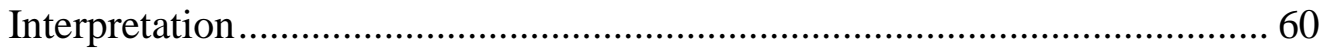

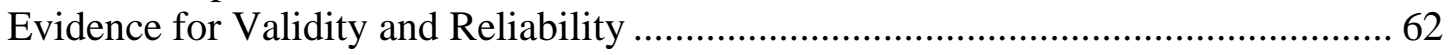

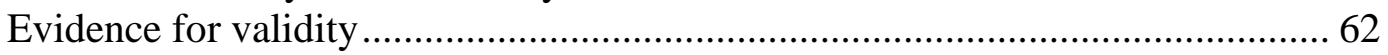

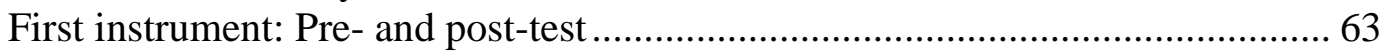

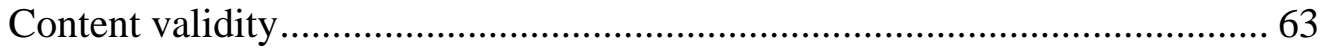

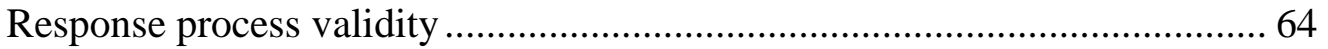

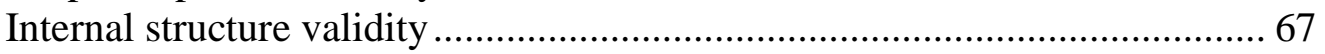

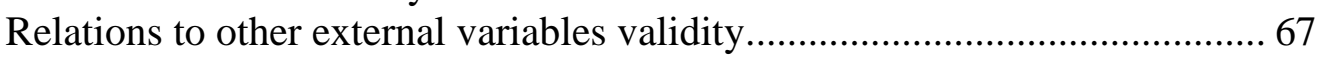

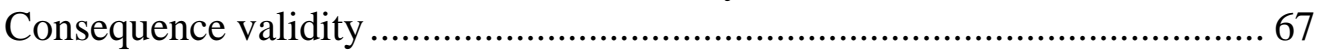

Second Instrument: Small-group collaborative sessions ........................................ 67

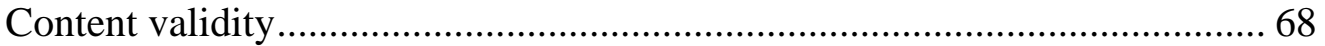

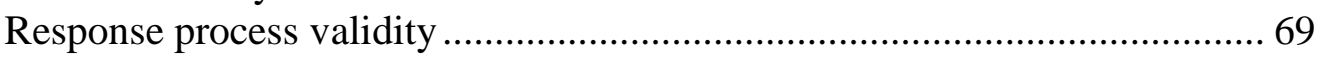

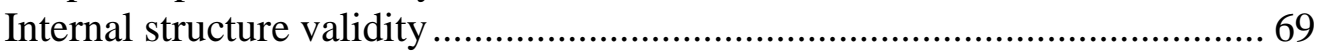

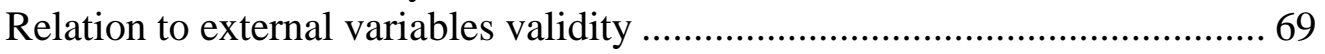

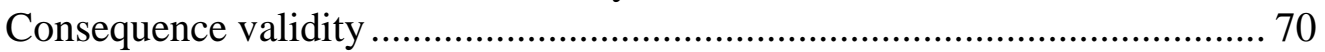

Third Instrument: Teachers' Questionnaire ...................................................... 70

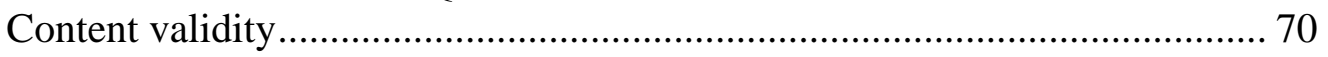

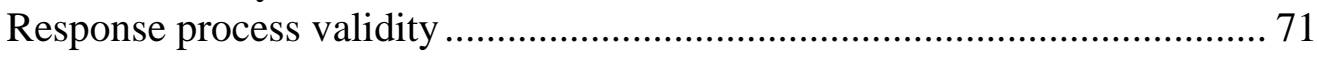

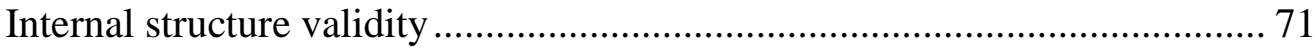

Relation to external variables................................................................... 72

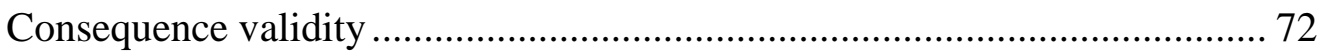

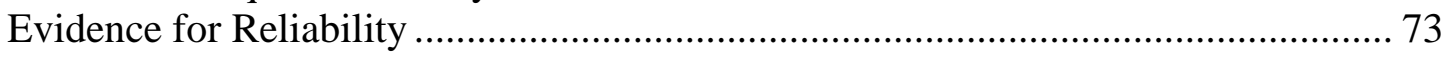

Reliability for the quantitative data instrument (pre- and post-test) ..................... 73

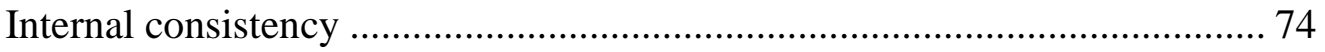

Alternate form, test-retest, and rater reliability .............................................. 74

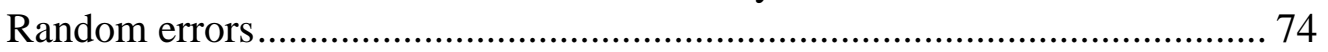

Reliability for the qualitative data instruments .............................................. 75

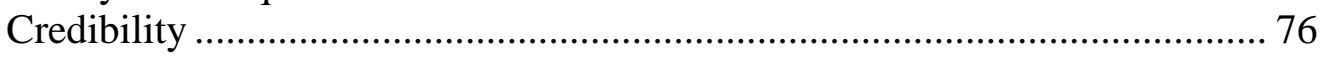

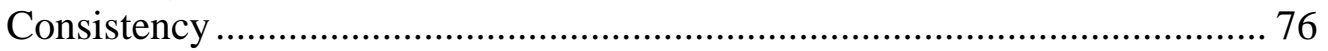

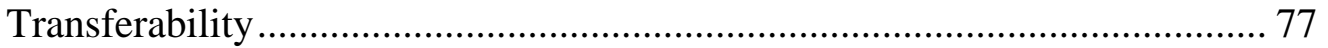

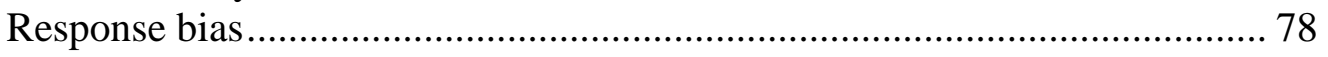

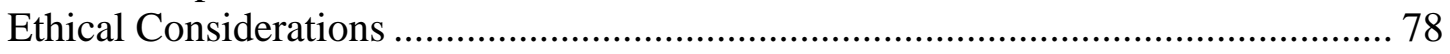




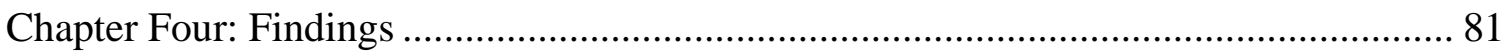

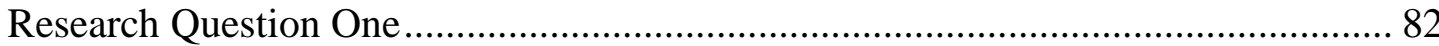

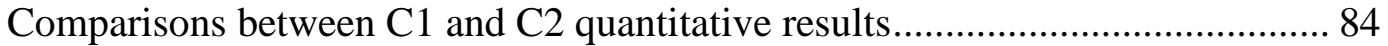

Research Question Two ................................................................................. 89

Thematic Analysis: Small-Group Collaborative Sessions .................................... 91

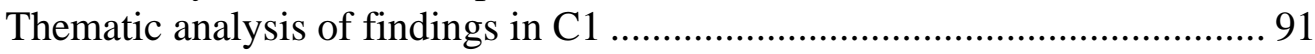

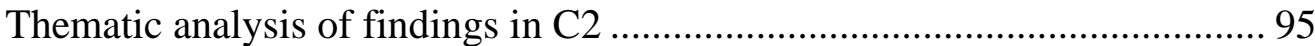

Discourse Analysis: Small Group Collaborative Sessions …………………….... 98

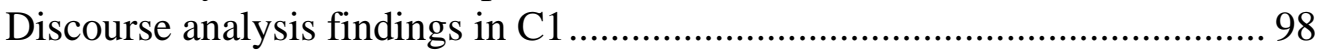

Discourse analysis findings in C2 .......................................................... 105

Comparative Analysis: Teachers' Questionnaire............................................... 113

Analysis of Quantitative and Qualitative Data ........................................................ 117

Chapter 5. Discussion and Conclusion ................................................................... 118

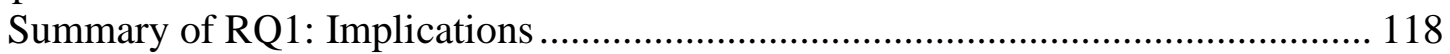

RQ1: Implications for teachers and school administrators ................................. 119

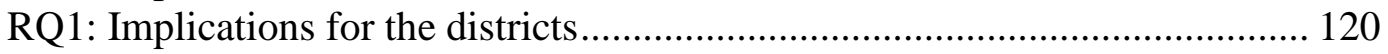

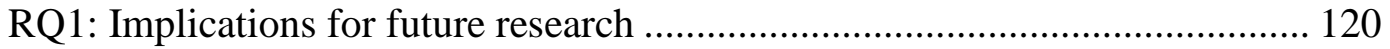

Summary of RQ2: Implications ..................................................................... 120

RQ2: Implications for teachers and school administrators .................................. 122

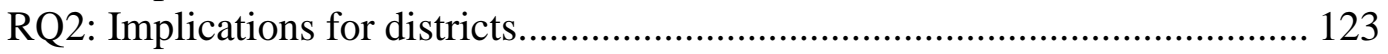

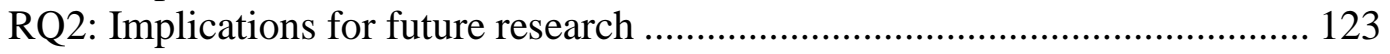

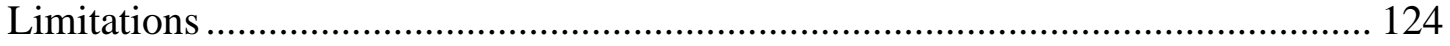

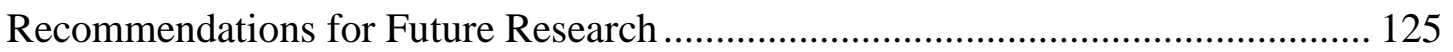

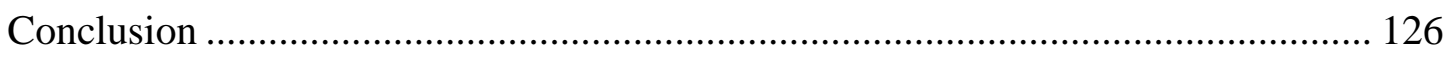

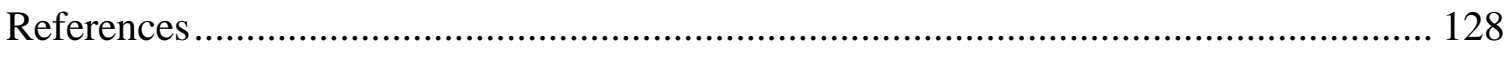

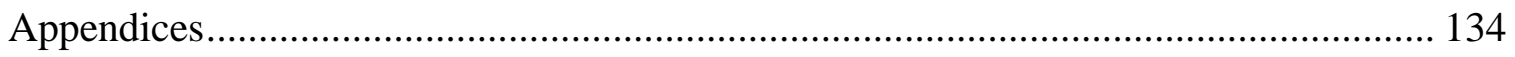

Appendix A: Email to the Assistant Superintendent …………………………….... 134

Appendix B: Recruitment Teacher Email .......................................................... 135

Appendix C: Teacher Consent Form ………………………………………..... 136

Appendix D: Teacher Questionnaire ………………………………………….... 139

Appendix E: Parent Consent Form (English) .......................................................... 141

Appendix F: Parent Consent Form (Spanish) ....................................................... 144

Appendix G: Assent Script for Getting Verbal Assent from Children (English) ..... 147

Appendix H: Assent Script for Getting Verbal Assent from Children (Spanish)..... 149

Appendix I: Pre-Post-Test (English)................................................................... 151

Appendix J: Pre-Post-Test (Spanish) ................................................................. 153

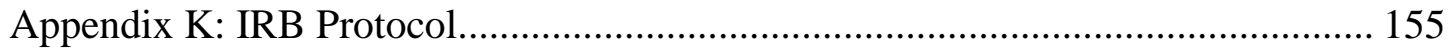

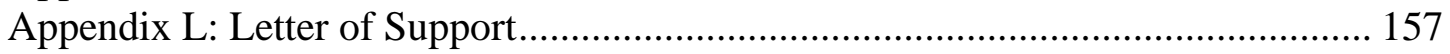

Appendix M: Verification of Translation Form..................................................... 158 


\section{LIST OF TABLES}

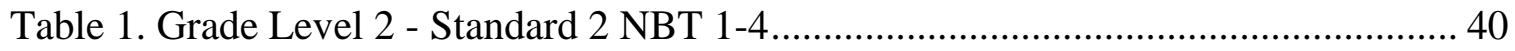

Table 2. School 1 and School 2 Demographics for the 2019-2020 School Year ............. 43

Table 3. Population Demographics: Entire C1 Classroom ............................................... 44

Table 4. Population Demographics: Entire C2 Classroom ............................................. 45

Table 5. Summary of C1 Participant Demographics ....................................................... 46

Table 6. Summary of C2 Participant Demographics .................................................... 48

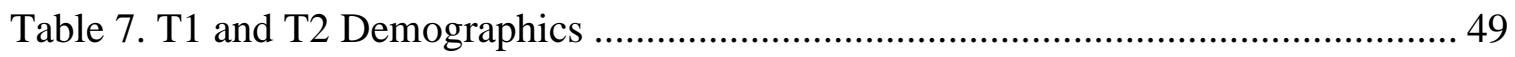

Table 8. C1 and C2 Parallel Data Collection ................................................................ 53

Table 9. Pre-and Post-Test-Items Scale and Standards Addressed by Each Item ............ 66

Table 10. C1 Pre- and Post-Test Results and Increase (or Decrease) in Scores ............... 84

Table 11. C2 Pre- and Post-Test Results and Increase (or Decrease) in Scores............... 85

Table 12. Small-Group Collaborative Work Schedules for C1 and C2......................... 89

Table 13. Summary of Mathematical Topics Challenging to Learn (C1, Session 1) ....... 92

Table 14. Academic Mathematical Language Related to Place Value (C1, Session 2) ... 94

Table 15. Summary of Mathematical Topics Challenging to Learn (C2, Session 1) ....... 96

Table 16. Academic Mathematical Language Related to Place Value (C2, Session 2) ... 98

Table 17. Academic Mathematical Language Related to Place Value (C1, Session 3) . 104

Table 18. Academic Mathematical Language Related to Place Value (C2, Session 3) . 112

Table 19. Summary of Similarities in Teacher Responses to the Questionnaire............ 114

Table 20. Summary of Differences in Teachers Responses to the Questionnaire .......... 116 


\section{LIST OF FIGURES}

Figure 1. Convergent Parallel Mixed-Method (CPMM) approach................................ 41

Figure 2. Instrumentation: place value end-of-unit assessment .................................. 55

Figure 3. Instrumentation: Small-group collaborative sessions.................................. 57

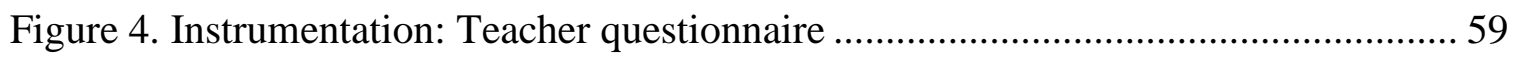

Figure 5. C1 and C2 pre- and post-test mean scores with error bars ........................... 87

Figure 6. Graphic models used by C1 participants in Session 2 ............................... 103

Figure 7. Graphic models used by C2 participants in Session 3 .............................. 110

Figure 8. C2 participants use of manipulatives to support place value learning ........... 111 


\section{LIST OF ABBREVIATIONS}

$\begin{array}{ll}\text { AERA } & \text { American Educational Research Association } \\ \text { APA } & \text { American Psychological Association } \\ \text { BICS } & \text { Basic Interpersonal Communicative Skills } \\ \text { C1 } & \text { Classroom One } \\ \text { C2 } & \text { Classroom Two } \\ \text { CAASPP } & \text { California Assessment of Student Performance and Progress } \\ \text { CCM } & \text { Constant Comparative Method } \\ \text { CA CCSS-M } & \text { California Common Core State Standards for Mathematics } \\ \text { CALP } & \text { Cognitive Academic Language Proficiency } \\ \text { CDE } & \text { California Department of Education } \\ \text { CPMM } & \text { Convergent Parallel Mixed Method } \\ \text { D-ELD } & \text { Designated English Language Development } \\ \text { EBs } & \text { Emergent Bilinguals } \\ \text { ELD } & \text { English Language Development } \\ \text { ELs } & \text { English Learners } \\ \text { ELP } & \text { English Language Proficiency } \\ \text { I-ELD } & \text { Integrated English Language Development } \\ \text { NBT } & \text { Number and Operations in Base Ten } \\ \text { NCME } & \text { National Council on Measurement in Education } \\ \text { NRC } & \text { National Research Council } \\ \text { PCF } & \text { Parent Consent Form } \\ \text { SEI } & \text { Structured English Immersion program } \\ \text { SES } & \text { Socio-economic status } \\ \text { T1 } & \text { Teacher One } \\ \text { T2 } & \text { Teacher Two }\end{array}$




\section{Chapter 1: Introduction}

\section{The Unresolved Issue in Education}

In the state of California, the California Assessment of Student Performance and Progress (CAASPP) has been used as the instrument to measure the progress that students make toward meeting the state language and mathematics standards. Despite considerable progress over the past two decades, the achievement gap between English Learners (ELs) and their English proficient peers in mathematics and science continues to be a matter of concern for researchers, policymakers, and educators. Although several factors, including the out-of-school factors, may cause this achievement gap (Berliner, 2009), the language proficiency levels have been seen as a strong barrier for ELs to understand essential mathematics content (Abedi \& Lord, 2001; Bernardo \& Calleja, 2005).

There is a common assumption among educators that young bilingual mathematics learners in Structured English Immersion (SEI) classrooms do not struggle to learn mathematics. This assumption suggests that since the mathematics content is sufficiently language-independent, then teaching and learning mathematics does not require intensive use of language as other content areas do (Van Rinsveld, Schiltz, Brunner, Landerl, \& Ugen, 2016). Nonetheless, understanding mathematical concepts poses major challenges for young bilingual mathematics learners (Moschkovich, 2007). Also, the California Common Core State Standards for Mathematics (CA CCSS-M) include a focus on language, particularly Mathematical Practice 3: "Construct viable arguments and critique the reasoning of others" (CDE, 2013-2014, p. 10). It implies that mindful and intentional 
use of language is needed to understand, express understanding, and construct reasonable explanations of mathematical ideas. The relationship between mathematics cognition and language is presented in more detail in Chapter Two.

When Proposition 58 was approved by voters with a 73.5\% majority on Nov. 8, 2016, California public schools obtained more control over dual language immersion and transitional bilingual programs. This proposition repeals the English-only requirement of Proposition 227 (passed in 1998) that required all ELs to be taught in SEI classrooms unless parents signed waivers to enroll their children in bilingual or dual immersion programs. Under Proposition 58, students can learn English through multiple programs outside SEI classroom settings (Hopkinson, 2017).

Within this context, deciding what language to use for teaching mathematics in Spanish-English bilingual settings is a matter of concern for teachers and school administrators. Studying the effects of classroom language of instruction on early learning and linguistic proficiency is very challenging since many factors play significant roles in this process (Ackerman \& Tazi, 2015).

Deciding what language to use to teach mathematics is very critical when this decision affects students in Low Socio-Economic Status (Low-SES) communities. For instance, in the schools selected for this study, around $76 \%$ of the students enrolled for the 2019-2020 school year qualified for free or reduced-price school meal, as stated on the district's webpage (the median for each of the two schools is $82 \%$ for School 1 and $72 \%$ for School 2). Although the focus of the study is not SES, it is important to note that Low-SES is one of the characteristics of the two schools selected. 
The decision over the language of instruction to teach mathematics is even more crucial when the majority of the students in schools with bilingual programs are Latino or Latina English Learners (ELs). In this study, the term EBs refers to children who speak a language other than English at home, Spanish in this particular case, and are learning English and grade-level academic content. Garcia, Kleifgen, and Falchi (2008) recommended this term as an option for the term English Learners (ELs), which lacks to recognize the resources that these students already have and bring into the classrooms. Also note that in this study, the term Latinx precedes the term EBs. Latinx is a genderneutral, nonbinary alternative to Latino or Latina and describes the EBs' ethnicity.

The instructional language for teaching mathematics in Spanish-English bilingual settings within a district is a critical part of the multiple aspects of classroom practice that affect Latinx EBs' understanding of mathematical concepts and skills development. It might prevent them from getting a complete understanding of the concepts and higher performance in state standardized tests for mathematics. Consequently, it was necessary to examine this problem and determine whether and how the language of instruction had an impact on Latinx EBs' understanding of mathematical concepts such as place value and their patterns for communication around this mathematical concept during smallgroup collaborative work.

\section{Statement of the Problem}

Third- and fourth-grade students in two schools with Spanish-English bilingual programs in a district were underperforming in mathematical state standardized tests, as evidenced by the 2018-2019 CAASPP test scores for mathematics (CAASPP, 2019). Half 
of the students in third- and fourth-grade in these two schools were Latinx EBs enrolled in the bilingual program strands within the schools. This situation justified the need for examining if the language of instruction, among other important aspects of the classroom practice, would impact second-grade Latinx EBs' understanding of the mathematical concept of place value and their subsequent mathematical performance. More explicitly, the need called for focusing on how second-grade Latinx EBs are learning mathematics and how to support them in this learning process.

Several research studies have pointed out the importance for students to understand the mathematical concepts related to place value due to its widespread application and connection to other mathematical concepts and skills such as basic operations with multidigit numbers (Carpenter \& Lehrer, 1999; Fuson \& Briars, 1990; Major, 2012; Varelas \& Becker, 1997). Supported by this research, the researcher focused this study on a specific second-grade CA CCSS-M, Number, and Operation in Base Ten (CDE, 2013-2014). The notation to refer to this focal standard in second-grade is 2.NBT. The CA CCSS-M 2.NBT has two cluster-headings: 1) Understand place value, 2) Use place value understanding and properties of operations to add and subtract. This study only focused on the first cluster-heading: Understand place value. Under this cluster-heading, four standards are considered relevant knowledge necessary for developing an understanding of the concept of place value in this grade level. As noted, the second cluster-heading refers to the use of place value understanding, not to the process of developing this understanding. Third- and fourth-grade Number and Operation in Base Ten (3.NBT and 4.NBT) also called for the use of the understanding of place value in mathematics basic 
operations. CA CCSS-M 2.NBT standards 1-4 represent the last opportunity for students to understand the concept of place value. After this moment on, it is expected that students already understood and are ready to apply this concept. This information became an important reason for the researcher to focus this study on the participants' understanding of the concept of place value.

\section{Significance of the Problem}

The purpose of this study was to determine whether and how the language of instruction impacted second-grade Latinx EBs' understanding of key knowledge related to place value. It also examined if the impact (if any) was extensive to the participants' patterns of communication around this mathematical concept in two Spanish-English bilingual classrooms. According to the $\operatorname{CDE}$ (2018), a total of 1,195,988 students in California public schools (19.3\%) are ELs, with the majority of them enrolled in elementary schools (70.2\%). Furthermore, in California public schools, $41.8 \%$ of students speak a language other than English in their homes (CDE, 2018). As it is stated in the same document, $93 \%$ of ELs speak one of the top ten languages spoken in the state of California. Spanish is the top language—other than English—in the list, with 81.56\% (CDE, 2018).

To support ELs, the CDE gets committed to assisting districts and schools to focus on two main goals: (1) to ensure that all ELs become English proficient and (2) to ensure their achievement of rigorous academic content standards. English language development (ELD) standards have been designed to support ELs in becoming English proficient students. Schools must provide instructional opportunities for students to develop and 
acquire English through both Integrated and Designated English Language Development (I-ELD and D-ELD) instruction in every classroom serving ELs to improve their academic achievement. ELD standards (I-ELD and D-ELD) are equally rigorous and specific as the standards for English Language Arts. However, in two schools with Spanish-English bilingual programs in a school district, the CAASPP (2019) test results in mathematics showed an achievement gap between Latinx EBs and their counter racial, social, and linguistic peers.

Although providing Latinx EBs with ELD instruction contributes to supporting them in becoming proficient in English, it is not sufficient to support them in understanding essential mathematical concepts that lead to mathematics proficiency on assessments in English. Zavala (2012) explored the role that language and race play in learning mathematics by the time Latinx EBs are in high school. The researcher of the current study claims that it is necessary to look backward and, as researchers, learn more about the everyday mathematics learning process for Latinx EBs in the early elementary classrooms.

\section{Research Questions}

This study was aimed to explore the following research questions:

RQ1: How does the language of instruction impact second-grade Latinx EBs' understanding of the mathematical concept of place value (CA CCSS-M 2.NBT 1-4) in two Spanish-English transitional bilingual classrooms? 
RQ2: How does the language of instruction impact second-grade Latinx EBs' communication patterns in small-group collaborative work around place-value tasks in two Spanish-English transitional bilingual classrooms?

A pre- and post-test was given to the participants in the beginning and at the end of the place-value unit. These test scores constituted the data to explore RQ1. In approaching RQ2, audio recordings of the students' linguistic interactions provided the data corpus to examine the impact (if any) of the language of instruction on participants' communication patterns when solving collaborative mathematical tasks around place value. Besides, the two classroom teachers responded to a questionnaire about their teaching experiences, preferred strategies, and preferred language to teach and support students' learning of mathematics in their classrooms. The questionnaire was designed based on a pilot interview given to bilingual teachers at a different site in the previous year. The questions refer to important aspects of classroom environments that support or hinder mathematics learning, as well as elements that reflect teachers' beliefs and preferred practices to teach mathematics.

\section{Key Definitions}

This study uses the following terms:

Academic Language Proficiency: Academic Language Proficiency refers to the ability to understand and express concepts and ideas that relate to students' success in school. It takes three to five years for children to learn academic language that allows them to interact with native speakers at high proficiency levels (MacSwan \& Pray, 2005). Researchers have also found that academic language proficiency in the students' native 
language is highly related to mathematics achievement (Borgioli, 2008; Riches \& Genesee, 2006). The concept of academic language proficiency first proposed by Cummins (1976) has been challenged by recent research. Although this conceptual disagreement is not the focus of the current study, it is briefly discussed in Chapter Two, when explaining the language and mathematics cognition relationship and mathematics and bilingualism (see Language and Mathematics Cognition in Chapter Two).

Conceptual understanding: This is the first of the five components that define mathematics proficiency. It refers to the ability to comprehend mathematical concepts, operations, and relations to support learners' capability of drawing on this knowledge and applying it to different situations and problems (NCR, 2001a).

Curriculum: Refers to the knowledge and skills in subject areas or cognitive disciplines that teachers teach, and students learn. It includes the scope of content and a sequence for learning and relates the specific methods to teach and learn that lead to the learning goals (NRC, 2001b).

English Learners (ELs): As suggested by the CDE (2018), an English Learner is a student whose primary language is a language other than English. ELs are required to learn academic content and English knowledge simultaneously in the classroom.

Emergent Bilingual students (EBs): In the context of this study, this term refers to students who speak one or more languages other than English and are learning English and core content areas in school at the same time (ELs). More information on the use of this term is provided in Chapter Two. 
Instruction: According to the National Research Council, instruction refers to methods of teaching and learning activities used to help students master the content and skills specified by a curriculum. It includes activities for both teachers and learners. (NRC, 2001b).

Latinx: Although still controversial, this term is used to describe a person of Latin American origin or descent. It is a gender-neutral, nonbinary alternative to Latino or Latina. It refers to the ethnic spectrum of participants and family's origin, either from Central or South America, also called Latin America.

Mathematical proficiency: The National Research Council (NRC, 2001a, p.116) defines mathematical proficiency, through five integrative components: (1) conceptual understanding, (2) procedural fluency, (3) strategic competence, (4) adaptive reasoning, and (5) productive disposition (see Chapter Two: Mathematical proficiency).

Place Value (Number Base-Ten NBT): Place value refers to the value of a digit. Such value depends on the digit's place in a multidigit number. Understanding place value demands from the learner knowledge on the English system of number words and the systems of a written multidigit symbol (Fuson, 1990). Major (2012) points out that students' understanding of place value is a strong predictor for later mathematics success.

Structured English Immersion (SEI) program: The SEI program is defined by the CDE (2018) as a language acquisition program designed for ELs in which nearly all classroom instruction is provided in English. Nonetheless, the program is accompanied by a curriculum and a presentation carefully designed for students who are learning 
English. Students enrolled in this program are offered ELD and access to grade-level academic subject-matter content.

Title I Designation: Schools must have a child poverty rate of at least $40 \%$ to implement a school-wide Title I program. Title I eligibility is usually calculated based on the number of students who sign up for free and reduced-price school meals.

Transitional Bilingual Program: Refers to a classroom setting for English Language Learners (ELs) in which literacy and academic instruction are provided to students in their native language (CDE, 2018). All the students in the program are native speakers of a language other than English and are learning the specific content area and English simultaneously. The goal for these programs is to support the transition to English, not the learning of the first language.

\section{Site Selection and Sample}

The main participants of this study were fourteen second-grade Latinx EBs whose ages range from 7 to 8 years old, enrolled in two second-grade bilingual classrooms in two different schools in a school district in the state of California. The two respective classroom teachers are the secondary participants of the study. The selection of the two sites was based on the following criteria:

- Both schools have bilingual programs within the schools.

- Both schools are urban elementary schools with classroom demographics made up of over $80 \%$ Latinx EB student population.

- Both schools use the materials provided by the district-adopted-curriculum for teaching and learning mathematics. 
- Both schools are located in Low-SES neighborhood schools, as indicated by the percentage of free and reduced-price school lunch (Title I schools).

\section{Scope and Limitations of the Study}

The study's findings are expected to inform teachers in decision making on the language of instruction to support Latinx EBs' understanding of essential mathematical concepts. The researcher explored the impact of the language of instruction on secondgrade Latinx EBs' understanding of one specific mathematics standard (2.NBT. 1-4) in two different bilingual schools. In the study, the benefits of teaching mathematics standards in either Spanish or English to support Latinx EBs development of mathematics proficiency are highlighted. This study also contributes to existing research on the importance of linguistic and academic knowledge (or academic language) development to support higher levels of mathematics cognition. More research studies on mathematics instructional language across grade levels in Spanish-English bilingual elementary settings, with larger samples, might be needed to enlighten policy recommendations and decisions in this regard. The researcher did not examine whole-class mathematics instruction details, nor did she witness the teachers' strategies in action. Neither teachers nor students were interviewed for this study.

\section{Assumptions, Background, and Role of the Researcher in the Study}

The researcher in this study challenged the common assumption that because mathematics is a language-independent content area, it does not require high levels of language from students to understand key concepts. The researcher also questioned whether Latinx EBs in a Spanish-English bilingual setting should be taught mathematics 
in their native language or in their other language to ensure higher levels of conceptual understanding and build a stronger foundation for mathematics proficiency.

Having learned mathematics in my native language and being Latinx made me more empathetic with Latinx EBs in elementary grades when they are requested to learn mathematics content in their second language, with minimal support. Furthermore, they are expected to show mathematical fluency before constructing their conceptual understanding of vital concepts such as place value. Mathematics instruction in students' native language, at least in primary grades (K-2), might support higher levels of mathematics understanding. The advocacy for EBs, more specifically, Latinx Spanish speakers' rights to a high quality of education, is supported by a dense body of research. Several researchers have found that traditionally, in America's Educational System, students from different socio-economic backgrounds continue to receive types of knowledge that differ in quality (Anyon, 1981; Borgioli, 2008; Bowles \& Gintis 1976; Major, 2012). Latinx EBs need quality mathematics instruction to support their learning of mathematics. If the language of instruction turned to be a barrier for Latinx EBs to reach higher levels of understanding, then schools would need to implement changes and refine strategies to teach mathematics and link them to the language of instruction.

Current research points out the need for mathematical reflection and communication skills to develop a deeper understanding of mathematical concepts (Greeno \& Boaler, 2000; Moschkovich, 2011). To reflect on what one is learning, one might need to be proficient in the language of instruction and a safe environment where one's language is validated. As an ELD coach, I support teachers in helping Latinx EBs become proficient 
in English, but I am aware that we cannot do so by risking their mathematical proficiency.

This contextual information has motivated me to conduct this study. I, the researcher, aimed to examine whether and how the language of instruction (either Spanish or English) impact second-grade Latinx-EBs' understanding of place value as measured by participants' mathematics performance in a pre- and post-test and their communication patterns in small-group collaborative work with tasks around the concept of place value, in two Spanish-English transitional bilingual classrooms in a district in the state of California. 


\section{Chapter Two: Review of the Literature}

As previously stated, third- and fourth-grade students in two schools with transitional Spanish-English bilingual programs in a district in California underperformed in mathematical state standardized tests, as evidenced by the 2017-2018 CAASPP test scores for mathematics (CAASPP, 2019). There is a compelling need to focus on how second-grade students are learning mathematics. If additionally, $50 \%$ of the students enrolled in third- and fourth-grade were also enrolled in the transitional bilingual strands within the schools, and were Latinx EBs, the reasons for examining how second-grade Latinx EBs are learning mathematics makes sense. The need to focus on one standard or mathematical concept that has been considered difficult for mathematics learners, such as place value, adds to the equation. Place value is one of the most challenging mathematical concepts for young learners, as reported by research (Carpenter \& Lehrer, 1999; Fuson \& Beckman, 2012; Fuson \& Briars, 1990; Fuson \& Li, 2009; Major, 2012; Varelas \& Becker,1997).

The purpose of this study was to examine the impact of the language of instruction, either Spanish or English, on second-grade Latinx EBs' understanding of the concept of place value, as stated in the CA CCSS-M 2.NBT. 1-4, in two Spanish-English transitional bilingual classrooms in a school district in California. A transitional bilingual program differs from a two-way bilingual immersion program in that the first one provides instruction to students in their native language. At the same time, students learn English and progress towards becoming English-proficient through ELD instruction. In contrast, the two-way bilingual immersion program provides language learning and academic 
instruction for native speakers of both English and another language with different percentages for each language.

The term Latinx was used in this study because it is a more inclusive term for Latino and Latina students. The term Emergent Bilingual students or Emergent Bilinguals (EBs) used in this study was suggested by Garcia et al. (2008). It defines the learners based on their strengths in opposition to the deficit viewpoint of the term ELs. These authors highlight the inequities derived from policies that ignore research findings regarding the importance of building on children's native language as they learn English and become English proficient. The fact that the term ELs continues to be used in official documents, such as the CDE, suggests a discrepancy between research findings and educational policy regarding equity in education. Thus, the researcher in the current study intentionally used the term EBs to refer to ELs, specifically students whose home language is Spanish and who are learning English and other content areas in school.

From the sociocultural perspective, the researcher explored one important aspect of classroom practice that contributes to students' understanding of mathematical concepts: the language of instruction. However, three other aspects of classroom practice were interwoven closely with the language of instruction: (1) formative assessments, (2) smallgroup collaborative norms and tasks, and (3) the classroom environment for learning mathematics. From this perspective, the social nature of learning and development is spotlighted, as well as student participation in different academic ways of knowing and performing cognitive tasks. Across these aspects, the language of instruction is believed 
to play a key role in understanding mathematical concepts. Consequently, the researcher in this study explored the following research questions:

RQ1: How does the language of instruction impact second-grade Latinx EBs' understanding of the mathematical concept of place value (CA CCSS-M 2.NBT 1-4) in two Spanish-English transitional bilingual classrooms?

RQ2: How does the language of instruction impact second grade Latinx EBs' communication patterns in small-group collaborative work around place value tasks in two Spanish-English transitional bilingual classrooms?

This chapter includes an analysis of the extant literature on the relationships between mathematics learning, language, and bilingualism, synthesizing them into three topic sections. The first topic section is the importance of mathematics in elementary education settings. Under this topic, three subtopics were discussed: The components of mathematics proficiency, teaching for understanding in mathematics, and the need for learning place value with understanding in elementary classrooms. Under the second topic section, the researcher reviewed the arguments behind language and mathematics cognition, including the distinction between linguistic and academic knowledge and language and academic proficiency. The relationships between mathematics learning and bilingualism were also explored in this section. The third topic section focused on the importance of the classroom environment for Latinx EBs to learn mathematics and how the mathematics classroom environment reflects teachers' beliefs and knowledge about mathematics proficiency. Finally, the research gaps were presented, followed by the 
theoretical framework from which the problem of practice and the research questions were examined.

\section{Importance of Mathematics in Elementary Education Settings}

The process of teaching and learning mathematics is considered of extreme importance not only in the United States educational system but all around the world. Some authors consider that mathematics in this country is a "privileged" subject area due to the excessive attention and central role it plays in people's lives (Davis, 1995). Furthermore, research suggests that mathematics prevent racially and linguistically marginalized students from accessing and pursuing higher levels of education (Murata, 2004). Nevertheless, the fact that for students to succeed in today's world, they need to be mathematically proficient and able to communicate their mathematics knowledge to others clearly and precisely, is well sustained. The third mathematical practice in the California Common Core State Standards for mathematics (CA CCSS-M) makes this relationship between mathematics proficiency and language very evident (CDE, 20132014).

Learning mathematics is an important goal in the educational system, although it begins before the formal schooling process (Carpenter and Lehrer, 1999). Thus, it is critical to ensure that all students continue to understand and develop mathematical skills throughout their elementary school years in the process of reaching mathematics proficiency or academic knowledge in mathematics. The researcher focused the study on one standard of the CA CCSS-M, understand place value (2.NBT. 1-4) because place value is an important mathematical concept that is also considered a "gatekeeper" in 
developing mathematics understanding (Major, 2012). This concept relates to many other mathematical tasks, as research has pointed out. It is considered of extreme importance for mastering multi-digit addition, subtraction, multiplication, and division of whole numbers and the same operations with fractions by the time the students reach upper grades.

Mathematical proficiency. The NRC (NRC, 2001a, p. 116) defines mathematical proficiency through its five integrative components:

1. Conceptual Understanding: Refers to the comprehension of mathematical concepts, operations, and relations. When the students comprehend the fundamental ideas, operations, and relations among numbers, mathematical symbols, diagrams, representations, etc. in a conceptual manner, they are capable of drawing from this knowledge and apply it to other situations.

2. Procedural Fluency: Denotes a skill in carrying out procedures flexibly, accurately, efficiently, and appropriately.

3. Strategic Competence: Alludes to the ability to formulate, represent, and solve mathematical problems.

4. Adaptive Reasoning: Defines the capacity for logical thought, reflection, explanation, and justification.

5. Productive Disposition: Refers to a habitual inclination to see mathematics sensible, useful, and worthwhile coupled with a belief in diligence and selfconfidence in one's performance. 
These components are interrelated and interdependent to ensure mathematics proficiency. Among these components, the conceptual understanding might determine the subsequent flow. When the students comprehend mathematics' central ideas, operations, and relations among numbers, math symbols, diagrams, or representations, etc., they can use this knowledge in different situations and problems. Hence, it is critical in mathematics instruction to support students to reach high levels of understanding that leads to mathematics proficiency. Conceptual understanding in mathematics is commonly defined as opposed to rote memorization of facts, which refers to the second component, procedural fluency. Most mathematics teachers lean towards one of the two first components of mathematics proficiency. Therefore, sometimes mathematics classroom instruction might have an emphasis on the active use of concepts and ideas (conceptual understanding development), while in other classrooms, the emphasis is on mechanical, rote, and repetitive procedures. As stated before, the five components of mathematics proficiency are integrated and interdependent. Needless to say that an isolated focus of either one of them does not result in mathematics proficiency.

Teaching for understanding in mathematics. According to Carpenter and Lehrer (1999), teaching and learning for understanding in mathematics have been around educational research since the early years of the nineteenth century. In the beginning, the idea of teaching and learning for understanding was linked to replicating the ways mathematicians understood and explained mathematics. As this research-based approach evolved, it focused more on describing how learners construct meaning for mathematical concepts and procedures, and equally important, how the classroom environment 
supports or hinders this construction. The social construction of knowledge is highly valued in the sociocultural perspective of learning. This perspective provides the framework for this study. Within this view, the importance of teaching and learning for understanding is at the core of the instructional practices used to teach mathematics.

Teaching and learning for understanding suggest that when the learners understand a concept, they can apply it with not much effort to new and different situations or contexts. Learners who understand a concept make sense of it and connect it to a previously learned concept or bring it to a new learning context. Carpenter and Lehrer (1999) also suggested five forms of mental activity, from which mathematical understanding and knowledge arise: a) Constructing concepts relationships, b) extending and applying mathematical knowledge, c) reflecting about experiences, d) articulating what one knows, and e) making mathematical knowledge one's own. These forms are closely related to the five components that define mathematical proficiency, as proposed by the NRC (2001). The leading questions in this research study are connected to at least three of the five forms proposed by Carpenter and Lehrer (1999): Constructing concepts relationships, reflecting about experiences, and articulating (communicating) what students know.

Learning place value with understanding. Major (2012) points out that students' understanding of place value is a strong predictor for later mathematics success. The understanding of place value is fundamental to perform more complex mathematical tasks such as multi-digit addition and subtraction, as well as multiplication and division (Fuson \& Briars, 1990). Multi-digit basic mathematical operations are usually taught as 
"sequential procedures of adding and subtracting single-digit numbers and writing digits in certain locations" (Fuson \& Briars, 1990, p.181). Following a pre-determined procedure to solve a mathematical operation does not mean that the concept that underlies the operation was understood. It is reasonable to imagine how challenging for EBs it is to learn mathematics in English, since they would need to understand two systems: The English language system and the number system that gives different values to a single number, depending on the place it is in a multi-digit number.

Place value understanding requires the same mental activity needed from students to develop fractional and algebraic reasoning (MacDonald, Westenskow, MoyerPackenman, \& Child, 2018). Therefore, the understanding of place value is fundamental in mathematics learning. Lacking this understanding leads to having students who can work relatively well in mathematics classrooms but would struggle to develop more sophisticated mathematics strategies to solve place value problems and provide reasonable explanations about their choices for solutions to a problem.

Research has investigated the development of students' understanding of place value in upper elementary grades (Fuson \& Briars, 1990; Fuson et al., 1997). Nevertheless, research on the development of this concept in early elementary grades is still very limited, considering the importance of the concept in building a strong number sense foundation. The understanding of place value is fundamental to perform more complex mathematical tasks such as multi-digit addition and subtraction, as well as multiplication and division (Carpenter \& Lehrer, 1999; Fuson \& Briars, 1990; Fuson et al., 1997; Major, 2012; Varelas \& Becker, 1997). 
The studies of Fuson and Briars (1990) and Fuson et al. (1997) have broadly contributed to the research on place value learning. Their analyses referred to English proficient students' difficulties in understanding place value. Other minorities' spoken and written numerical systems had been considered at a lower rate (Fuson \& Li, 2009).

Despite the similarities that might exist between Spanish and English linguistic structures and the numerical systems used in both languages, Latinx EBs might find it challenging to understand place value in mathematics classrooms where the language of instruction is English.

In the current study, the importance of creating visual models to understand the concept of place value was also highlighted. Fuson and Beckman (2012) stated that leaders in mathematics education need to help teachers, parents, and administrators understand that standard algorithms are explained through and related to visual models. Models help students understand the underlying methods that highlight mathematical concepts, such as place value in this study.

Major (2012) stated that the importance of place value knowledge becomes evident in the students' ability to read, write, and understand large numbers. Place value knowledge is needed to solve complex operations. It is embedded in a wide range of mathematical ideas because it is derived from a deep understanding of single-digit numbers, also called number sense. This study aimed to support the place value understanding in early elementary grades through the close examination of the language of instruction as a key aspect of the mathematics classroom environment. If students in primary grades understood the concept of place value, it would be easier for them to connect it and apply 
it to other mathematical concepts. It would not be viewed as an obstacle for our Latinx EBs to be successful in mathematics learning.

Varelas and Becker (1997) added to the extensive body of research on place value by analyzing the two components of the place value system. They designed an intermediate system called Face Value-Complete Value to support children in differentiating the value of each digit in a multi-digit place value number representation. These authors proposed a semiotic lens to analyze the difficulties children have when learning place value in school. The study had some limitations regarding the use of two-digit numbers only to test the authors' design. The researcher in the present study questions whether and how Latinx EBs learn place value concepts in the classroom. One possibility is to think that by using their language of proficiency, they might learn place value and key constructs related to it with much more understanding and would be able to expand this knowledge to higher quantities.

Carpenter and Lehrer (1999) refer to the relationship between addition and subtraction, multiplication, and division of multidigit numbers to the basic concepts of place value. Place value understanding is fundamental to mathematics learning. However, as reported by research, students show increasing difficulties with place-value related tasks from grades two and up. In many cases, these difficulties become barriers to low achieving populations (Murata, 2004).

The focus of this study is the understanding of place value as it relates to many other mathematical concepts and procedures that are essential to support second-grade Latinx EBs' understanding of other mathematical concepts throughout their schooling. 


\section{Language and Mathematics Cognition}

Recent studies continue to explore the relationship between language and mathematics cognition, and more specifically, mathematics learning in bilingual settings. To better understand this relationship, it is necessary to discuss the different aspects of both language and mathematics learning.

\section{Linguistic and academic knowledge vs. linguistic and academic proficiency. The}

Threshold Hypothesis and the concepts of cognitive academic language proficiency (CALP) and its counterpart, the basic interpersonal communicative skills (BICS), have been widely used in educational research and policy since they were proposed by Cummins (1976, 1979, 2008). MacSwan (2000) and MacSwan and Rolstad (2014) called attention to problems derived from these constructs. Although their critique is powerful in questioning the validity of such a widely accepted theory, this conceptual disagreement is not the focus of the current study. Nonetheless, it is important to briefly address it since it is related to the purpose of the study.

The Threshold Hypothesis pointed to ability levels in the students' first language as a mechanism that facilitated the learning of the second language. However, the ability levels lacked grounded theoretical support to describe them and simply associated them with students' linguistic ability (MacSwan, 2000). According to MacSwan and Rolstad (2014), the Threshold Hypothesis and the concepts of CALP and BICS contributed to a deficit viewpoint of linguistic minority children. Both concepts referred to the language of school, and they happened to have many similarities with traditional prescriptivism, which emphasized complex grammatical structures and strict rules of language. 
Since Cummins $(1976,1979,2008)$ seemed to use the academic language proficiency to refer to both competence and performance, MacSwan and Rolstad (2014) proposed an alternative distinction: linguistic competence (or linguistic knowledge) and linguistic performance (or academic linguistic knowledge). MacSwan (2000) stated that all children have access to linguistic competence, regardless of their cultural background and individual or social life experiences. Academic linguistic performance, on the other hand, refers to the use of that linguistic competence in concrete, everyday situations, as well as the knowledge of particular communities within the school such as science, social studies, and mathematics learning communities.

The transfer of academic subject knowledge (academic linguistic performance) that takes place in bilingual settings has been found to be accessible to any language or languages the students know (MacSwan and Rolstad, 2014). From this standpoint, language should not be an obstacle for bilingual learners to reach academic achievement. The implication is that even if the bilingual student is still learning the second language, academic content learning is happening. Linguistic knowledge in the present study alludes to particular linguistic structures that may or may not be part of oral language development. Still, forms of language learned in the school facilitate communication amongst teachers and students, and students and peers, in either the first or second language. Academic linguistic knowledge refers to concepts and skills learned in the classroom within a learning community; in this case, the mathematics classrooms. The language used in mathematics classrooms is different from that used in other school contexts. The distinction between these terms was necessary because part of this study 
explored the impact of the language of instruction on the participants' use of communication patterns around the mathematical concept of place value (academic linguistic knowledge).

Additionally, experts in academic knowledge assessment have pointed out the need for new ways of thinking about teaching and learning processes in science and mathematics classrooms that benefit all students, specifically ELs (Castellano, Duckor, Wihardini, Tellez, and Wilson, 2016). These researchers support the idea of changing the tendency to teach language in isolation to one in which features about language are learned by using it for communication and learning in other disciplines.

\section{Language and mathematics learning for bilingual students in SEI classrooms.}

According to Moschkovich (2007), the relationship between mathematics and languageand the way this relationship is viewed - influences mathematics cognition and mathematics teaching. She described three ways through which bilingual mathematics learners are viewed and supported in the SEI classrooms. The first and second views focus on vocabulary and meaning-making, respectively. The third view uses the sociocultural perspective of learning lens through which the process of constructing and negotiating meaning in the classroom interactions is analyzed. This view values social interaction within the mathematics classroom in the process of knowledge development. In the present study, the sociocultural perspective of learning is used as a framework to highlight students' linguistic interactions as a means to construct mathematical knowledge. 
Borgioli (2008) called attention on the difficulties that young ELs (EBs in this study) have when they are asked to read and understand a text, read word problems, and explain and justify their mathematical strategies in an English (SEI) environment. Her suggestions encourage mathematics teachers to relate language objectives and literacy tasks, attend to both language and mathematics learning, and create supportive mathematics environments for ELs to succeed. The researcher of the present study valued Borgioli's suggestions and examined if choosing the students' native language to provide mathematics instruction helped them understand key mathematical concepts, such as place value, that students will need for future success in this subject area.

Bilingualism and mathematics learning. Research has found that teaching mathematics in the students' native language is highly related to mathematics achievement (Borgioli, 2008; Riches \& Genesee, 2006). Kempert, Saalbach, and Hardy (2011) studied the positive cognitive effects of bilingualism and demonstrated that these effects could be observed and measured not only on highly proficient bilingual students, but also those with a low command of the instructional or native language. These scholars highlighted research findings that explain how bilingual students constantly deal with conflicting response options for the same purpose. This process gives them the ability to focus on relevant information and ignore linguistic noise when solving mathematics word problems with distractors. They also found that monolingual students outperformed or equally performed in comparison to the bilingual students with problems free of distractors. These researchers have added to the extensive body of research on mathematics cognition and bilingualism. However, their focus was on comparison 
measures between monolingual and bilingual students' behaviors when solving mathematics word problems. The researcher of the present study contends that the influence of the language of instruction, as an essential element of the mathematics classroom environment, goes beyond solving word problems. It begins with how the classroom is intentionally set up to support or hinder mathematics learning with understanding. The Language of instruction is an important aspect of the mathematics classroom environment, and as such, it has merited close observation.

MacSwan and Rolstad (2014) proposed the facilitation theory to overcome the Threshold Hypothesis and the BICS and CALP effects they critiqued. The facilitation theory favored the view of cognitive gains in bilingual students that allow the transfer of knowledge, more specifically, the transfer of literacy. Transfer, in this sense, was viewed as allowing learners to access knowledge stored in their brains, regardless of how this knowledge was acquired. In other words, students could access the knowledge they have acquired in their native language to facilitate their learning in the second language. Riches and Genesse (2006) had also referred to this idea when they posited common underlying storage of literacy abilities that become available to students who were good readers in their first language and were learning a second language. MacSwan (2000) and MacSwan and Rolstad (2014) have made significant contributions to research on the relationship between bilingualism and content learning. Their studies suggest that bilingual students need to be allowed to use either their native language or the language they are learning in the classroom in order for them to understand subject-matter content and communicate it to others. 
In the context of this study, students might have linguistic and cognitive resources available, regardless of the language chosen as the language of instruction, then use these resources when they communicate their mathematics learning. Latinx EBs in the study had different reservoirs of knowledge, such as their linguistic knowledge in Spanish and English, and their mathematics academic knowledge in either or both languages. Moreover, the qualitative data analysis in the present study referred to linguistic and mathematical patterns of knowledge that participants activated during the small-group collaborative sessions solving place value tasks.

Language and mathematical learning have strong links, and this relationship has been highlighted for decades. Research on the intersection between the language of instruction, mathematics understanding, and racial biases has also increased lately (Borgioli, 2008; Major, 2012; Moschkovich, 2011; Zavala, 2012). Most of these studies pay special attention to either the word problems and their linguistic structure to support mathematical understanding or focus on middle or high school settings.

This research study's purpose is to explore the intersection between the language of instruction and mathematics learning in an early elementary school setting, with the belief that language is an important aspect of the classroom environment. The level of understanding mathematical concepts when they are taught mathematics in a meaningful, interactive way enhances what the students bring into the classroom learning community. From the social construction of knowledge perspective, mathematical learning occurs when the classroom is seen as a learning culture in which students get involved in sensemaking activities that require explanations, negotiation, sharing, and evaluation 
(Clements \& Battista, 1990; Clements, Sarama, \& Wolfe, 2010). Consequently, language plays a key role in mathematics learning. Recognizing this role is essential to develop an understanding and sense-making of mathematical concepts.

Language of instruction and mathematics learning. The decision over the language of instruction to teach mathematics is critical when most of the students in the selected schools are Latinx EBs, which is also the case for many schools in California (CDE, 2018). According to CDE (2018), Spanish is the top spoken language other than English in California schools. Research that favors the use of the native language to deliver mathematics instruction highlights its benefits for ELs' comprehension of mathematics concepts and the development of mathematics skills (Abedi \& Lord, 2010; Bernardo \& Calleja, 2005).

Furthermore, several studies have demonstrated that learning mathematics in a second language may cause greater mathematics learning difficulties than those observed in students who learn mathematics in their first language (Yushau \& Bokhari, 2015). Bernardo and Calleja's (2005) findings suggest that mathematics students perform mathematics better in their first language than in their second language. These researchers have pointed out that bilingual children's proficiency in the language of instruction during mathematics class is one of the most critical factors that impact bilingual students' mathematical proficiency.

According to Bernardo and Calleja (2005), bilingual children's proficiency in the language of instruction for learning mathematical concepts is a critical factor that is believed to impact their overall mathematical proficiency. In the selected samples for the 
study, all participants were Latinx EBs in whose homes, Spanish is the spoken language. Among this group, some just have arrived in the country in the past six months and have no command of English. Understanding mathematical concepts when the lessons are delivered in English might become a big challenge for these Latinx EBs. These challenges might increase the achievement gap between Latinx EBs and English Proficient students in mathematics standardized test scores. The need to examine if the language of instruction had an impact on the target group's understanding of mathematics content, in transitional bilingual classrooms, was compelling to conduct this study.

\section{Latinx-Emergent Bilinguals in the Mathematics Classrooms}

Khisty (2002) conducted informal classroom observations in which most Latino students were not exposed to the rich, challenging mathematics curriculum. She also suggested that effective instruction for Latino and Latina students in mathematics requires to consider biased assumptions that guide teachers' instruction. One common assumption is that since mathematics is not directed linked to language, then teaching mathematics in English would not affect Latinx EBs' understanding of mathematical key concepts. The same assumption appears to guide teachers' decisions on the language of instruction. It leads to the belief that teaching mathematics in English to all EBs helps them understand mathematical concepts and perform at a proficient level in state standardized tests in English, by the time they are in third-grade. However, this assumption has been tested by the results of standardized tests in the present study's selected settings. 
The purpose of Razfar and Leavitt's (2011) was to understand an effective model of mathematical meaning-making in classrooms with mostly Latino students. These researchers focused on sentence starters to mediate discussions and develop metacognitive awareness for ELs. Although Razfar and Leavitt's (2011) study encourages teachers to provide linguistic support to Latino students through the use of sentence starters, this support might not be enough for Latinx EBs to make sense of the concepts presented. In Razfar and Leavitt's (2011) study, the problem is examined from a perspective that focuses on vocabulary and meaning-making without considering other factors that might add to the overall meaning-making process on the part of the students. These factors might be other elements of the classroom environment that foster or inhibit the use of their native language to construct and negotiate multiple meanings (Moschkovich, 2011).

Students' content knowledge development is highly determined by the pedagogical practices in which they engage in the classroom environment (Greeno \& Boaler, 2000). The mathematics classroom environment set the ambiance for Latinx EBs to develop a positive and active relationship with mathematics learning. They need to experience engagement, success, inquiry, and creativity in these environments so that they can develop interest and self-confidence for learning mathematics. Latinx EBs begin their journey as mathematics learners in early elementary classrooms and will carry it out throughout their lives. Language and race, among the aspects of the classroom environment, play very important roles. The current study contributes to research on the classroom environment by focusing on some aspects that support or hinder the 
mathematics learning process, such as the language of instruction and its impact on Latinx EBs' understanding of mathematical concepts.

Zavala (2012) has referred to the lack of research on Latinx EBs in mathematics education that emphasizes their voices and examines their strategies to navigate the mathematics classrooms while building their mathematics identities. The researcher of the current study recognized the importance of Zavala's (2012) research. Still, she contends that the mathematics learning process starts in elementary classrooms where multiple aspects of the classroom environment might contribute to engaging young mathematics learners to continue developing interest and mathematical proficiency through and beyond their schooling years.

\section{Research Gaps and Opportunities}

This literature review highlighted the intersections between three main topics of research regarding mathematics learning and language. First, a dense body of studies has documented the importance of mathematics in educational settings. Still, most of these studies examined the mathematics learning processes in middle and high school, putting aside the importance of learning mathematics in early elementary education settings. Another caveat is that the majority of these studies focused on mathematics problemsolving. This review enhanced the importance of place-value studies in early elementary grades to support Latinx EBs' conceptual understanding of this mathematical concept and their subsequent success in mathematics. Still, research on mathematics learning in bilingual early elementary classrooms is needed. The studies that explored Latinx students' interest and performance in mathematics are more oriented to the outcomes of 
the whole process of K-12 schooling. These studies need to acknowledge that mathematical learning for Latinx EBs or any other marginalized group starts at early age. The process of finding mathematics interesting, applicable, and engaging begins in primary grades. It can be supported by teachers, parents, and communities that value mathematics as a discipline with which they can succeed. This study aimed to explore such relationships in two-second grade Spanish-English bilingual classrooms where the majority of students were Latinx EBs.

\section{Theoretical Framework}

The sociocultural theory is a research framework based on the seminal work of Vygotsky (1978) and his followers. According to Kozulin (2002), Vygotsky related the child's development stages from Piaget and the social and cultural factors to define the social situation of learning and development. Vygotsky's (1978) findings have supported educational, psychological, and sociological research for decades.

The sociocultural perspective emphasizes the importance of the social and cultural aspects that contribute to a child's development and learning. More recently, Moschkovich (2011) emphasizes the importance of the sociocultural perspective of learning to analyze bilingual students' behaviors when learning mathematics. This perspective involves the analysis of the process of constructing and negotiating meaning through classroom interactions and the validation of the mathematics knowledge that students bring into the classroom. In this sense, parents, teachers, classmates, and the community shape children's view of the world, the subsequent interaction with it, and their social and cultural being. 
From the sociocultural perspective, culture (including race and language), plays an essential role in learning. Nevertheless, the recognition of this perspective in mathematics education is relatively new in the United States (Cobb, 1998). From this perspective, analyzing the culture in the classroom for mathematics learning has become a muchneeded focus that looks forward to testing common assumptions or introducing theoretical notions (Cobb, 1998). Sociocultural theories of learning provide the framework for the present study. According to this viewpoint, the language of instruction was an important aspect of the mathematics learning communities in which the participants of this study were immersed.

Clements and Battista (1990) and Clements, et al. (2010) emphasize the fact that mathematical learning happens when the classroom is seen as a culture in which students get involved in sense-making activities that require the use of explanations, negotiations, sharing, and evaluation. In the same direction, Moschkovich (2007) studied bilingual classroom mathematics learning from the sociocultural perspective since it provides a view of language and mathematics learning that shifts from deficiency models of bilingual learners to describing the resources they have and use to communicate their mathematical understanding.

Although research has widely documented the underperformance of Latinx students in mathematics for decades, only recently, researchers have focused on the role that culture and language play in the development of Latinx students' mathematical identities. Zavala (2012) studied how Latinx EBs in high school responded to issues regarding the importance of race and language in learning mathematics and the different characteristics 
of mathematics classrooms that supported them in structuring their mathematical identities. Nevertheless, it is necessary to go further back in the schooling process and explore the process' initial stages to build mathematics identity in early elementary classrooms.

The sociocultural approach of this study allowed the researcher to examine how second-grade Latinx EBs engaged with academic mathematical content and developed an understanding of a concept considered a "gatekeeper" (Major, 2012), particularly for the Latinx school population. Current research findings on mathematics learning highlight the importance for students to construct and negotiate multiple meanings and participate in mathematical communication and discussions (Khisty, 2002; Moschkovich, 2007). When students learn subject matter with understanding, they make sense of the reasons for learning it and can apply knowledge to different situations (Brophy, 2004).

This research study focused on one problem of practice and research questions from the social construction of knowledge or the sociocultural perspective of learning. This perspective rests on the idea that knowledge is socially constructed and is impacted by the activity, context, and culture in which it happens. The sociocultural perspective of learning in this study framed the knowledge about place value that Latinx EBs bring into the classroom, and how they negotiate this knowledge in the social learning interaction with teachers and peers to build new knowledge or modify it.

The researcher of this study also explored some aspects of the mathematics classroom and how they support students' mathematics learning. This exploration was made through the completion of a teacher questionnaire. It inquired teachers about the strategies and 
classroom practices used in the mathematics learning context. Questions included teachers' planning, use of the standards in the planning, collaboration between teachers during planning time, preferred language to plan lessons, preferred mathematics classroom routines and procedures, and decisions over the language of instruction, among others.

To sum up, it is critical for this research study to examine the language of instruction and the relationships to other classroom practices such as pre-and-post assessments and the teachers' preferred strategies. These elements are important pieces of the sociocultural dynamic happening in the mathematics classrooms selected and might make a significant difference for Latinx EBs' understanding of place value. 


\section{Chapter Three: Research Design and Methodology}

As previously mentioned, language and mathematics learning intersect in multiple ways during the learning process, more particularly, in the process of constructing and negotiating meaning through classroom interactions (Moschkovich, 2011). Focusing on multiple aspects of classroom practice widens researchers' and educators' perspectives to comprehend how Latinx EBs negotiate their mathematics identities in school (Zavala, 2012).

There is vast research that supports the claim that bilingual children's proficiency in the language of instruction for learning mathematical concepts is a critical factor that impacts their overall mathematics proficiency (Bernardo \& Calleja, 2005; Khisty, 2002). In contrast, other researchers claim that, regardless of the language of instruction, what young Latinx EBs need in the bilingual mathematics classroom is more supportive learning environments in which they feel successful at both learning mathematics and reaching higher levels of proficiency in English (Borgioli, 2008; Zavala, 2012).

This study investigated two research questions. First, how does the language of instruction impact second-grade Latinx EBs' understanding of the concept of place value in two Spanish-English bilingual classrooms? And second, how the language of instruction impacts second-grade Latinx EBs' communication patterns during smallgroup collaboration time when solving mathematical tasks related to place value in two Spanish-English transitional bilingual classrooms. To examine the impact of the language of instruction on the participant's understanding of the concept of place value and their communication patterns around it, both quantitative and qualitative data were collected. 
The quantitative data consisted of a pre- and post-test that was given to the participants in the beginning and at the end of the place value unit. The two classroom teachers provided the researcher with the pre- and post-test scores and the rubric used.

Qualitative data were collected and analyzed to examine the impact of the language of instruction on the participants' understanding of the concept of place value, as evidenced by the changes in the communication patterns used in three small-group collaborative sessions around this topic. The first set of qualitative data consisted of the audio recordings of participants' linguistic exchanges when solving place value tasks. The second qualitative dataset consisted of teachers' responses to a questionnaire. The teachers' questionnaire included items about their demographics and teaching experiences, strategies to teach mathematics, etc.

As previously stated, this study focused on one standard (2.NBT. 1-4). The notation used by the CA CCSS-M labels the standard domain "Number and Operations in Base Ten for second grade" as 2.NBT; there is a cluster-heading under this domain that specifies the cluster of standards' focus: Understand place value (CDE, 2013-2014). Under this cluster-heading, four standards are presented (1-4). Although there is a second cluster-heading for the standard domain Number and Operations in Base Ten (Use place value understanding and properties of operations to add and subtract), the researcher of this study only focused on the first cluster-heading and the four standards under it. The second cluster- heading and the five standards below it are out of the scope of this study. Table 1 shows the formal description of the 2.NBT. 1-4 standard. 
Table 1

Grade Level 2 - Standard 2 NBT 1-4

\begin{tabular}{|c|c|}
\hline Cluster Heading & Understand place value \\
\hline \multirow[t]{4}{*}{ Standards } & $\begin{array}{l}\text { 1. Understand that the three digits of a three-digit number } \\
\text { represent amounts of hundreds, tens, and ones; e.g., } 706 \\
\text { equals } 7 \text { hundreds, } 0 \text { tens, and } 6 \text { ones. Understand the } \\
\text { following as special cases: } \\
\text { a. } 100 \text { can be thought of as a bundle of ten tens - called a } \\
\text { "hundred." } \\
\text { b. The numbers } 100,200,300,400,500,600,700,800 \text {, } \\
900 \text { refer to one, two, three, four, five, six, seven, eight, } \\
\text { or nine hundred (and } 0 \text { tens and } 0 \text { ones). }\end{array}$ \\
\hline & $\begin{array}{l}\text { 2. Count within } 1000 \text {; skip-count by } 2 \text { s, } 5 \text { s, } 10 \text { s, and } 100 \text { s. } \\
\text { (CA) }\end{array}$ \\
\hline & $\begin{array}{l}\text { 3. Read and write numbers to } 1000 \text { using base-ten numerals, } \\
\text { number names, and expanded form. }\end{array}$ \\
\hline & $\begin{array}{l}\text { 4. Compare two three-digit numbers based on meanings of the } \\
\text { hundreds, tens, and ones digits, using }>,=\text {, and }<\text { symbols to } \\
\text { record the results of comparisons. }\end{array}$ \\
\hline
\end{tabular}

The standard notation provides details about the relevant knowledge that is necessary for students to grasp a deep understanding of the concept of place value.

\section{Research Methodology and Study Design}

In this exploratory mixed-method research study, a Convergent Parallel MixedMethod (CPMM) approach, in which quantitative and qualitative data collection began concurrently, was used. The CPMM approach entails that the researcher conducts the quantitative and qualitative sets of data in the same phase of the research process, ponders the methods equally, analyzes both datasets separately, and interprets the results as a whole (Creswell \& Plano Clark, 2011). Figure 1 illustrates the flow of the data collection process and analysis for the study. 


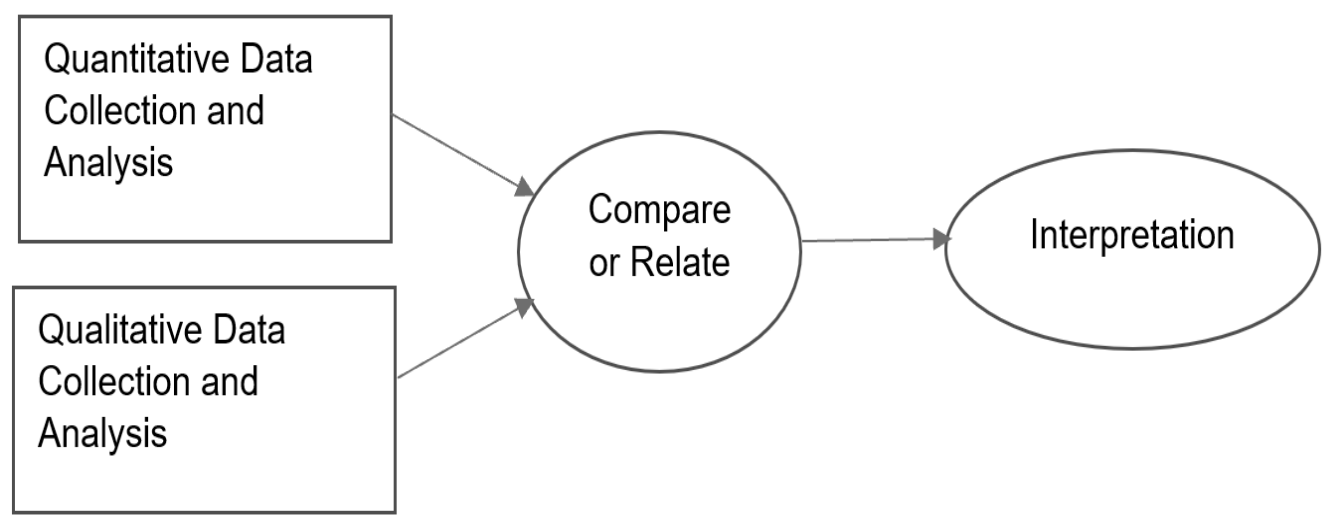

Figure 1. Convergent Parallel Mixed-Method (CPMM) approach.

The CPMM approach was put in action once the first set of quantitative data was collected and analyzed to explore RQ1 and continued with the collection and transcription of the audio recordings of the first small-group session and the teachers' self-reported questionnaire. Each set of data was analyzed, and the results were compared to one another concerning the research questions. The process ended with the interpretation of results that are reported in Chapter Four.

Research methods. The quantitative and qualitative data collection began in the fall of the 2019-2020 school year. Both sets of data were analyzed and compared to determine relevance concerning the research questions. For the quantitative part of the research, pre- and post-test were given to the participants in the beginning and at the end of the place-value unit. The test scores constituted the data to explore RQ1. Two data corpora formed the qualitative part of the mixed-method study: the audio-recordings collected during three small-group sessions in which participants had to work collaboratively to solve place-value tasks and the responses to the teachers' questionnaire. The audio-recordings provided the researcher with the opportunity to find 
the patterns of communication most used by the participants to communicate their learning of the concept. This data helped to explore RQ2. The teachers' questionnaire inquired the two classroom teachers involved in the study for their preferred strategies and other instructional practices used to support Latinx EBs to understand the concept of place value. Both datasets were analyzed through the use of the constant comparative method (CCM). Once the quantitative and qualitative data were collected and analyzed separately, the researcher proceeded to find commonalities, differences, and patterns for the interpretation.

Study population. As previously mentioned, after Proposition 58 passed in 2016, dual language immersion and transitional bilingual schools were given more freedom on deciding what language of instruction to use for each subject matter. Districts delegate the discussion and decision-making on schools' leaders and classroom teachers. In most cases, many educators are guided solely by the misconception that, since mathematics uses symbols and numbers, it is not problematic to provide Latinx EBs with mathematics instruction in English, even though it is a language that they are still learning.

Participant demographics. This exploratory mixed-method research study was conducted in two-second-grade Spanish-English bilingual intact-classrooms located in two different schools within a district in California. These two sites were selected because they both have bilingual programs or strands within the schools, and are urban elementary schools with over 85\% Latinx EBs enrolled. Additionally, both schools use the materials provided by the district-adopted-curriculum for teaching and learning 
mathematics in grades K through 6, and both schools are Low-SES neighborhood schools (Title I). Both schools' demographics can be seen in Table 2.

Table 2

School 1 and School 2 Demographics for the 2019-2020 School Year

\begin{tabular}{|c|c|c|c|c|c|c|c|}
\hline & $\begin{array}{l}\text { Enroll } \\
\text {-ment }\end{array}$ & $\begin{array}{l}\text { Low- } \\
\text { SES }\end{array}$ & ELs & $\begin{array}{c}\text { ELA* } \\
\text { Performance }\end{array}$ & $\begin{array}{c}\text { Math } \\
\text { Performance }\end{array}$ & $\begin{array}{c}\text { Progress } \\
\text { toward } \\
\text { ELP** }\end{array}$ & $\begin{array}{c}\text { Academic } \\
\text { Engagement }\end{array}$ \\
\hline School 1 & 423 & $74.0 \%$ & $53.2 \%$ & $\begin{array}{c}38.7 \% \\
\text { below standard }\end{array}$ & $\begin{array}{c}40.4 \% \\
\text { below standard }\end{array}$ & $38.5 \%$ & $\begin{array}{c}8.8 \% \text { chronically } \\
\text { absent }\end{array}$ \\
\hline School 2 & 375 & $75.7 \%$ & $41.6 \%$ & $\begin{array}{c}21.2 \% \\
\text { below standard }\end{array}$ & $\begin{array}{c}32.8 \% \\
\text { below standard }\end{array}$ & $32.2 \%$ & $\begin{array}{c}11 \% \text { chronically } \\
\text { absent }\end{array}$ \\
\hline \multicolumn{8}{|c|}{$\begin{array}{l}\text { Notes: Progress Level Scale }- \text { Very High }=65 \% \text { or higher; High }=55 \% \text { to less than } 65 \% ; \text { Medium }=45 \% \text { to less than } \\
55 \% \text {; Low }=35 \% \text { to less than } 45 \% \text {; Very Low }=\text { Less than } 35 \% . \\
\text { *ELA = English Language Arts } \\
\text { **ELP = English Language Proficiency. } \\
\text { Source: CA Dashboard }\end{array}$} \\
\hline
\end{tabular}

As shown in Table 2, these two schools had many things in common. They both had transitional bilingual strands within the schools with similar percentages of ELs enrollment. Both schools exhibited less than 50\% success in ELA and Mathematics performance, and both schools had a low percentage in progress toward ELP. Both schools were Title I schools located in Low-SES neighborhoods. In-School 1, the percentage of students who qualified for free and reduced-price lunch was $82 \%$, and in School-2, 71.52\%. This high percentage of students who qualified for free and reducedprice school lunch makes the two sites Title I Schools.

Within two schools, the two Spanish-English bilingual classrooms, Classroom 1 (C1) and Classroom 2 (C2), were selected to conduct the study. Teachers in these two classrooms had made their choice for the language of instruction to deliver mathematics lessons based on their own beliefs or school leaders' advice. 
Both teachers had the belief that the language of instruction for mathematics learning at this grade level should be the students' native language (Spanish in both cases).

Nevertheless, one of the teachers followed the principal and school leaders' suggestion of teaching mathematics in English to increase the students' exposure to academic English in the classroom. Students in this classroom shared similar age range and racial-ethnic origins, as well as linguistic backgrounds (Spanish as home language). Table 3 delineates the student demographics of the whole $\mathrm{C} 1$ class.

Table 3

Population Demographics: Entire C1 Classroom

\begin{tabular}{|c|c|c|c|c|}
\hline Age & $\begin{array}{c}\text { English } \\
\text { Proficiency }\end{array}$ & Ethnicity & Gender & $\begin{array}{c}\text { Primary } \\
\text { Disability }\end{array}$ \\
\hline 10 Ss: 8 years old & $1 \mathrm{EO}$ & 16 Latinx & Female: 7 & None \\
\hline 6 Ss: 7 years old & $15 \mathrm{EBs}$ & & Male: & \\
\hline
\end{tabular}
Notes: Total number of students $=16 ; \mathrm{EO}=$ English only; Ss = Students.

As shown in Table 3, there were 16 second-grade Latinx EBs enrolled in C1. Out of this amount, seven students participated in this study (44\%). In the entire C1, 93\% of students were EBs, and only one student was classified as English Only. This student was not part of the study. In the entire class, there were seven female students and nine males. All students in this classroom were Latinx. Age-wise, ten students out of sixteen were eight years old (born in 2011), and six students were at the age of seven (born in 2012).

Other than the total number of students enrolled, the entire $\mathrm{C} 2$ classroom demographics did not differ much from that in C1, as shown in Table 4. 
Table 4

Population Demographics: Entire C2 Classroom

\begin{tabular}{|c|c|c|c|c|}
\hline Age & $\begin{array}{c}\text { English } \\
\text { Proficiency }\end{array}$ & Ethnicity & Gender & $\begin{array}{c}\text { Primary } \\
\text { Disability }\end{array}$ \\
\hline 13 Ss: 8 years old & $1 \mathrm{R}-\mathrm{FEP}$ & 24 Latinx & Female: 14 & None \\
\hline $11 \mathrm{Ss}: 7$ years old & $23 \mathrm{EBs}$ & & Male: & \\
\hline
\end{tabular}

In C2, seven students out of twenty-four (29\%) participated in the study upon signature on the parent consent form (PCF). From the total number of students, twentythree were EBs (96\%), with one student classified as R-FEP. This student did not participate in the study. Their home language was Spanish, according to the home language survey in the enrollment form. They also received most content area instruction in Spanish while they learned English in school through I-ELD and D-ELD instruction. All the students in C2 were Latinx. Age-wise, eleven students were seven years old, and thirteen students were eight.

Sampling. This study's sample $(n=14)$ included children from two different classrooms, $\mathrm{C} 1$ and $\mathrm{C} 2$, ages 7 to 8 years old, second-grade Latinx EBs enrolled for the 2019-2020 school year in two Spanish-English transitional bilingual classrooms within two different schools in a school district in California. Their families were either Latinx or Latinx descendants in whose homes Spanish was the language spoken. The sample population for the study was also the two respective classroom teachers who agreed to participate through the signature of a Teacher Consent Form.

The researcher used Excel to record the data for each classroom and then proceeded with the coding process. Table 5 shows demographic details for $\mathrm{C} 1$ participants. 
Table 5

Summary of C1 Participant Demographics

\begin{tabular}{ccccccc}
\hline Student & Age & $\begin{array}{c}\text { English } \\
\text { Proficiency }\end{array}$ & Race/Ethnicity & Gender & $\begin{array}{c}\text { Home } \\
\text { Language }\end{array}$ & $\begin{array}{c}\text { Primary } \\
\text { Disability }\end{array}$ \\
\hline S1 & 7 & EL & Hispanic/Latina & Female & Spanish & None \\
S2 & 7 & EL & Hispanic/Latino & Male & Spanish & None \\
S3 & 7 & EL & Hispanic/Latina & Female & Spanish & None \\
S4 & 8 & EL & Hispanic/Latino & Male & Spanish & None \\
S5 & 7 & EL & Hispanic/Latino & Male & Spanish & None \\
S6 & 8 & EL & Hispanic/Latina & Female & Spanish & None \\
S7 & 8 & EL & Hispanic/Latina & Female & Spanish & None \\
\hline
\end{tabular}

As shown in Table 5, the group of participants shared various demographic aspects such as the same English proficiency level (EL), race/ethnicity, and home language. There was not any student in the participants' group with primary disabilities. The age range accepted for the study to be conducted was seven to eight years old. Four students (57\%) in C1 were seven years old; three participants were eight years old. Another category in the demographic report was gender. Four participants in $\mathrm{C} 1$ were female (57\%); three participants were male.

In $\mathrm{C} 1$, eleven out of sixteen students' families attended the informational meeting in which the researcher presented the study. The researcher obtained ten signed parent consent forms (PFCs). As the unit began, one participant dropped out of the study, leaving the study with a small sample size of 9 participants. In $\mathrm{C} 2$, ten parents out of twenty-four attended the informational meeting, but only seven signed the parent consent forms. It was highly recommended to the researcher to collect information from the same number of individuals in each classroom on both quantitative and qualitative databases to have an even sample that facilitated the comparisons. Following this recommendation, 
the study's sample size was reduced to fourteen participants, seven from each of the two Spanish-English bilingual classrooms, to have an equal sample size per classroom. Since two students out of nine in $\mathrm{C} 1$ missed two of the three small-group audio-recorded sessions, their data was not included in the analysis.

In $\mathrm{C} 2$, the total number of students was 24 . From this amount, only 10 attended the informational meeting, and 7 (33\%) returned the signed PCF that allowed them to participate in the study. In the whole group, there was one student who was classified as R-FEP or reclassified from EL to English proficient. This student did not participate in the study. Regarding gender, there were 14 female students in this classroom and ten males. Concerning age, 13 students were eight years old, and ten were seven years old. All students in this classroom were Latinx.

In $\mathrm{C} 2$, the participants' demographics slightly differ from that in $\mathrm{C} 1$. Since the number of students in this classroom was larger (24) than that in C1 (16), more participants were expected to participate. It was not in the scope of this study to investigate the reasons as to why there was low attendance to the informative meeting. The information given in the meeting was sent home, and there was no response from parents, although many students in the classroom showed interest in participating. Table 6 shows $\mathrm{C} 2$ participants' demographics. 
Table 6

Summary of C2 Participant Demographics

\begin{tabular}{ccccccc}
\hline Student & Age & $\begin{array}{c}\text { English } \\
\text { Proficiency }\end{array}$ & Race/Ethnicity & Gender & $\begin{array}{c}\text { Home } \\
\text { Language }\end{array}$ & $\begin{array}{c}\text { Primary } \\
\text { Disability }\end{array}$ \\
\hline S8 & 7 & EL & Hispanic/Latina & Female & Spanish & None \\
S9 & 7 & EL & Hispanic/Latina & Female & Spanish & None \\
S10 & 7 & EL & Hispanic/Latina & Female & Spanish & None \\
S11 & 7 & EL & Hispanic/Latino & Male & Spanish & None \\
S12 & 7 & EL & Hispanic/Latina & Female & Spanish & None \\
S13 & 8 & EL & Hispanic/Latina & Female & Spanish & None \\
S14 & 8 & EL & Hispanic/Latino & Male & Spanish & None \\
\hline
\end{tabular}

As Table 6 portrays, the second group of participants had similar demographics as $\mathrm{C} 1$, such as English proficiency level (EL), race/ethnicity, home language, and the fact that none of these students had a primary disability. Regarding age, in C2, five participants (71\%) were at the age of seven years old, and only 2 participants were eight years old. Regarding gender, C2 had five female participants out of seven (71\%), one more than in $\mathrm{C} 1$.

The two classroom teachers - who allowed the researcher to conduct the study in their classrooms - were also participants of the study. They were supportive and willing to facilitate the process. They responded to nine questions in the questionnaire with candor. They responded verbally to the first two questions about their demographics (gender and home language) when the study was initially presented to them. The question about their ethnicity was included in the written questionnaire to which they responded in writing (see Question 1 in Appendix D: Teacher Questionnaire). Table 7 shows T1 and T2 demographics. 
Table 7

T1 and T2 Demographics

\begin{tabular}{lllccl}
\hline Teacher & Ethnicity & Gender & $\begin{array}{c}\text { Years of } \\
\text { Teaching } \\
\text { Experience }\end{array}$ & $\begin{array}{c}\text { Years of } \\
\text { Teaching in } \\
\text { Bilingual Settings }\end{array}$ & $\begin{array}{l}\text { Home } \\
\text { Language }\end{array}$ \\
\hline T1 & Latinx & Female & 28 & 20 & Spanish \\
T2 & Latinx & Female & 25 & 22 & Spanish \\
\hline
\end{tabular}

Both classroom teachers have the same ethnicity, gender, and home language. The years of experience in the education field slightly differs, as well as their years of experience in teaching in bilingual settings.

Instrumentation. Three instruments were used to collect data for this study. The first instrument was the end-of-the-unit assessment (EngageNY.org, 2015) used to test for place value understanding before and after the unit or module development. The second instrument was the audio-recordings of three small-group collaborative sessions, and the third instrument was a questionnaire that the two classroom teachers involved in the study got committed to answering. These three instruments were intended to explore the relationship between three constructs, the place value concept measured by the CA mathematics standard 2.NBT. 1-4 (pre- and post-test ), the language of instruction (Spanish or English), and the teachers' preferred strategies and classroom practices.

Pre- and post-test design. The two classroom teachers provided the researcher with the scores of the NYS Common Core Mathematics Curriculum: End-of-Module 3 Assessment Task 2-3 (EngageNY.org, 2015). The district adopted this curriculum for teaching mathematics since 2015; thus, it was expected that all schools (K-6) use it for instruction. The assessment instrument was designed to assess the students' progress in the understanding and use of the concept of place value in different academic tasks 
related to the standard 2.NBT.1-4. The test consisted of five items corresponding to the four standards under the place value concept. See Appendices I and J for the details of this instrument.

Small-group collaborative sessions and place-value tasks. Audio-recordings of small-group collaborative work in which participants had to solve place-value tasks were collected using a non-internet-connected device. They were transcribed, saved on a password encrypted computer, and deleted from the recording device, once the participants' names were pseudonymized. The researcher solely accessed this data.

The first task queried participants to work with a thinking partner and talk about the mathematical topics that had been difficult for them to learn. Once they shared with their thinking partner, they were asked to share out loud what they discussed with the partner. The task's purpose was to have participants reflect on what mathematical concepts or ideas had been challenging for them during the schooling process up to this grade level.

The task for the second small-group collaborative session had to do with making a three-digit number using manipulatives or other resources available. For this task, participants were provided with colorful cubes, paper, pencil, and crayons. Participants in both classrooms were highly excited to work with manipulatives. It was expected that the majority of students used manipulatives first and paper and pencil after, to represent the three-digit number. They were asked to work in pairs or groups of three and discuss their solutions. This task was directly testing standard 2.NBT. 1.

The third small-group collaborative session requested participants to use the same number they constructed in the previous session and add a two-digit number to it. This 
task was not directly related to the standard 2.NBT 1-4 that the study is testing, but it was related to the use of the place-value concept. The purpose of this task had to do with some preparation for future tasks (multi-digit addition) and to challenge students to use their knowledge on place value to solve more complex numerical problems.

Teachers' questionnaire. A second instrument to gather qualitative data was the questionnaire that the two classroom teachers responded to. The questionnaire contained nine open-ended questions. Teachers were asked to provide information about different aspects. The first question queried demographic information; the second question interrogated their years of teaching experience in bilingual settings, and the third question probed their classroom environment for mathematics instruction. The fourth question searched for their belief regarding the language of instruction and its impact on mathematics learning for Latinx EBs in Spanish-English bilingual settings. The fifth question aimed to find out their opinions on the most challenging mathematical concepts for them to teach and their students to learn. Question number six asked for their mathematics lesson structure. Questions seven and eight inquired for their use of CA CCSS-M for planning and their preferred language to use during planning time. Finally, item nine searched for additional teaching practices and instructional strategies to support their students learning of the CA CCSS-M: Number and Operations in Base Ten 1 through 4 (2.NBT.1-4). See Appendix D: Teacher Questionnaire for more detail on the teachers' questionnaire.

Data collection procedures. The District Assistant Superintendent of Educational Services was informed about the study via email (see Appendices 
Appendix A: Email to the Assistant Superintendent) and in person. Once he signed a Letter of Support (Appendix L), the researcher sent an email with a recruitment letter to the two classroom teachers inviting them to participate (see Appendices B \& C). Sixteen Latinx EBs in classroom one (C1) and twenty-four in classroom two (C2) and their parents were invited to an informative meeting about the study. Unfortunately, there was poor attendance at this meeting.

The parents who attended were informed of the study and invited to sign the PCF either in English or Spanish (see Appendices E \& F). The information given to the parents was printed and sent home with the PCF attached to it. In C1, two more students returned the signed form and were included in the study. The focused sample population ended with seven participants from each classroom upon the signature of the PCF. The researcher collected these forms and started the coding process by assigning the letter $\mathrm{S}$ followed by a number to each participant (S\#); for example, S1, S2, S3, and so on, so forth. The researcher used Excel to create a spreadsheet with these codes. The researcher also met with the participants in each classroom, explained the study using kids friendly language, and have them sign the verbal assent form, in English and Spanish (Appendix $\mathrm{G} \& \mathrm{H})$.

The two classroom teachers gave the end-of-unit assessment (that was used in the study as the pre- and post-test) to all students in their classrooms. The researcher then continued to collect qualitative data through the audio recordings of the small-group collaborative sessions using a manual voice recorder (Olympus WS-852). Once this process was completed, the audio recordings of the first session were transcribed and 
saved as a word document in the researcher's laptop for the sole purpose of analysis.

Later in the process, the researcher used the same codes (S\#) to enter every participant's "discourse" recorded during the sessions. Table 8 exhibits the procedures followed during the data collection process to approach RQ1 and RQ2.

Table 8

C1 and C2 Parallel Data Collection

$\mathrm{C} 1$

\begin{tabular}{ll}
\hline Teachers Questionnaire & Teachers Questionnaire \\
$\begin{array}{l}\text { Pre-Test: End of Place Value Module- } \\
\text { EngageNY Curriculum (district-adopted) }\end{array}$ & $\begin{array}{l}\text { Pre-Test: End of Place Value Module- } \\
\text { EngageNY Curriculum (district-adopted) }\end{array}$ \\
$\begin{array}{l}\text { First Small Group Session solving place } \\
\text { value tasks collaboratively (audio-recordings) }\end{array}$ & $\begin{array}{l}\text { First Small Group Session solving place } \\
\text { value tasks collaboratively (audio-recordings) }\end{array}$ \\
$\begin{array}{l}\text { Math instruction in Spanish (3-weeks) } \\
\text { Second Small Group Session solving place value } \\
\text { tasks collaboratively (audio-recordings) }\end{array}$ & $\begin{array}{l}\text { Mecond Small Group Session solving place value } \\
\text { tasks collaboratively (audio-recordings) }\end{array}$ \\
$\begin{array}{l}\text { Math instruction in Spanish continues (3- } \\
\text { weeks) }\end{array}$ & $\begin{array}{l}\text { Math instruction in Spanish continues (3- } \\
\text { weeks) }\end{array}$ \\
$\begin{array}{l}\text { Third Small Group Session solving place } \\
\text { value tasks collaboratively (audio-recordings) }\end{array}$ & $\begin{array}{l}\text { Third Small Group Session solving place } \\
\text { value tasks collaboratively (audio-recordings) }\end{array}$ \\
$\begin{array}{l}\text { Post-Test: at the end of the place value unit } \\
\text { (Unit 3) }\end{array}$ & $\begin{array}{l}\text { Post-Test: at the end of the place value unit } \\
\text { (Unit 3) }\end{array}$ \\
\hline
\end{tabular}

As shown in Table 8, the procedures for data collection were planned to be identical in both $\mathrm{C} 1$ and $\mathrm{C} 2$. Nevertheless, the study was open to dealing with some small changes from a site to a site regarding schedules or events that could modify this initial set of procedures that would have to be reported in the study. Fortunately, the procedures were ultimately followed as planned. 
Only data from students whose parents signed and dated the parent consent forms were used for this study.

\section{Data Analysis}

As previously explained, this exploratory mixed-method research study used the CPMM approach. In this approach, the researcher concurrently conducted the quantitative and qualitative data collection process. The data analysis was conducted separately by using different procedures. After the analysis, the results of both sets of data were compared and interpreted concerning the two research questions.

Quantitative data analysis. A small sample size of seven students from each of the two classrooms $(n=14)$ provided the researcher the opportunity to collect valuable information on the participants' changes in performance via test scores in a pre- and posttest about mathematical concepts related to the place value.

The first research question that guided the study (RQ1) - How does the language of instruction impact second-grade Latinx EB students' understanding of place value, in two Spanish-English transitional bilingual classrooms? - was designed to explore the relationship between the language of instruction, either Spanish in $\mathrm{C} 1$ or English in $\mathrm{C} 2$, and the participants' understanding of the place value concept as measured by the increase in percentage points from the pre- to the post-test.

Quantitative data analysis: The end of unit assessment (pre- and post-test). The instrument used in the study to collect quantitative data was already designed and widely adopted across the United States as an assessment in the Engage New York curriculum (EngageNY.org, 2015). It was assumed that since it was commonly used as part of the 
district adopted curriculum and given to students in the classrooms in the beginning and at the end of each mathematics unit, it has been tested against different assessment models. Nevertheless, the researcher of this study decided to assess the instrument using the assessment triangle provided by the NRC (NRC, 2001b). With this model, the NRC also provided the researcher with a framework and rationale to support the data analysis (Figure 2).

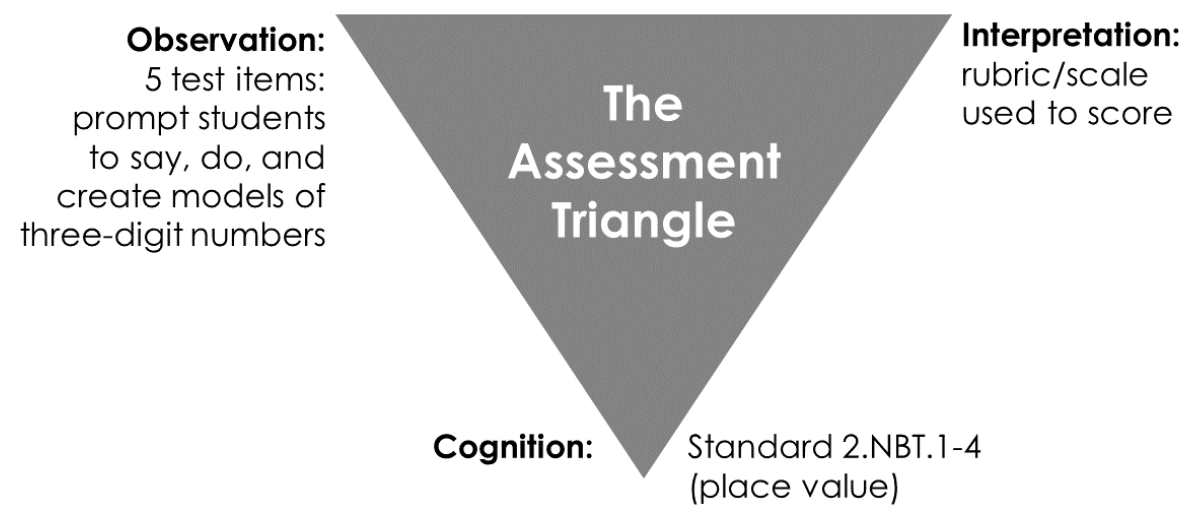

Figure 2. Instrumentation: place value end-of-unit assessment.

Cognition. The first corner of the triangle represents a key element that underlies any assessment, and it is defined as a model of student cognition and learning in a domain. The pre- and post-test instrument was designed to assess the concept of place value. From the cognitive perspective of learning, the end of unit assessment is derived from cognitive and educational research about how people learn. For the particular concept of place value, a set of relevant knowledge that is necessary for the development of an understanding of place value such as counting patterns, skip counting, and strategies to approach explanations of place value were taken into consideration by the designer. (see Appendices I \& J for English and Spanish versions). 
Observation. The second vertex of the assessment triangle is observation. It refers to "a set of beliefs about the kinds of tasks or situations that will prompt students to say, do, or create something that demonstrates important knowledge and skills." (NRC, 2001b, p. 47). It implies that the tasks students needed to respond were not random, but rather carefully thought to offer evidence connected to the concept or model of learning. It also provides a foundation to support the inferences and decisions made based on the scores.

Interpretation. Interpretation is the third vertex of the assessment triangle. For this key element, the patterns derived from the assessment tasks are evidence that support the knowledge and skills being tested. As for the end-of-place-value-unit assessment used as pre- and post-test in this study, the interpretation method was a descriptive statistical model characterized by a set of summaries of patterns observed and analyzed in conjunction with the tasks included to measure different levels of competency. Note that this assessment was based on assumptions that guided the data interpretation. This analysis was applied to the pre-test scores as well as the post-test scores and then compared following RQ1.

Qualitative data analysis. The second research question (RQ2) - How does the language of instruction impact the patterns of communication used by second grade Latinx EBs in small-group collaborative work around place value in Spanish-English transitional bilingual classrooms? - was thought to explore the relationship between the language of instruction, either Spanish or English, and the participants' use of either language, as evidenced by changes in patterns of communication in collaborative conversations solving place value tasks. The assessment triangle (NRC, 2001b) once 
again was used by the researcher to examine the process of reasoning from the evidence that allowed the researcher to decide what to look for in the students' interactions in small-groups based on what they said, did, or created and the reasons for those actions. This process, by itself, constitutes evidence about what was being assessed (NRC, 2001b).

Qualitative data analysis: Small-group collaborative sessions. For the first set of qualitative data that consists of the audio recordings of the participants working in smallgroups to solve place-value tasks, the study used the thematic and discourse analysis to examine participants' discursive patterns. The categories found from the analysis of the audio recordings (after transcription) informed the researcher with the discourse patterns of the students' conversations about the construct of place value. There was a process of reducing the data collected to manageable pieces of information as part of the analysis.

The assessment triangle for the small-group collaborative sessions is displayed in Figure 3.

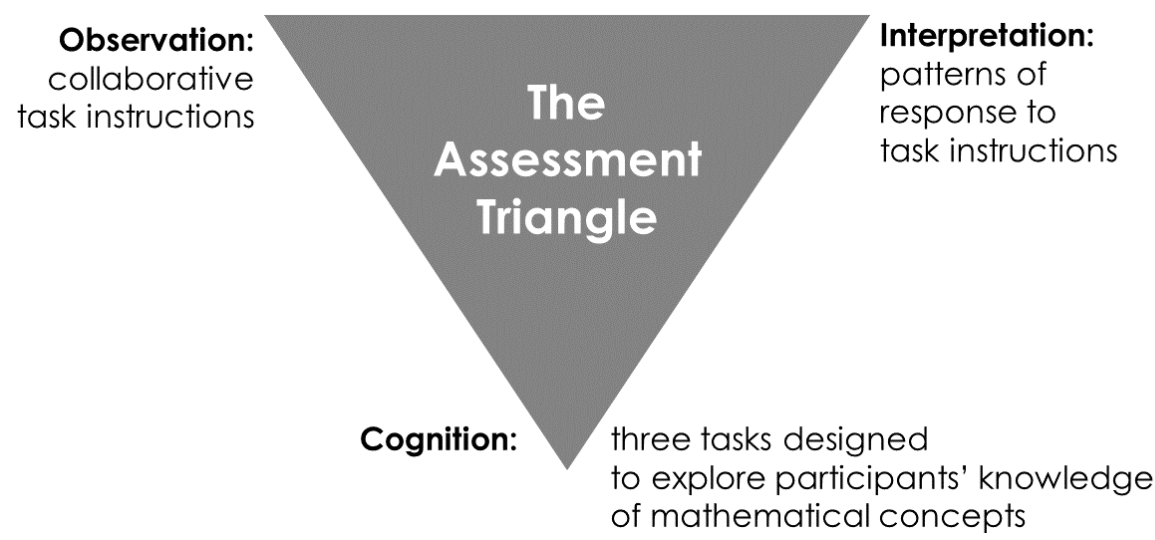

Figure 3. Instrumentation: Small-group collaborative sessions. 
Cognition. The three tasks given to the main participants in each of the small-group collaborative sessions were part of an interview protocol that was used in another classroom with similar demographic characteristics and the same grade level at the beginning of the 2018-2019 school year. These tasks were designed to examine not only the accumulation of factual information and procedures about the concept of place value (quantitative set of data) but also the participants' use of academic linguistic knowledge and cultural artifacts such as graphic representations of place value concepts and language. According to the sociocultural perspective, if students learn to participate in practices, goals, and habits of mind of a particular community, then the group's activity is mediated by different cultural values (NRC, 2001b).

As stated above, the sociocultural perspective is the theoretical framework for this study. Hence, this assessment was a measure of the degree to which participants got involved in the form of practice, such as small-group collaboration. Special attention was given to the way these small communities of learners in two second-grade SpanishEnglish transitional bilingual classrooms generated artifacts and use the language of instruction that was shaping their cognitive activity.

Observation. The set of beliefs that generated the tasks for this assessment was based on the researcher and teacher's experiences. These tasks were not arbitrarily proposed. They were intended to provide the researcher with evidence linked to the cognitive model of learning that was being assessed in the study, the conceptual understanding of place value. The participants' use of language and their behavior during these small-group collaborative sessions provided the researcher with important qualitative data. 
Interpretation. The interpretation of qualitative data collected with this instrument was based on an intuitive or qualitative model rather than a formal statistical one. The interpretation framework specified patterns of response to the task instructions given by participants in the small-group collaborative sessions. The researcher organized them into emerging categories and analyzed them thematically and discursively.

Qualitative data analysis: Teachers' questionnaire. For this set of qualitative data, the study used comparative analysis. The purpose was to compare and contrast teachers' responses regarding mathematics classroom structure and practices, since these aspects play an important role on how second-grade Latinx EBs learn mathematics with either language of instruction, according to the sociocultural framework explained above. The researcher tested this instrument against the assessment triangle, as shown in Figure 4.

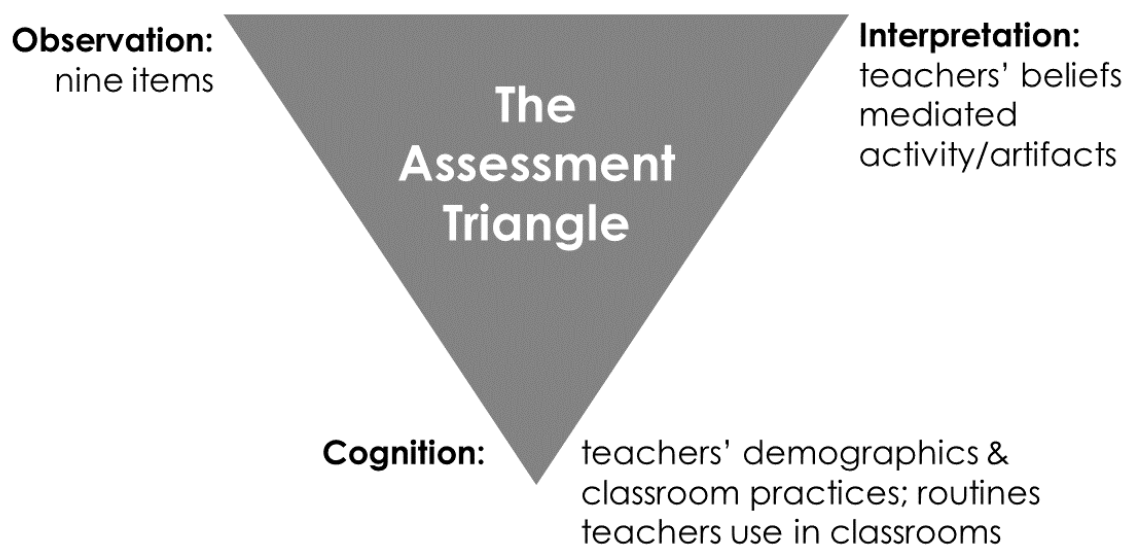

Figure 4. Instrumentation: Teacher questionnaire.

Cognition. This third instrument was used in the study to explore other aspects of the classroom environment that play a key role in the participants' understanding of the place value concept, such as teachers' experience, beliefs, and preferred classroom strategies and practices. This assessment was designed to inform the researcher on the extent to 
which teachers' responses to the items were linked to the main participants' (Latinx EBs) pre- and post-test scores and their patterns of conversations in small-group collaborative sessions. In other words, the questionnaire items were designed to provide a bridge between the other two sets of data collected. From the sociocultural standpoint, the instrument examined the classroom practices and routines that teachers had put in place to provide Latinx EBs in the study with a mathematics learning context.

Observation. Some of the items in the teachers' questionnaire inquired for the demographic information, years of teaching experience in bilingual settings, and beliefs regarding the importance of the language of instruction. These nine items were designed to support the researcher in seeking commonalities and differences between the two teachers involved in the study that might have affected the participants' performance in the pre- and post-test about the place-value concept. The teachers' responses to these items provided the study with a set of specifications that support inferences and discussions based on the data collected with this instrument.

Interpretation. For the interpretation of this instrument (teachers' questionnaire), the unit of analysis is called mediated activity, meaning that a person's or group activity is mediated by widely used cultural artifacts that facilitate mathematics learning. Such artifacts include classroom procedures and routines, graphic representations, anchor charts, use of manipulatives, learning centers, and so forth. The consistent use of these artifacts reflects the teacher's beliefs that guided teachers' decision-making in structuring the mathematics classroom environmentthis. 
The descriptive statistical analysis started to be applied to analyze the pre-test scores once collected, and the post-test at the end of the data collection process. The descriptive statistics analysis helped the researcher describe the basic characteristics of the data in the study through summaries. Descriptive statistical analysis is at the center of any quantitative data analysis.

The process of analyzing the first set of qualitative data collected (audio recordings) started with a simple step of reading and re-reading the transcripts to gain depth and make sure that the findings of the study reflect what the data collected said. Following Harding's (2019) suggestions, the second step in this inductive process was to make summaries to reduce the participants' responses to key points and see if they were relevant to the research questions. Another step followed in this process was to separate the pieces of information that were most relevant to the research questions and those that were not. This process allowed the researcher to eliminate repetition in the responses. Two categorical matrices were created to enter the information as it was collected.

For the analysis of both sets of qualitative data, the researcher used the qualitative data analysis called the CCM. Although CCM was originally advocated by Glaser and Strauss (1967) as part of their Grounded Theory, Barbour (2008) suggested that this method was at the heart of all qualitative data analysis since it relies on comparing and contrasting information from two or more groups. Boeije's words (as cited by Harding, 2019) remind us that "qualitative analysis mostly consists of breaking data apart and putting it back together in relevant and meaningful ways." The qualitative data analysis process for this study was continuous. It began with transferring all the information from 
the instruments to Excel matrices for both teachers' questionnaires and the first smallgroup collaborative session and continued throughout the data collection phase. The purpose was to start making meaning from the participants' use of language, find patterns in the communication process activated in each collaborative session, and relate teachers' responses to the other two pieces of data.

Qualitative data analysis process included thematic, discourse, and comparative analyses, as suggested by Dawson's work (as cited by Harding, 2019). The thematic analysis implies that the researcher identifies themes that emerge from the data. The discourse analysis focuses on patterns of speech and the way that language is used to convey meaning. The comparative analysis involves comparing and contrasting data collected from different respondents. This study used thematic and discourse analysis to approach the first set of qualitative data (audio recordings of participants' small-group collaborative sessions) and the comparative analysis to approach the data obtained from the two teachers' responses to the questionnaire. Throughout the process, the researcher also collected documents such as models, drawings, or other visual representations students learned in the classroom or produced during mathematics classes.

\section{Evidence for Validity and Reliability}

The researcher used the Standards for Educational and Psychological Testing (AERA, APA, \& NCME, 2014) as the main guide to check for validity and reliability of the three instruments.

Evidence for validity. According to the American Educational Research Association, the American Psychological Association, and the National Council on Measurement in 
Education, "Validity refers to the degree to which evidence and theory support the interpretation of test scores for proposed used of tests." (AERA, APA, \& NCME, 2014, p.11). Content validity, response process validity, internal structure validity, relations to other external variables validity, and consequential validity are the five types of validity evidence. To construct a solid validity argument, the numerous strands of evidence must be integrated into a coherent claim that states that the evidence along with theory supports the interpretation of data gathered for a specific purpose (AERA, APA, \& NCME, 2014). The five types of validity evidence were integrated for the first instrument used to collect quantitative data, and the two instruments to collect qualitative data.

First instrument: Pre- and post-test. The pre- and post-test that the researcher used to examine RQ1 - How does the language of instruction impact second grade Latinx EBs' understanding of the mathematical concept of place value (CA CCSS-M 2.NBT. 14) in two Spanish-English transitional bilingual classrooms? - was checked for validity concerning the researcher's use for the study.

Content validity. Although this instrument was already designed to measure a progression toward mastery of the mathematical concept of place value, the researcher decided to use it to measure participants' growth in the understanding of the construct (place value) before and after a series of lessons delivered in the language chosen in each class. AERA, APA, and NCME (2014) recommend including the specific construct the test is intended to measure. This assessment construct is the concept of place value scattered into four standards related to the understanding of three-digit numbers and the fact that these numbers represent amounts of hundreds, tens, and ones. Counting and 
skip-counting, reading and writing numbers to one thousand, and comparing and contrasting three-digit numbers using mathematical symbols are also skills required for participants to demonstrate an understanding of the concept. The knowledge over this construct is measured by the test takers' competency to understand the instructions given in the assessment and the skills used to respond to each item.

The district-adopted curriculum provided the end-of-unit assessment to measure the students' learning outcomes regarding the standards 2.NBT., 1-4. This assessment is used by the classroom teachers in the study as a formative assessment. As such, it measured the participant's understanding of the concept assessed and the skills developed to solve place-value related tasks. The standards addressed in this assessment showed evidence of the relevant knowledge needed for the development of the understanding of place value. For example, participants' knowledge of counting patterns is necessary to understand the concept of place value as well as the ability to explain it. Young-Loveridge (2008) stated that children could be taught place value when they have clarity on the concept of ones and the number of relationships that set the foundation for the concept of ten as a unit.

Response process validity. The end-of-unit-assessment in this study was used as a pre- and post-test to assess the mathematical understanding of the concept of place value or standard 2.NBT. 1-4 to determine growth from the pre- to the post-test and correlate this growth with an important aspect of the classroom environment, such as the language of instruction. According to AERA, APA, and $\operatorname{NCME~(2014,~p.15),~"Evidence-based~on~}$ response processes generally comes from analyses of individual responses." Right after the participants took the pre-test, they were invited to discuss mathematical topics that 
they found more difficult to learn. It was evident that the most common difficult topic for the participants was to deal with big numbers. Big numbers is a term highly associated with multi-digit numbers, which are at the heart of the place value understanding.

The district-adopted curriculum also provided, and advised teachers to use, the rubric or progression-toward-mastery tool to describe the steps that spotlight the gradually increase in concept understanding to the point when students use the concept proficiently. This tool was used by the teachers as the rubric to score the pre- and post-test. It provided the scale to measure the participants' performance that evidenced their understanding of the concept. The test definitely measured what it was intended to measure. Table 9 illustrates items, number of points, and standards addressed in the rubric used to score each response to the assessment used as pre- and post-test in this study. 
Table 9

\begin{tabular}{|c|c|c|c|c|}
\hline $\begin{array}{l}\text { Assessment } \\
\text { Task Item } \\
\text { (Standard } \\
\text { Measured) }\end{array}$ & $\begin{array}{l}\text { STEP 1 } \\
\text { Little evidence } \\
\text { of reasoning } \\
\text { without a } \\
\text { correct } \\
\text { answer. } \\
\text { (1 point) }\end{array}$ & $\begin{array}{l}\text { STEP } 2 \\
\text { Evidence of } \\
\text { some reasoning } \\
\text { without a } \\
\text { correct answer. } \\
\text { (2 points) }\end{array}$ & $\begin{array}{l}\text { STEP } 3 \\
\text { Evidence of some } \\
\text { reasoning with a } \\
\text { correct answer or } \\
\text { evidence of solid } \\
\text { reasoning with an } \\
\text { incorrect answer. } \\
(3 \text { points) }\end{array}$ & $\begin{array}{l}\text { STEP } 4 \\
\text { Evidence of solid } \\
\text { reasoning with a correct } \\
\text { answer. }\end{array}$ \\
\hline $\begin{array}{l}\text { Item 1 } \\
\text { (2.NBT.3) }\end{array}$ & $\begin{array}{l}\text { Student is } \\
\text { unable to solve } \\
\text { any of the parts } \\
\text { correctly. }\end{array}$ & $\begin{array}{l}\text { Student solves } \\
\text { one out of three } \\
\text { parts correctly. }\end{array}$ & $\begin{array}{l}\text { Student solves two } \\
\text { out of three parts } \\
\text { correctly. }\end{array}$ & $\begin{array}{l}\text { Student correctly draws the } \\
\text { number in place value disks, } \\
\text { writes in expanded form or } \\
\text { word form }\end{array}$ \\
\hline $\begin{array}{l}\text { Item } 2 \\
(2 . N B T .3)\end{array}$ & $\begin{array}{l}\text { Student solves } \\
\text { one or two out } \\
\text { of six parts } \\
\text { correctly. }\end{array}$ & $\begin{array}{l}\text { Student solves } \\
\text { three or four out } \\
\text { or six parts } \\
\text { correctly. }\end{array}$ & $\begin{array}{l}\text { Student solves five } \\
\text { out of six parts } \\
\text { correctly. }\end{array}$ & $\begin{array}{l}\text { Student correctly answers: } \\
\begin{array}{ll}\text { a. } 235 & \text { b. } 168 \\
\text { c. } 634 & \text { d. } 480 \\
\text { e. } 213 & \text { f. } 730 \\
\end{array}\end{array}$ \\
\hline $\begin{array}{l}\text { Item 3 } \\
(2 . N B T .1)\end{array}$ & $\begin{array}{l}\text { Student solves } \\
\text { one out of four } \\
\text { parts correctly. }\end{array}$ & $\begin{array}{l}\text { Student solves } \\
\text { two out of three } \\
\text { parts correctly. }\end{array}$ & $\begin{array}{l}\text { Student solves } \\
\text { three out of four } \\
\text { parts correctly. }\end{array}$ & $\begin{array}{l}\text { Student correctly answers: } \\
\begin{array}{ll}\text { a. } 1 & \text { b. } 1 \\
\text { c. } 10 & \text { d. } 16\end{array}\end{array}$ \\
\hline $\begin{array}{l}\text { Item 4 } \\
\text { (2.NBT.2) }\end{array}$ & $\begin{array}{l}\text { Student solves } \\
\text { one out of four } \\
\text { parts correctly. }\end{array}$ & $\begin{array}{l}\text { Student solves } \\
\text { two out of four } \\
\text { parts correctly. }\end{array}$ & $\begin{array}{l}\text { Student solves } \\
\text { three out of four } \\
\text { parts correctly. }\end{array}$ & 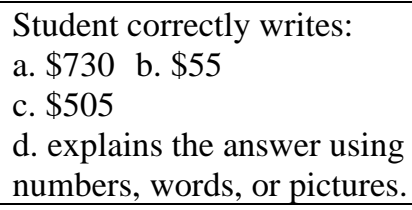 \\
\hline $\begin{array}{l}\text { Item 5 } \\
(2 . N B T .4)\end{array}$ & $\begin{array}{l}\text { Student solves } \\
\text { one out of five } \\
\text { parts correctly. }\end{array}$ & $\begin{array}{l}\text { Student solves } \\
\text { two or three out } \\
\text { of five parts } \\
\text { correctly. }\end{array}$ & $\begin{array}{l}\text { Student solves four } \\
\text { out of five parts } \\
\text { correctly. }\end{array}$ & $\begin{array}{l}\text { Student correctly answers: } \\
\begin{array}{ll}\text { a. }<\quad \text { b. }> \\
\text { c. }> & \text { d. }= \\
\text { e. }= & \end{array}\end{array}$ \\
\hline
\end{tabular}

Source: EngageNY.org. (2015). NYS common core mathematics curriculum: End-of-module assessment task 2-3. Washington, D.C.: EurekaMath ${ }^{\mathrm{TM}}$ and Great Minds.

As seen in Table 9, the items in the assessment instrument were directly related to the place value standards. An imbalance was observed in the number of items with the standards measured. For example, two test items were to measure standard 2.NBT. 3 (Read and write numbers to 1,000 using base-ten numerals, number names, and expanded form), whereas only one test item measured the other standards (2.NBT. 1, 2, and 4). Nonetheless, this imbalance was not a threat to the response process validity. 
Internal structure validity. Explicit relationships between the items and the construct and the analysis of the patterns to be found in participants' responses are the evidence for the validity of the pre- and post-test internal structure

Relations to other external variables validity. The relationship of test results to variables that are external to the tests provided another source of validity evidence that supported the interpretation of the test for the purpose given in this study. The pre- and post-test were given to all students in each of the two classrooms involved in the study. Within the sociocultural theoretical framework, the scores in the pre- and post-test were expected to relate closely to other measures of knowledge and skills about the construct (place value concept). In this study, the participants' knowledge and skills about place value were also examined by some categories in the communication patterns used by participants during small-group collaborative work. These patterns were expected to mirror at least two similar categories scored in the pre- and post-test.

Consequence validity. According to validity standards for validity, this type of evidence might have to do with the expectation that some benefit was going to be derived from the use of scores and the interpretations by the researcher (AERA, APA, \& NCME, 2014). An additional benefit from the use of test scores and the subsequent interpretation of them was the improvement of classroom practice based on the attention paid to the critical dimensions of classroom practice suggested by Carpenter and Lehrer (1999), tasks, tools, and classroom norms, to promote understanding of mathematical concepts.

Second Instrument: Small-group collaborative sessions. Audio-recordings of three small-group collaborative sessions, in which participants had to solve place-value tasks, 
were collected using a non-internet-connected device. They were transcribed, saved on a password encrypted computer, and deleted from the recording device, once the participants' names were coded. The researcher solely accessed this data. Validity evidence was collected for this instrument, as described below.

Content validity. As previously stated, the three tasks that were given to the participants in each of the three small-group collaborative sessions were part of an interview protocol that was used in another classroom with similar demographic characteristics and the same grade level at the beginning of the 2018-2019 school year. The interview protocol was shared with an expert in mathematics education research who later suggested that four of the questions from the interview were used as collaborative tasks for being closely related to what needed to be measured in this study, the understanding of mathematics standard 2.NBT.1-4, place value. The instruction in the first small-group collaborative session requested the participants to think and discuss with partners their opinions on what were the most challenging concepts of mathematics class to learn. This item in the small-group discussion was intended to enhance participants' reflection on their own learning process. The instruction for the second small-group session queried the participants to represent a three-digit number using different resources and models they had learned. This task instruction addressed the same standard item 1 in the pre- and post-test did (2.NBT.3). This instructional task aimed to explore the interrelationships between counting, the knowledge of number, grouping, and partitioning, which are common principles that highlight the complexities of the concept of place value. The third instructional task asked participants to reconstruct the three-digit 
number they made in session two and add a two-digit number to it. The purpose of this task was to identify procedures or learned ideas that participants used to solve a problem that had not been explicitly taught to them at the time of the task or required the exploratory use of current knowledge.

Response process validity. By the standards for validity, "Evidence of response processes can contribute to answering questions about differences in meaning or interpretations of test scores across relevant groups" (AERA, APA, \& NCME, 2014, p. 15). One way to verify the validity of the response processes of this instrument was to categorize and compare side by side the participants' responses for each small-group collaborative session. Understanding the differences in meaning or interpretation of responses across the two selected groups, helped the researcher explain those differences in participants' responses.

Internal structure validity. Evidence for this type of validity was not explicitly discussed for this instrument since the purpose was to explore participants' responses to the items in it. Nevertheless, it has been said in the study that in designing the three tasks that conform to this assessment, the researcher made sure that at least two of the task instructions were aligned to the mathematics standard being examined (2.NBT. 1-4).

Relation to external variables validity. As previously stated, the relationship of test results to variables that are external to the tests provides another source of validity evidence that supports the interpretation of the test for the study (AERA, APA, \& NCME, 2014). In this study, the participants' knowledge and skills about place value were also examined by some categories in the communication patterns used by 
participants during small-group collaborative work. Within the sociocultural theoretical framework, the participants' interactions in the small-group collaborative work relate closely to other elements of the classroom environment such as collaboration norms, tasks, and mathematics teaching strategies to develop knowledge and skills about the construct of place value.

Consequence validity. Within the sociocultural learning framework, having students reflect on their own learning process and share their thoughts with others supports their understanding of the concept, whether it is easy or difficult for them. This study claimed that the first item in the small-group discussion had benefits that went "beyond the direct interpretations or uses" of the assessment (AERA, APA, \& NCME, 2014, p.20). The instruction in the first small-group collaborative session requested participants to think and discuss with partners their opinions on what were the most challenging concepts of mathematics class to learn. As has been emphasized, the purpose of the task was to enhance participants' reflection on their own learning process. This practice in many different formats supports students' metacognition and provides teachers with more formative information to customize support given to students who needed it.

Third Instrument: Teachers' Questionnaire. A nine-item questionnaire was responded by each of the two teachers involved in the study.

Content validity. The content validity evidence for this instrument was previously explained under the element "Cognition" when tested against the assessment triangle. As aforementioned, this instrument supported the researcher in the exploration of other aspects of the classroom environment that affected the participants' understanding of the 
concept of place value. This assessment was designed to inform the researcher on the extent to which teachers' responses to the items were linked to the main participants' understanding of the concept of place value, as measured by the pre- and post-test scores and their patterns of conversations in small-group collaboration. From the sociocultural lens, the instrument examined all classroom practices and routines that were already in place in each mathematics classroom. All the interactions that happened within this context contributed to the students' social construction of knowledge.

Response process validity. "Theoretical and empirical analysis of the response processes of test-takers can provide evidence concerning the fit between the construct and the detailed nature of the performance or response actually engaged in by test-takers." (AERA, APA, \& NCME, 2014, p. 15). The interpretations that the researcher made from the teachers' responses collected by this instrument were intrinsically related to the construct since many of the items were intended to examine the mathematics classroom practices used by each of the participating teachers, as well as their preferred teaching strategies. Additionally, this study acknowledged another benefit derived from this assessment: the improvement of mathematics instructional practices through the enhancement of teachers' reflection on decisions they have to make daily to deliver instructions. The structure of the mathematics classroom environment to facilitate their students' learning was an important takeaway for the participating teachers.

Internal structure validity. Validating the researcher's interpretations of teachers' responses to the questionnaire was necessary to examine the degree to which the relationships among the instrument's items related to the construct on which such 
interpretations were based, as the Standards in Educational Testing (AERA, APA, \& NCME, 2014) suggest. The first four out of nine items aimed to obtain demographic information, and the remaining items inquired for more specific data regarding the teaching strategies and pedagogical practices that each teacher activated for mathematics learning in each classroom during the place value unit of study. There was a strong connection between the questions included in this instrument and the purpose of the study. The interpretations the researcher made out of the data collected by this instrument supported the purpose of the study.

Relation to external variables. The intended interpretation for this instrument implied that the construct was related to some other variables that were in different ways external to the instrument. For example, the number of years of teaching experience in bilingual settings was a criterion that the study was expected to predict and interpret upon the study's purpose. It also followed the Standards for Educational and Psychological Testing, "Categorical variables, including group membership variables, become relevant when the theory underlying a proposed test use suggests that group differences should be present or absent if a proposed test scores interpretation is to be supported." (AERA, APA, \& NCME, 2014, p. 16). Categories included in this instrument, such as mathematics class structure or the use of mathematics standards for planning, were relevant from the sociocultural learning theory and allowed the researcher to compare the presence or absence of such structures in each of the two mathematics classrooms.

Consequence validity. Although the researcher's interpretation of the data obtained through the use of this instrument did not provide the questionnaire takers any concrete 
benefit, such interpretations were expected to be useful to support elementary teachers in the improvement of the mathematics classroom environment, including instructional practices. It was providing teachers with a tool that called attention on aspects that were difficult to see on a day to day basis. This tool, by itself, was benefitial to promote teachers' reflection and consistent improvement of mathematics classrooms to facilitate students' learning.

\section{Evidence for Reliability}

Reliability is a concept used for testing or assessing quantitative research.

Considering that this study used a mixed methods approach in which the first instrument collected quantitative data, the reliability assessment for this instrument was guided by the Standards for Educational and Psychological Testing (AERA, APA, and NCME (2014). Evidence of the qualitative data instruments' reliability was still analyzed using the appropriate terms that applied to qualitative research in alignment with the theoretical framework of the study.

\section{Reliability for the quantitative data instrument (pre- and post-test). This} instrument was assessed for reliability using the Standards for Educational and Psychological Testing as a guide. The term reliability in this book was used to refer to the idea of consistency and to differentiate it from the term reliability coefficients of the classical theory (AERA, APA, \& NCME, 2014). This distinction was key to the purpose of this study. Since the interpretations of the instrument used to collect quantitative data did not lead to decisions that were difficult to reverse, a higher degree of reliability was 
not required. Although there are various types of reliability evidence, this instrument was evaluated for three of them.

Internal consistency. Internal consistency reflects the extent to which items within an instrument measure various aspects of the same construct. As previously stated, the preand post-test construct is the concept of place value. It was already explained in the check for validity evidence that all the items included in this instrument referred to each of the standards being measured. For example, item 1 in the test was intended to assess the understanding of standard 2.NBT. 3: Read and write numbers to 1000 using base-ten numerals, number names, and expanded form.

Alternate form, test-retest, and inter-rater reliability. Alternate forms make reference to assessments that "are designed to have the same general distribution of content and item formats, the same administrative procedures, and at least approximately the same score means and standard deviations in some specified population" (AERA, APA, \& NCME, 2014, p.35). For this study, there was only one form of the test used, and there was not an alternative version of it that evaluated the same items. The test-retest part of the reliability evidence might correspond to the administration of the same test as posttest at the end of the place value unit for which the conditions or contextual settings (place and time) were the same. Regarding the rater reliability, since the test was used to collect and measure quantitative data, and a rubric was used to score the participants' responses, it was not feasible to the instrument.

Random errors. As stated in the Standards for Educational and Psychological Testing report, random errors in instrument score data are potential threats to the reliability of the 
instrument when the responses are unpredictable as a result of contexts that influence how respondents engaged with the instrument (AERA, APA, \& NCME, 2014).

Considering the study's population, some conditions that could have influenced random error in this study included time, motivation, and distractions. A few strategies were employed to reduce random error, such as administering both the pre- and post-test in the morning, so participants were fresh and focused. The two classroom teachers gave the test to all students in their classrooms following the procedures already established to control distractions. For example, the time assigned to complete the test was from 30 to 45 minutes. The format used by classroom teachers was paper and pencil since they consider students already have sufficient time in front of their computers. Also, it was easier to handle the scored tests to the researcher. The rubric provided by the districtadopted-curriculum was used to score both pre- and post-test.

Reliability for the qualitative data instruments. As aforementioned, reliability is a concept mostly used for testing quantitative research. Nevertheless, reliability is frequently used in qualitative research, although it is not completely appropriate. Since the purpose of qualitative research is "generating understanding," then the concept of reliability might be irrelevant in qualitative research (Golafshani, 2003). This study relied on Patton's (2001) statement that reliability is a consequence of the validity in a study and Lincoln and Guba's (1985) statement, "Since there can be validity without reliability, a demonstration of the former is sufficient to establish the latter" (p. 316). This mixedmethods study also considered the idea that mixing methods is completely different from mixing paradigms (Barbour, 1998). In qualitative research, many terms are used to 
describe the consistency and pertinence of data interpretations, including trustworthiness, rigor, and quality (Golafshani, 2003). In assessing this study's qualitative instruments' reliability, the researcher was encouraged to use terms that applied to qualitative research and were aligned with the theoretical framework of the study. The terms used for the analysis were credibility, consistency, and transferability.

Credibility. The credibility of the two instruments to collect qualitative data for this study was assessed by using two of the four procedures that Merriam and Tisdell (2016) suggested, detailed or thick description, and establishing trust. Rich, thick descriptions have to do with the strength of the analysis to ensure that readers understand the context and the results of the study. In this study, efforts were put in providing detailed description when reporting participants' responses to both the small-group collaborative tasks and the teachers' questionnaire by using quotes when needed. Establishing trust was also an important strategy to gain participants' honesty and openness to respond to the two instruments. Building rapport was the first step to establish trust. The researcher met with the two classroom teachers to explain the study and get their buy-in. The researcher also collaborated with them in between small-group collaborative sessions at least once a week throughout the study and supported them in delivering their mathematics lessons. The students in their classes familiarized with the researcher's presence and felt safe during the audio-recordings.

Consistency. As has been stated, the consistency across instruments to measure what they were intended to measure has been assessed for reliability in this study. The researcher made sure that the small-group instructional tasks were directly or closely 
related to the knowledge required for the standard 2NBT. 1-4. Furthermore, the teachers' questionnaire inquired the classroom teachers for their preferred strategies to teach place value as well as mathematics concepts they found to be difficult to teach, among other items. As stated in the IRB, the researcher processed transcriptions herself to protect the participants' identity. To ensure the reliability of the raw qualitative data, a careful review of the transcribed audio recordings was conducted. Moreover, the researcher and her advisor met every two weeks to review the process and the raw data matrix and discuss the changes needed.

Transferability. Transferability invites research readers to make connections between selected elements of a study and their own situation or experience. Generalizability, on the other hand, can be defined as the extension of research findings and conclusions from a study conducted on a sample population to the population at large. Sound generalizability requires data on large populations. Quantitative experimental research is most likely to produce higher generalizability. Since the current study described findings from a small sample size, its findings were not generalizable, but transferable. Also, considering that this study focused on a well-defined ethnic group, the potential for findings to be transferred to other contexts might be more difficult because there was not a maximum variation involved. According to Merriam and Tisdell (2016), maximum variation has to do with the diverse population represented in the study. Nonetheless, this research's readers can make connections between different elements of the study and their own work. For instance, teachers in schools with high percentages of Latinx EBs in 
the classroom might take the teachers' questionnaire to self-assess their beliefs about the mathematics classroom environment.

Response bias. This term is defined as the tendency of a person to answer questions on a test or survey to portray themselves as "good" or "bad" at certain abilities (AERA, APA, \& NCME, 2014, p. 155). For example, they may feel pressure to give answers that are socially acceptable or unacceptable for various reasons. In this study, the risk of response bias was minimal because the students were used to take the end of unit assessment in the beginning and at the end of each unit as formative assessment, and had been told that this was useful for the teacher to know how to support them during the development of the unit. The researcher noted that this is a habit of mind that was growing in these classrooms.

Regarding the small-group collaborative sessions, the researcher also noted that the students felt free to make mistakes and correct themselves or one another without judgment. As for the teachers' questionnaire, teachers understood that their participation in the study was voluntary and did not have any evaluative purpose. By emphasizing the non-evaluative aspect of the questionnaire, the researcher controlled the response bias for this instrument.

\section{Ethical Considerations}

This study got the approval from the San Jose State University Institutional Review Board (Protocol \# S19120, see Appendix K: IRB Protocol). The Assistant Superintendent authorized the researcher to collect data in these two classrooms and to use the resources provided by the district for the purpose of the study. The assessment used as pre- and 
post-tests and the rubric used to score them were part of the district adopted curriculum and counted as district resources for the study (see Appendix L: Letter of Support). Classroom teachers from the two classrooms were informed of the study and invited to participate via email. The researcher met with them to go over the Teacher Consent Form and get it signed to initiate the study (see Appendices C \& D). All second-grade Latinx EBs in the two classrooms involved were invited to participate. Participation was voluntary. Participants and their parents in each classroom were informed of their rights and identity protection measures. Parents were invited to an informational meeting at the end of which, they signed the PCF authorizing their children to be audio-recorded and their pre-and-post test scores to be used for the study.

Unfortunately, the attendance at these meetings was not as expected. Data were collected only for students whose parents signed the PCF in English or Spanish (see Appendices E \& F). A verbal assent script in English and Spanish was required once participants were verbally informed of the study and invited to participate (see Appendices G \& H). Once data was collected, the researcher pseudonymized the participants' names to ensure confidentiality. There were not any risks for participants. Certain discomfort due to the presence of a third person in the classroom during smallgroup sessions was anticipated and solved as rapport was built. After a few days, participants found the researcher's presence more familiar.

To sum up, this chapter described the procedures followed by the researcher to ensure that the data collection process was safe, transparent, and ethical. The instruments used to collect the data intended to explore the two research questions were examined for validity 
and reliability, as suggested by the Standards for Education and Psychological Testing (AERA, APA, \& NCME, 2014).

The mixed-method research study was exploratory. The method allowed the researcher to relate both quantitative and qualitative data sets and interpret them from the sociocultural perspective, which enhances the social nature of learning, including the importance of the classroom environment and the language used for mathematics instruction in bilingual settings. 


\section{Chapter Four: Findings}

The language of instruction has been considered an important aspect that contributes to learning and performing successfully in mathematics classrooms.

The purpose of this study was to explore the impact of the language of instruction, either Spanish or English, on second-grade Latinx EBs' understanding of the mathematical concept of place value. The participants' performance in a pre- and posttest and their patterns of communication in three small-group collaborative sessions were the evidence to explore the impact of the language of instruction on the participants' understanding of the concept studied.

Examining whether the language of instruction had an impact on the participants' understanding of the concept of place value supports teachers and school administrators in making decisions regarding what language to use for delivering mathematics instruction in classrooms with large numbers of Latinx EBs.

This exploratory mixed methods study used a convergent parallel mixed-method design that involved simultaneous quantitative and qualitative data collection. The key idea with the convergent parallel mixed method design (CPMMD) was to collect both quantitative and qualitative sets of data using similar or parallel variables, constructs, or concepts.

This study investigated two research questions: RQ1 - How does the language of instruction impact second-grade Latinx EBs' understanding of the mathematical concept of place value (CA CCSS-M 2.NBT. 1-4) in two Spanish-English transitional bilingual classrooms? - RQ2 - How does the language of instruction impact the patterns of 
communication used by second-grade Latinx EBs in small-group collaborative work around place value in Spanish-English transitional bilingual classrooms? - This chapter presents a summary of the participants' demographics, followed by a description of the findings concerning the two research questions that guided the study.

\section{Research Question One}

The first research question (RQ1) examined two groups of Latinx EBs' understanding of the concept of place value in the beginning and at the end of the place-value unit, as measured by participants' changes in scores from a pre to a post-test. More specifically, the researcher wanted to investigate whether the language of instruction, Spanish in C1 and English in C2, affected the students' understanding of the target concept. This question was approached through a comparison between the pre- and post-test scores.

Analysis of the quantitative data findings. Since this study was not intended to reach conclusions that were generalizable beyond the immediate data, descriptive analysis was applied to analyze this set of quantitative data. The descriptive analysis helped the researcher describe the basic characteristics of the data in the study by using summaries about the sample and measures.

The sample was composed of fourteen Latinx EBs' enrolled in two second-grade Spanish-English transitional bilingual classrooms for the 2019-2020 school year in two schools with bilingual programs. The quantitative set of data was the end of unit assessment provided by the district adopted mathematics curriculum and given to all students in the classrooms as a pre- and post-test. The purpose of collecting this set of data was to compare each group of participants' knowledge about the concept of place 
value, before and after the place value unit was delivered in the language chosen for instruction. These results were correlated with the language of instruction and other classroom environment aspects. In C1, the unit lessons were in Spanish, whereas, in C2, they were in English.

The data were described via reports of averages and noted scores of individual participants. This quantitative data did not require sophisticated analysis, but a clear and meaningful report of the data collected. The two classrooms teachers gave and collected the paper-based pre- and post-test in the beginning and at the end of the place value unit. They scored the pre-test first and the post-test when the place unit ended, using the rubric provided by the district-adopted curriculum and handled them to the researcher. The researcher copied the scored tests and coded them before returning the originals to the classroom teachers. The researcher recorded the scores in a spreadsheet that was coded and aligned with the coding system for the qualitative data. The pre- and post-test scores were correlated to determine growth in the participants' understanding of the concept assessed. Other variables such as students' age, cultural and linguistic background (Table 5 and Table 6), and language proficiency levels were also collected and recorded in the spreadsheet as raw data.

It was hypothesized that in $\mathrm{C} 1$, where all the lessons for the place value unit were presented in Spanish, the participants would obtain higher scores in the post-test, implying higher levels of their understanding of the concept of place value. Meanwhile, in $\mathrm{C} 2$, where the unit was taught in English, the participants' second language, it was hypothesized that the post-test scores would exhibit lower scores implying less increase 
in the understanding of the concept taught, due to the language of instruction chose (English).

The pre- and post-test scores were discussed with the classroom teachers after the post-test was scored. According to the $\mathrm{C} 1$ teacher (T1), the decision to teach mathematics in Spanish in this classroom was supported by research that suggested that learning mathematics in the student's primary language might be beneficial for students' learning. When T1 gave the place value unit assessment (pre-test) to all her students, she expected better results since the students had been in the school for at least two consecutive years and used the same mathematics curriculum.

Comparisons between $\mathrm{C} 1$ and $\mathrm{C} 2$ quantitative results. Although $\mathrm{C} 1$ pre-test scores were surprisingly low, it was rewarding for T1 to find, at the end of the study, a mean increase of 64 percentage points from the pre- to the post-test (Table 10). She considered it a significant increase in percentage points. C2 showed a mean increase of 71 percentage points (Table 11).

Table 10

C1 Pre-and Post-Test Results and Increase (or Decrease) in Scores

\begin{tabular}{cccc}
\hline Student & Pre-Test Score & Post-Test Score & Increase/Decrease* \\
\hline S1 & $15 \%$ & $85 \%$ & 70 \\
S2 & $5 \%$ & $60 \%$ & 55 \\
S3 & $15 \%$ & $80 \%$ & 65 \\
S4 & $5 \%$ & $90 \%$ & 85 \\
S5 & $35 \%$ & $90 \%$ & 55 \\
S6 & $5 \%$ & $60 \%$ & 55 \\
S7 & $5 \%$ & $65 \%$ & 60 \\
\hline
\end{tabular}

*Note: The last column shows an increase (or decrease) in percentage points between pre-test and post-test. 
Table 11

C2 Pre-and Post-Test Results and Increase (or Decrease) in Scores

\begin{tabular}{cccc}
\hline Student & Pre-Test Score & Post-Test Score & Increase/Decrease* \\
\hline S8 & $10 \%$ & $85 \%$ & 75 \\
S9 & $10 \%$ & $80 \%$ & 70 \\
S10 & $10 \%$ & $100 \%$ & 90 \\
S11 & $25 \%$ & $90 \%$ & 65 \\
S12 & $25 \%$ & $60 \%$ & 35 \\
S13 & $20 \%$ & $100 \%$ & 80 \\
S14 & $20 \%$ & $100 \%$ & 80 \\
\hline
\end{tabular}

*Note: The last column shows an increase (or decrease) in percentage points between pre-test and post-test.

As shown in Table 10, there was only one outlier (S5) who scored 35 percent in the pre-test, which was the highest percentage for both groups. Still, even though S5 scored 90 percent in the post-test, his increase in percentage points was identical to that of S2 and S4, whose increase was also 55 percentage points. As shown in Table 11, S12's scores only increased 35 percentage points from pre- to post-test. This result suggests that she was not confident in dealing with place value. Furthermore, she repeatedly expressed how difficult it was for her to do mathematics. She brought up some preconceptions about her performance and attitude toward mathematics that appeared to prevent her from trying. However, despite her misgivings, during the small collaborative sessions (as it is shown in the Qualitative data analysis section of Chapter Four), she still engaged in the tasks. Even though she did not sound confident, she participated and waited for her peers' guidance.

Whenever a study aims to compare the average performance between two groups, a ttest for differences between groups is the best way to perform the comparison, whether it 
is a descriptive or inferential statistical design. A t-test is commonly used to decide the extent to which the value of two variables is actually different from one another.

The researcher considered the following three assumptions before running a t-test. First, a t-test statistic method is used to determine if there was a significant difference between the means of two groups based on a sample of data. Next, the test relies on a set of assumptions for it to be interpreted properly and with validity. Among these assumptions, the data must be randomly sampled from the focused population. Additionally, the data variables follow a normal distribution.

This study satisfied the first assumption since the mean scores for each group needed to be compared to find out if there was a statistically significant difference in mathematics performance. Since the study was conducted with students whose parents signed the required form, it could be said that participants were randomly chosen from two-second grade Spanish-English classrooms. Finally, the study also assumed normal distribution for this small sample size.

Participants in $\mathrm{C} 2$ - where mathematics instruction was in English—exhibited higher scores in their pre-test as compared to $\mathrm{C} 1$, and that trend continued in the post-test as well. When comparing $\mathrm{C} 2$ pre- and post-test scores, the average increase in scores was 71 percentage points, indicating an overall difference in the performance of 7 percentage points of $\mathrm{C} 2$ (71 points) over $\mathrm{C} 1$ (64 points). Figure 5 shows the participants' increase in percentage points in performance following the post-test for both classrooms. 


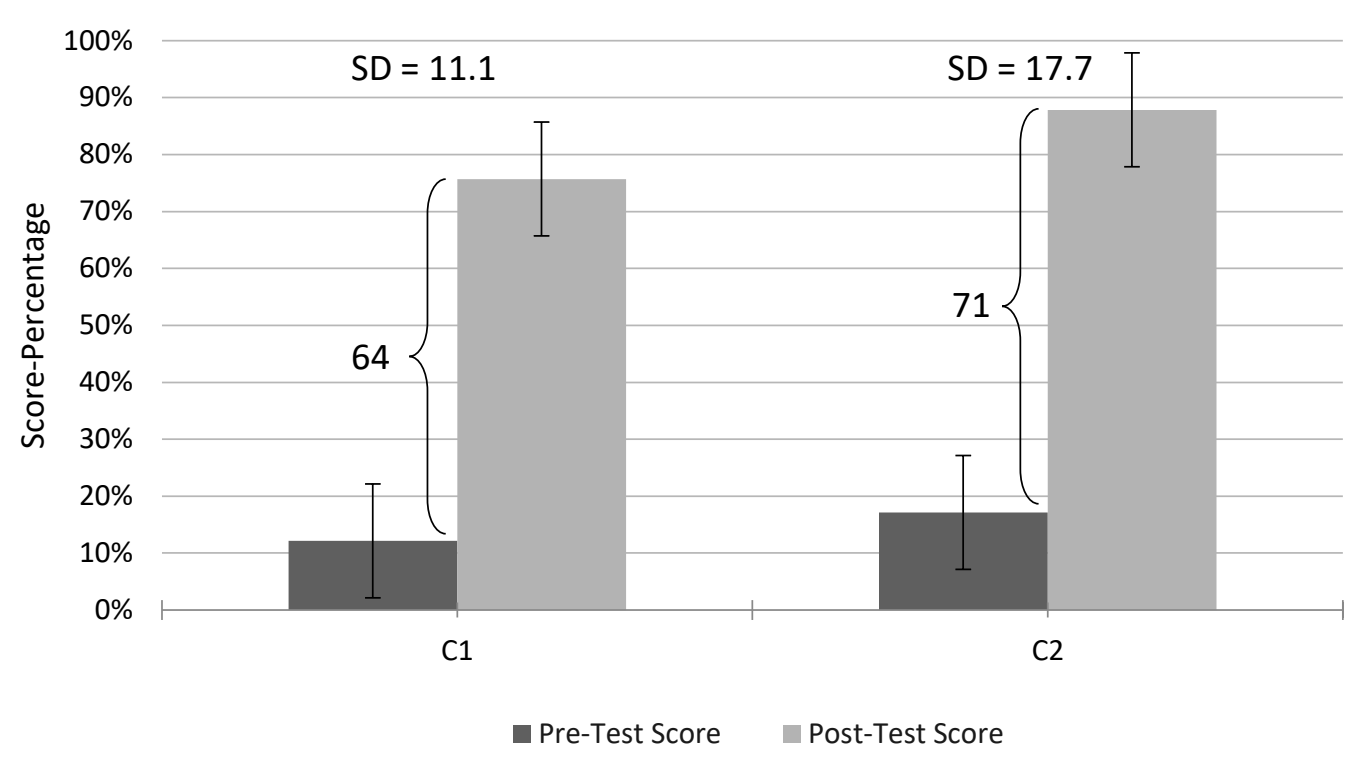

Figure 5. $\mathrm{C} 1$ and $\mathrm{C} 2$ pre- and post-test mean scores with error bars which represents +/- 2 SE.

Figure 5 shows the results of the paired samples t-test, comparing the pre- and posttest performance in $\mathrm{C} 1$ and $\mathrm{C} 2$. While $\mathrm{C} 2$ students' performance increases, on average, by 71 percentage points across pre- and post-tests, compared to 64 percentage points in $\mathrm{C} 1$, this difference between the sampled populations was not statistically significant at the $95 \%$ level of significance, $t(12)=0.91, p=0.3825$. Since the $p$-value is greater than alpha (alpha $=0.05)$, it fails to reject the null hypothesis that the mean of the two classes is the same. The researcher had this analysis reviewed by two experts in statistics who confirmed the analysis. There was insufficient evidence to conclude that the mean increase was actually different. In other words, regardless of the language of instruction, the place value scores were, statistically speaking, the same in both classes. Thus, although C2 pre-test scores were higher than $\mathrm{C} 1$ participants' scores in the same test, the 
difference in performance in the mean increase (Figure 5) for this test did not have a significant impact concerning RQ1.

When comparing the mean and standard deviation of the sample population $1(\mathrm{C} 1)$ $(\mathrm{M}=64, \mathrm{SD}=11.1)$ to the mean and standard deviation of sample population $2(\mathrm{C} 2)(\mathrm{M}$ $=71, \mathrm{SD}=17.7), \mathrm{C} 1$ seems to be more closely distributed around the mean. In contrast, C2 seems to have a higher mean with more spread.

The overall results in pre- and post-tests across $\mathrm{C} 1$ and $\mathrm{C} 2$ suggest that the language of instruction used in each of the classrooms did not have an impact on the participants' understanding of the concept of place value across the two classrooms.

The error bars for the pre-test and the post-test in both $\mathrm{C} 1$ and $\mathrm{C} 2$ overlapped considerably, suggesting visually what the t-test showed — that the difference in performance for both the pre-test and the post-test between $\mathrm{C} 1$ and $\mathrm{C} 2$ was not significant for the overall performance.

This result suggested that both groups of participants exhibited an increase in the mathematical understanding of the place value concept, regardless of the language used for mathematics instruction, at least for this small sample size. Given this result, the researcher did not proceed to analyze other confounding factors that might have influenced the initially hypothesized outcome - that the language of instruction would make a difference.

This sample reflects the overall demographic and student population of second-grade Latinx EBs in the two Spanish-English bilingual classrooms selected for the study. An evaluation of other potential influences on the participants' mathematics performance, 
such as parent involvement, parent's and students' perspectives toward mathematics, and out-of-school factors, fall out of the scope of this dissertation. Such analyses may provide further insights into the analysis of the impact of the language of instruction on these two groups of Latinx EBs' understanding of mathematical concepts.

\section{Research Question Two}

The second question (RQ2) - How does the language of instruction impact the patterns of communication used by second-grade Latinx EBs in small-group collaborative work around place value in Spanish-English transitional bilingual classrooms?explored the patterns of communication used by participants in three small-group collaborative sessions with very specific tasks. Table 12 shows the dates that the three small-group collaborative sessions were held for each classroom.

Table 12

Small-Group Collaborative Work Schedules for C1 and C2

\begin{tabular}{cccc}
\hline Classroom & Session One & Session Two & Session Three \\
\hline C1 & $11 / 7 / 2019$ & $12 / 4 / 2019$ & $1 / 8 / 2020$ \\
C2 & $11 / 8 / 2019$ & $12 / 5 / 2019$ & $1 / 10 / 2020$ \\
\hline
\end{tabular}

There were approximately three weeks between session one and session two, and the same amount of time between sessions two and three in both classrooms.

In approaching RQ2, two sets of qualitative data were collected and analyzed. The first dataset consisted of the transcripts of the three small-group collaborative sessions, and the second dataset was the teachers' responses to a questionnaire that each of the two classroom teachers completed at the beginning of the study. The purpose of this set of qualitative data was to find similarities and differences between the teaching perspectives 
and teachers preferred practices regarding mathematics teaching and learning. These responses were analyzed concerning the language of instruction (Spanish or English) used in each of the classrooms.

Analysis of qualitative findings. Qualitative data can be approached in many ways. This study considered three of the four options provided by Dawson's work (as cited by Harding, 2019), to approach the analysis of the qualitative datasets in this study. Those options were: thematic, discourse, and comparative analysis; the fourth option, content analysis, was not included in this study. Thematic and discourse analyses were applied to the first qualitative dataset (audio recordings), and comparative analysis was applied to the second qualitative dataset (teachers' questionnaire).

As previously explained, the first set of qualitative data consisted of the audio recordings of three small-group collaborative sessions with the same seven students from each classroom. The purpose of this set of qualitative data was to examine the patterns of communication used by the participants when interacting to solve place-value related tasks and determine if there were differences in the use of the language between the three sessions and across classrooms. The audio recordings obtained in the small collaborative sessions were transcribed at the end of each session, coded, and recorded verbatim into a matrix. Seating maps in each session helped the researcher keep track of the students' participation in the sessions. All transcriptions from $\mathrm{C} 1$ were translated into English and revised by the official translators who signed the verification of translation form (see Appendix M: Verification of Translation Form). The translation was a needed step for easier management and accuracy of the data. 
Audio-recordings of small-group collaborative sessions. The first set of qualitative data consisted of the audio recordings of three small-group sessions in which the participants had to solve place value tasks. For the analysis of this set of data, the study chose to use thematic and discourse analysis. It was hypothesized that participants in $\mathrm{C} 1$ — where their home language, Spanish, was used for instruction—would exhibit higher levels of confidence and more sophisticated use of the mathematics academic language when communicating knowledge and wonderings about the concept learned.

Thematic Analysis: Small-Group Collaborative Sessions. Thematic analysis guided the researcher to identify themes that emerge from the data. In this study, the researcher read and re-read the data to find common themes or topics the data provided.

Thematic analysis of findings in C1. The analysis pointed out the need to make some considerations before evaluating the academic mathematical language related to the concept of place value that participants in C1 (math instruction in Spanish) exhibited. First, the district-adopted curriculum was initially written in English and then translated from English to Spanish. Translations to Spanish differ, depending on the nationality of the translators. This issue may have resulted in the use of different words to speak about the same concepts since Spanish varies from country to country. For example, the term "a hundred" appears in the students" workbook as "centenar," while T1 in C1 used the word "centena" to refer to the same idea of a hundred. To illustrate this issue even further, when reading a three-digit number, one hundred and thirty-five, for instance, T1 used the Spanish word "cien" (hundred) followed by the ten number "treinta y cinco" (thirty-five). All participants in $\mathrm{C} 1$ did the same as their teacher and read the whole number as "cien 
treinta y cinco." However, the number 135 is generally read in Spanish as "ciento treinta y cinco" This issue adds another level of difficulty to students' comprehension of the mathematical concept when solving place-value tasks in Spanish, due to the variety of terms used to refer to the same mathematical idea —in this case, "a hundred."

In the first small-group session in both classrooms, participants were asked to work in pairs or groups of three, to talk about the mathematical concepts or ideas they found to be more difficult to learn. In $\mathrm{C}$, the transcription of the audio recordings showed that participants focused on the task instructions and used sentence frames to express their ideas. Table 13 shows the mathematical topics perceived by participants in $\mathrm{C} 1$ as the most challenging.

Table 13

Summary of the Mathematical Topics Most Challenging to Learn (C1, Session 1)

\begin{tabular}{lccccccc}
\hline & \multicolumn{7}{c}{ Participant } \\
\cline { 2 - 7 } Themes & S1 & S2 & S3 & S4 & S5 & S6 & S7 \\
\hline Addition & X & & & & X & & \\
Subtraction & X & X & X & & & & \\
Multiplication & X & & & & & & X \\
Working with big numbers & X & X & X & X & X & & \\
Units, tens, and hundreds & & & & X & & X & \\
Story problems & & & & & & & X \\
\hline
\end{tabular}

In Table 13, we can see that participants found it very difficult to learn about working with big numbers (5 responses out of 7). Working with big numbers had five occurrences, which made it the hardest concept to learn in the participants' opinion.

If the number of occurrences for addition and subtraction were combined, there would be five occurrences. By the time students are in second-grade, it is expected that addition and subtraction with single-digit numbers (0-9) are already mastered. If this 
were the case, the participants who found addition and subtraction difficult to learn might have been referring to difficulties with adding and subtracting multidigit numbers. The concept of multiplication, whether it was a second-grade standard or not, is related to the concept of place value. Addition with the same addend leads to the idea of multiplication that is formally taught in third-grade. The topics that more participants in the study found challenging to learn were closely related to the understanding of the concept of place value, more explicitly to number sense.

It was also notable that $\mathrm{S} 1$ expressed difficulties in four of the six challenging topics. S1 limited himself to participating in the following small-group collaborative sessions. It was evident that he was in high need for support in mathematics learning in this classroom. The rest of the participants expressed difficulties in only two challenging topics, except for S6, who said he found only one challenging topic: units, tens, and hundreds meaning the whole place value concept.

The examination of the data provided by the audio recordings of the second smallgroup session with the same group (C1) was as follows. Session 2 took place at the midway point of the place-value module. The participants in this session were asked to work in pairs or groups of three to compose the number one hundred and thirty-five using manipulatives, or graphic representations. Table 14 displays the summary of $\mathrm{C} 1$ participants' use of basic academic mathematical language related to the concept of place value. 
Table 14

Academic Mathematical Language Related to Place Value (C1, Session 2)

\begin{tabular}{lccccccc} 
& \multicolumn{7}{c}{ Participant } \\
\cline { 2 - 8 } $\begin{array}{l}\text { Basic Concept of } \\
\text { Place Value }\end{array}$ & S1 & S2 & S3 & S4 & S5 & S6 & S7 \\
\hline Units/Ones & & & & & & & \\
Tens & $\mathrm{X}$ & $\mathrm{X}$ & $\mathrm{X}$ & $\mathrm{X}$ & $\mathrm{X}$ & $\mathrm{X}$ & $\mathrm{X}$ \\
Hundreds & & & & $\mathrm{X}$ & $\mathrm{X}$ & $\mathrm{X}$ & \\
\hline
\end{tabular}

As shown in Table 14, most participants used language related to the concept of ones and tens. Only three students out of seven used words and expressions related to the mathematical idea of "hundred" with confidence (S4, S5, and S6). The rest of the students were able to use such words and expressions with intentional prompting from the teacher. Although this is a thematic analysis, it frequently overlapped with the discursive one. When such an event happened, the researcher placed the observation where it made more sense. For example, in the next conversation, these two students were working together to make the number one hundred and thirty-five. S4 had the concept of a hundred and some tens more clear and was able to guide his classmate (S3) to understand this mathematical idea (S3 and S4, personal communication, 12/04/2019).

S3: I finished.

S4: No, you haven't. You need one less.

S3: One what?

S4: One ten less. You have too many.

S3: Why?

S4: Because it says one hundred and thirty-five and you put four tens here in the tens' place. You have one hundred here. These three together make three tens. You have to take one away. 
This dialogue showed that some students were more confident with the mathematical idea of tens than others. In almost every example, the collaboration worked very well to support those students who had not completely developed the place-value concept.

In the third small-group collaborative session in $\mathrm{C} 1$, participants appeared to be more confident in the use of the place-value concepts (or themes) and the academic language that they had learned up to that point. S3 was a student who showed some difficulties in understanding the place-value concept in Session 2, as illustrated above. The following quote exemplifies her progress when solving the task in Session 3, in which she demonstrated a more developed understanding of the place-value concept. "To add one hundred and thirty-five plus twenty-four, we need to make this number and then take two tens and four ones more and add them all" (S3, personal communication, 12/04/2019). This participant showed that she understood the concept implied in the procedure to add a three-digit number to a two-digit number before solving the problem.

Thematic analysis of findings in $\mathbf{C 2}$. For all the small-group collaborative sessions in $\mathrm{C} 2$, the task instructions were the same as for C1. Participants in this group were also asked to work in pairs or groups of three, within the group, about the mathematical concepts or ideas they have found to be more difficult for them to learn. In C2, the transcription of the audio recordings showed that participants were not attached to the use of sentence frames to express their ideas. They used the task to think, talk in pairs, and shared out loud their perspectives about learning mathematics. 
In the first small-group collaborative session, $\mathrm{C} 2$ participants referred to mathematical topics they found difficult to learn. Table 15 displays the themes found after eliminating repetition.

Table 15

Summary of Mathematical Topics Challenging to Learn (C2, Session 1)

\begin{tabular}{lccccccc}
\hline & \multicolumn{7}{c}{ Participant } \\
\cline { 2 - 7 } Themes & S8 & S9 & S10 & S11 & S12 & S13 & S14 \\
\hline Addition with the same & & $X$ & $X$ & & $X$ & & \\
addend & & $X$ & & $X$ & $X$ & & $X$ \\
Numbers in written form & & $X$ & & & $X$ & $X$ & $X$ \\
Writing two- and three-digit & & & & & X & \\
numbers & & & & & X & \\
Mathematics is hard & $X$ & & & $X$ & $X$ & & $X$ \\
English language difficulties & & $X$ & &
\end{tabular}

As shown in Table 15, C2 participants were more specific to talk about the topics they found difficult to learn in mathematics. Numbers in written form and linguistic difficulties were the themes with more occurrences. Four students found it hard to write numbers in letters because, as one student stated, they had to learn that in English, which is not their language of proficiency, but their language of instruction. The first theme in the table, "addition with the same addend," refers to multiplication, and it had three occurrences. Participants in C2 largely expressed language-related difficulties. This group of participants talked about their own feelings toward mathematics and themselves as mathematics learners. For the researcher, it was interesting to note this shift in the participants' responses even though they all received the same instruction. One student (S8) expressed dislike for the mathematics class: “I don't like math because I am not good at it. I don't understand" (S8, personal communication, 11/08/2019). With these 
words, this student is separating himself from the activity, and possibly missing the opportunity to enjoy and learn mathematics, perhaps due to some cultural influences that are not the object of this study. S8 did not say one word after this statement in Session 1. S12, on the other hand, took a different approach. Even though S12 stated that mathematics was a hard subject to learn, she was able to articulate what were those specific things making mathematics difficult for her to learn. In the second small-group collaborative session, S12 kept asking her peers for approval in the form of questions such as: "Do these match?" and "Can we take more of these (tens)?" Her discourse patterns suggested that she was in the process of building her confidence to deal with place-value ideas and also to use her second language. At the end of the study, T2 gathered S12 and other students who had shown a low understanding of the concept of place value to further work with them in a small-group setting after school.

Data provided by the audio recordings of the second small-group session with the same group offered another perspective. As previously stated, this session took place at the midway point of the place-value unit and was approached identically as in $\mathrm{C} 1$. Participants were asked to work in pairs or groups of three within the small-group to compose the number one hundred and thirty-five using manipulatives, or graphic representations. Table 16 depicts the summary of $\mathrm{C} 2$ participants' use of basic academic mathematical language related to the concept of place value. 
Table 16

Academic Mathematical Language Related to Place Value (C2, Session 2)

\begin{tabular}{lccccccc}
\hline & \multicolumn{7}{c}{ Participant } \\
\cline { 2 - 7 } $\begin{array}{l}\text { Basic Concept of } \\
\text { Place Value }\end{array}$ & S8 & S9 & S10 & S11 & S12 & S13 & S14 \\
\hline $\begin{array}{l}\text { Knowledge of ten and some } \\
\text { more (numbers 11-19) }\end{array}$ & X & X & X & X & X & X & X \\
$\begin{array}{l}\text { Knowledge of groups of ten } \\
(10-90)\end{array}$ & & X & X & X & X & X & X \\
Knowledge of hundred & & X & X & X & & & X \\
\hline
\end{tabular}

As shown in Table 16, C2 participants exhibited a good deal of basic academic knowledge related to the concept of "ten and some more," which is another way to call the "teen" numbers (11-19). Six out of seven students used mathematical academic language when referring to numbers that result from counting by tens $(10,20,30,4050$, $60,70,80$, and 90). Four students out of seven showed evidence of understanding the concept of hundreds when referring to either a bundle of ten-tens or a model that represents one hundred. Overall, C2 displayed a fair understanding of the basic knowledge required to build an understanding of the broad concept of place value.

Discourse Analysis: Small-Group Collaborative Sessions. Discourse analysis centers on patterns of speech or verbal communication, and the ways language is used by participants to carry out meaning (Dawson's work as cited by Harding, 2019).

Discourse analysis findings in C1. In C1, where the instruction was in Spanish, students were allowed to express their ideas without tying themselves to a sentence frame. Nonetheless, students appeared to be very connected to having the sentence frames available, and some of the responses sounded like repetitions in both classrooms. Linguistic elements such as hesitations or expressions that delay the linguistic output 
were also noticed in this group. For example, in $\mathrm{C} 1$, the student coded as $\mathrm{S} 4$ expressed his thoughts as follows: "Something that has been very difficult for me to learn in mathematics is umm...to learn....umm...is...big numbers such as units and tens, like bigger numbers than these and big numbers, and that" (S4, personal communication, 11/7/2019). From the mathematics conceptual standpoint, the participant shared that understanding multidigit numbers had been difficult for him. The effort he made to express his thoughts was evident even though instructions were in his home language. S4's hesitations, when speaking, could be interpreted as a lack of precision to name the concepts in Spanish or a concept that was not completely developed in his mind.

Nonetheless, his thought was clear as to what the difficulty was. The same student in the second session, however, showed much more confidence when describing how he made the number requested in the task: "I have one hundred, three tens, and five....ones and that makes one hundred and thirty-five" (S4, personal communication, 12/4/2019). Note that this is a translation of his speech from Spanish to English.

It was interesting to observe that he paused before numbering the ones but did not hesitate nor break words or use discourse strategies to delay the articulation of his thought. The researcher examined his response for session three, and this is his explanation of the task: "I added 135 to 24 like this. I took two tens because they made twenty and four ones because these are just ones. Then I added thirty-five that make fiftynine. After that, I took one hundred, put everything together, and I got one hundred and thirty-five" (S4, personal communication, 01/10/2020). 
S4's confidence in dealing with the manipulatives to make numbers grew from one collaborative session to another. The only problem observed was the way he named the hundreds in Spanish. As he had been taught, S4 read the number one hundred and thirtyfive in Spanish as "cien treinta y cinco," instead of "ciento treinta y cinco," which is the most accepted form.

The same progress described for S4 was observed in other participants in this group (S5, S6, S7). These students were engaged in collaborative group work, and even in the moments when they were not correct in their steps to solve the task at hand, they were willing to share and listen to their partners' perspectives. The following dialogue between S2, S5, and S6 happened in Session 3 (S2, S5, and S6, personal communication, 01/10/2020) and illustrated this observation:

S5: I took one (model) of one hundred and three tens, and that is one hundred and thirty. Then I took five little cubes, and that is five ones. Then I took two tens that are twenty and four ones.

S2: What did you do after?

S6: You can write the numbers, not the number words. You already said that you had five ones plus four, that is nine. I got that, then what happens?

S5's confidence in the use of the language, as well as the mathematical concepts involved, was also noticed by his peers who were actually motivated to continue with his explanations.

For the second small-group session, $\mathrm{C} 1$ participants were gaining more confidence when expressing their mathematical thinking. There were several times when students did not finish their sentences or omitted an academic term, and their teammates reminded them to reiterate the term. One possible interpretation of this phenomenon has to do with the fact that students who omitted the term had the manipulatives in front of them, and 
they assumed that the others around could see the amounts. For them, there was no need to say the term. However, since the students were learning to use precise language, their classmates demanded specificity and use of the right terms next to the amounts: for example, "ten tens," "three hundreds," "four ones," etc.

For the third and last small-group session in $\mathrm{C} 1$, the participants were instructed to add a 3-digit number (135) to a 2-digit number (24). The task required students to make the number one hundred and thirty-five (135) using manipulatives or any other representation and add twenty-four to it.

It was noted that in $\mathrm{C} 1$, the teacher provided students with sentence frames to respond to the questions. The results from the audio recordings for the second- and third-sessions suggested frequent use of terms to refer to place-value related concepts that were repeatedly utilized in both classrooms selected for this study. At this point in the study, it was also noticed that the thematic and discourse analysis tended to overlap. Still, the researcher proceeded forward by examining C1 participants' interactions in the smallgroup collaborative sessions.

The majority of participants used models to represent place-value ideas. Models of place value refer to physical items that can help students develop the idea of a "ten" as a single entity or as a set of ten units. These are materials or manipulatives that students use in most elementary classrooms; although they support students' understanding of the concept, they do not literally "show" the concept. Learners have to construct the concept in their minds and relate it to the model (Fuson, 1990). These representations can be analog (objects, manipulatives) or graphic models of numbers and operations. 
In the third small-group collaborative session, $\mathrm{C} 1$ participants were instructed to make the number one hundred and thirty-five using either manipulatives (unifix-cubes or paper and pencil). The use of manipulatives came after as a confirmation of what they found in the first attempt. Students were allowed to get organized as they pleased, and they self-organized into three groups of two students and one student on his own. Figure 6 displays the graphic models to represent the number 159-one hundred and thirty-five plus twenty-four - that the participants made when solving the task. Their models have been juxtaposed to make a four-quadrant figure (participants' names have been blocked out). 
Q-II

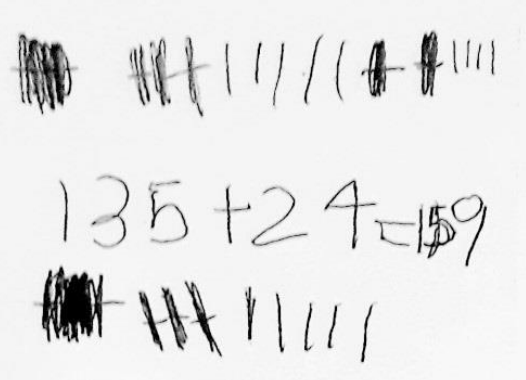

(20)

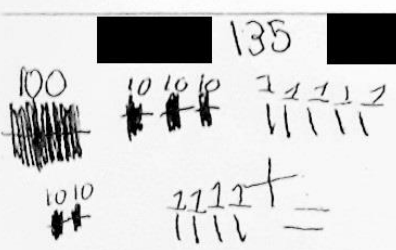

Q-III

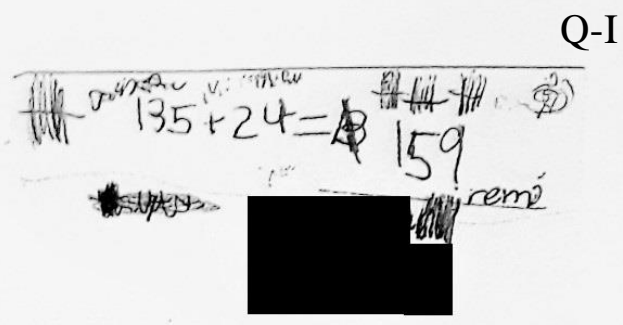

Q-I

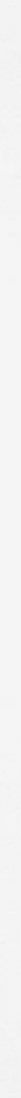

Figure 6. Graphic models used by $\mathrm{C} 1$ participants in Session 2.

As shown in Figure 6, students used graphic models to represent the mathematical idea of "a hundred," "a ten," and "a one." They then used this model to make up the given numbers they were asked to add. For instance, in quadrant four (Q-IV) in the figure, students add labels to each of their graphic representations. Students in quadrants one (Q-I) and three (Q-III) solved the task using a procedure they already knew and confirmed their answer through the graphical model. The participant in the second quadrant (Q-II) was able to represent "a hundred," but his model for tens and ones did not look clear. 
Two different sets of communication patterns were highlighted in the third session: linguistic patterns (linguistic knowledge) and mathematics patterns (linguistic-academic knowledge or content knowledge). The former refers to language structures that students need to introduce their thoughts or to collaborate. Linguistic patterns include expressions such as sentence frames or sentence starters. The latter, mathematics patterns, use words to name or describe mathematical content. Table 17 illustrates the use of these two patterns in $\mathrm{C} 1$, Session 3.

Table 17

\begin{tabular}{|c|c|c|}
\hline Student & Linguistic Patterns & Mathematics Patterns \\
\hline S1 & $\begin{array}{l}\text { Let's use ___ _ and __ _ }{ }^{\text {to make }} \text { _ } \\
\text { Everything together? }\end{array}$ & $\begin{array}{l}\text { two tens, four ones } \\
\text { twenty-four }\end{array}$ \\
\hline S2 & $\begin{array}{l}\text { Can we do add } \ldots \ldots-\ldots \text { and } \_-\ldots \\
\text { this way? } \\
\text { What will you do next? }\end{array}$ & $\begin{array}{l}\text { one hundred and thirty-five, } \\
\text { twenty-four }\end{array}$ \\
\hline S3 & $\begin{array}{l}\text { To make ___, we need ___ } \\
\text { The result is }\end{array}$ & $\begin{array}{l}\text { thirty, three tens } \\
\text { one hundred and fifty-nine }\end{array}$ \\
\hline $\mathrm{S} 4$ & 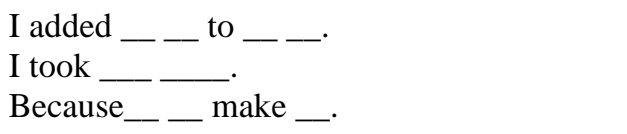 & $\begin{array}{l}\text { thirty-five, twenty-four } \\
\text { three tens } \\
\text { three tens, thirty }\end{array}$ \\
\hline S5 & $\begin{array}{l}\text { I took ___ of }{ }_{\text {That }} \text {. Then I took_____ that } \\
\text { go in the__ slot. } \\
\text { Aha! }\end{array}$ & $\begin{array}{l}\text { two tens, four ones } \\
\text { two, tens, four } \\
\text { ones, unit }\end{array}$ \\
\hline S6 & $\begin{array}{l}\text { Write the in the __ slot. } \\
\text { You said you had } \_ \text {. } \\
\text { I chose to use slots. It is what you have } \\
\text { taught us. }\end{array}$ & $\begin{array}{l}\text { number, hundred } \\
\text { five ones }\end{array}$ \\
\hline S7 & I add the ___ to the __ and I have the & $\begin{array}{l}\text { tens, ones } \\
\text { whole number }\end{array}$ \\
\hline
\end{tabular}

As exhibited in Table 17, both patterns of communication complement each other in this context. The mathematical patterns complete the linguistic patterns to make sense of 
mathematics learning. These patterns appeared to be more elaborated that the basic ones described in the second session.

Discourse analysis findings in C2. In the first small-group collaborative session, participants in $\mathrm{C} 2$ thought about mathematical ideas, concepts, or topics that were difficult for them to learn. These common themes were already discussed in the previous session. They also used this session to share some deep feelings they had for mathematics and how they saw themselves as mathematics learners. Although discussing these students' feelings for mathematics was not in the scope of this study, it is important to note that these young learners were in the process of building their interest for mathematics and the experiences they have in the classroom play a meaningful role in this process. S12's comments, for example, indicated difficulties with writing in English and Spanish.

The topic that was harder for me to learn is to do the number ninety-two in written form because I need to write in English and Spanish. I need to write the words that have numbers because in the written form, in written form, it is difficult for me to do because it is in another language I don't know which sounds or which letters make those sounds. (S12, personal communication, 11/08/2019).

First and foremost, this student had a clear understanding of what written form was when speaking about place value, as well as the idea that ninety-two implied place value because it is a two-digit number. This student's difficulties were not related to mathematics content but linguistic skills. She went beyond and explained even the cause of her challenge to perform in mathematical tasks. S9 shared a similar thought that illustrates the problem. "The difficult thing that I had is when my teacher says write 
something in English. I get confused because I do not know to write in English. I know just a little bit" (S9, personal communication, 11/08/2019).

As stated in Chapter Two, language and mathematics learning are related in so many ways. When examining $\mathrm{C} 2$ participants' responses to the first task, it is found that five of them expressed difficulties related to writing in English. In ELD instruction, the writing domain comes last because of its implicit complexity. For Latinx EBs, writing in English is even harder since they still have not fully developed the listening and speaking foundation and the reading levels to do so. Nonetheless, research has emphasized that by providing Latinx EBs a nurturing learning environment that supports both English learning and mathematics learning, classroom teachers ensure that this population has fair access to mathematical knowledge (Borgioli, 2008; Major, 2012; Moschkovich, 2011, Zavala, 2012).

For the second small-group session, C2 participants consistently demonstrated more confidence in the use of the language of instruction to communicate their mathematical knowledge about place value. It was evident that there was some sort of classroom norms that have become a mindset in this classroom. For example, once the students were instructed on the task, two students took the lead and assigned turns in their group of three to participate. The other participants followed this initiative.

It was also noted that this group had also worked on their classroom norms, which included sharing thoughts safely without making fun of others' mistakes and supporting each other's learning. These two norms were evident when S12, S13, and S14 were collaborating to solve the task (S12, S13, and S14, personal communication, 12/05/2019). 
S12: Can we take more of these (hundreds)?

S13: We just need one of them to make one hundred, just one of them.

S14: But you did three hundred. Remember the number we need to make is one hundred and thirty-five. Thirty goes here in the middle.

S12: Oh. I got it. I got confused. It is one hundred, not three hundreds.

In the context of this small-group interaction, these three students were using place value models of ones, tens, and hundreds. S12 was using a model for a hundred as it valued ten. The other members of the group tried to explain to her that she was taking three objects with one hundred values. They used a caring tone and kept their voices low when the interaction happened. Another interesting interaction occurred when S8 and S9 were solving the task as follows (S8 and S9, personal communication, 12/05/2019):

S9: $\quad$ So, the way we made this number is with one hundred, three tens, and five ones.

S8: We um, ones um, um

S9: The way to organize them was by taking one of one hundred first, then three tens, and then five ones.

S8: We put one hundred, and, and, three tens and five tens, no, no, five ones.

In this conversation, S9 supported S8's understanding by re-stating the way the threedigit number was made. S8 (who was highlighted above for expressing dislike toward mathematics classes and considering himself not good at it), confirmed this understanding when he reiterated the task result using academic language.

In the third small-group collaborative session, C2 participants were very excited about the task. They had manipulatives and paper available to solve the task. They selforganized in two pairs and one triad. They were very engaged in the task. This conversation between S11, S13, and S14 illustrates the level of engagement (S11, S13, and S14, personal communication, 01/10/2020):

S11: I got a different number. What do we have to do then? 
S13: Can we draw a line on top of the hundreds? We started to make a hundred.

S14: There are only one hundred here and three tens. Exactly.

S11: We already made one hundred and thirty-five. We need to add twenty-four to this number.

S11: That is easy. Let's put two tens here and four ones here. There!

S13: One hundred and thirty-five, plus twenty-four equal one hundred and fiftynine. See?

S14: We did it!

Some participants already knew the answer to the problem. They shared it with the teacher. She wrote the answer on the board and told them that what she wanted to see was how they got the answer. The classroom teacher helped the students make their thinking visible. When students collaborated to solve this task, they had the opportunity to share their ideas with others and modify or defend their own. Providing Latinx EBs with opportunities to collaborate is an important practice of the sociocultural learning process.

The use of mathematical models was discussed. Mathematical models offer concrete ways to visualize math concepts, either using drawings or graphic representations of real objects to express the number of ones, tens, and hundreds in a given two- or three-digit number. For example, participant S11 explained the value of one hundred in the second session task as follows: "Twelve sticks. Oh! We need one more because one hundred and thirty is thirteen tens" (S11, personal communication, 01/10/2020).

This participant showed evidence of understanding the place value idea that the number one hundred and thirty can also be represented in terms of tens. S11 explained: "One hundred and thirty is thirteen tens." In the second session, however, this same participant started to use this strategy. Still, S11's thought partner (S13) convinced S11 to change the group of tens to a model that represented one hundred and some more tens: one hundred, three tens. Frequently, students follow procedures that have been taught to 
them without understanding the concepts. The researcher noted that S11 did not argue with this thought partner (S13), just made the change suggested. When both participants solved the task, S11 explained their solution this way: "The way we made was by using one hundred, and then three, and then ones" (S11, personal communication, 01/10/2020).

It was noted that in S11's sentence, the student did not name the second amount they were representing (tens). When students miss the reference in the sentences, it might be interpreted as a lack of clarity or a lack of language command to name the needed categories. S11's partners then reminded S11 of the need for the term. Participants reminding each other of naming the number value was very common in both classrooms.

In the third small-group collaborative session, $\mathrm{C} 2$ participants were also instructed to make the number one hundred and thirty-five using either manipulatives (unifix-cubes or paper and pencil). Interestingly, participants in C2 used the objects (manipulatives) first to represent the assigned numbers. After they made the three- and two-digit numbers, they use the paper and pencil to represent with a graphic model what they did with objects. As in C1, students in C2 were allowed to sit as they pleased. They self-organized into two groups of two students and one triad. Figure 7 displays the graphic models to represent the addition of one hundred and thirty-five plus twenty-four - that the participants made when solving the task. As explained before, their models have been juxtaposed to make a four-quadrant figure. The participants' names have been blocked out to protect their privacy. 

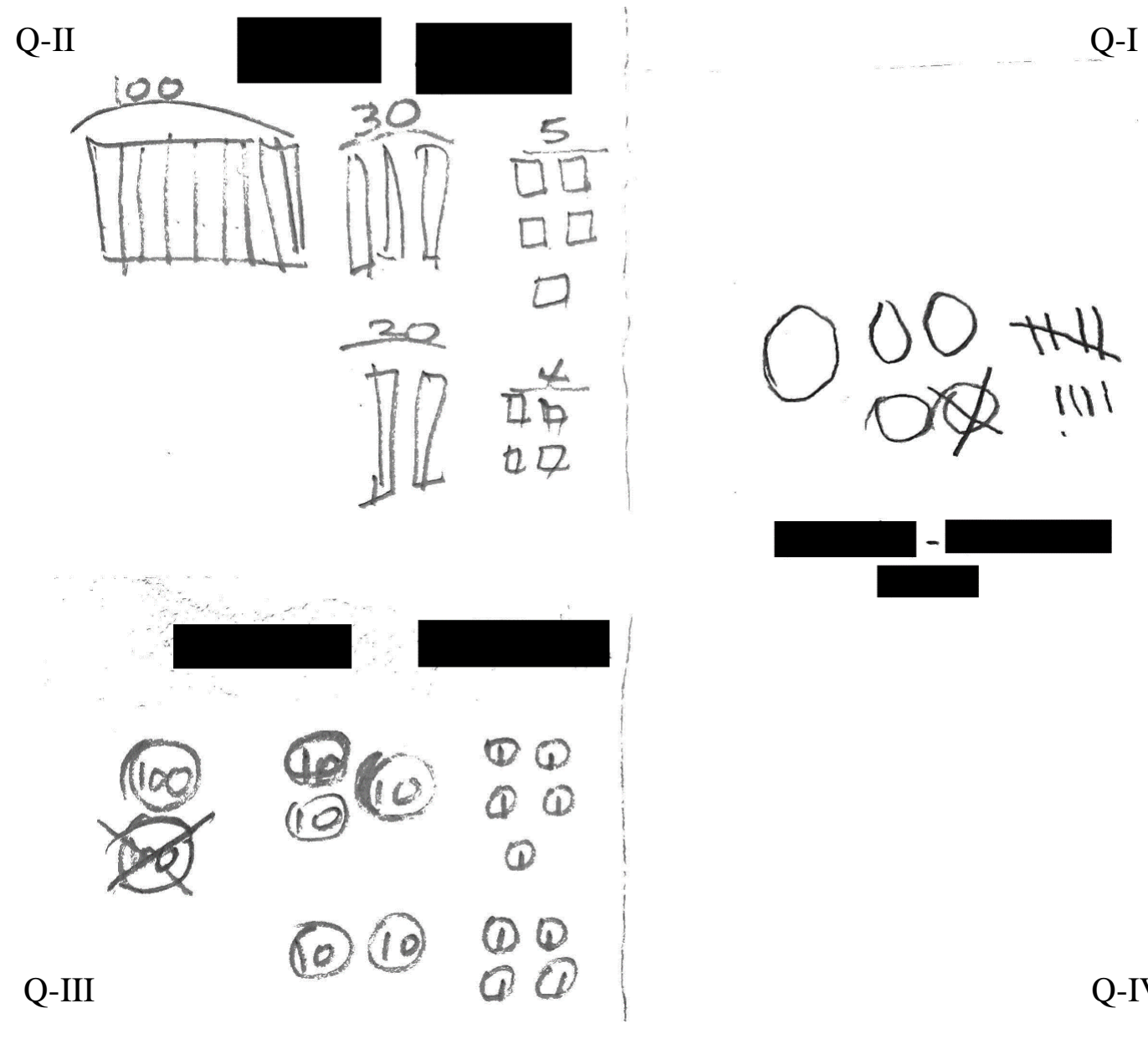

Q-IV

Figure 7. Graphic models used by C2 participants in Session 3.

As shown in Figure 7, participants in C2 used graphic models to represent the mathematical idea of "a hundred," "a ten," and "a one." This group of participants first used the manipulatives provided and then represented graphically the amounts involved in the task. The graphic models exhibited here are direct reflections of the models they made with the manipulatives. For instance, in the first quadrant (Q-I), participants used disks to represent the amounts, but instead of labeling them, they relied on the size of the disks to represent the value of the number. They were also self-correcting by crossing a disk out, as they figured they had drawn an extra hundred. In Q-II, participants added 
labels over the graphic models to indicate the value of each figure. They also used rectangular and square shapes to represent hundreds, tens, and ones. In Q-III, participants added labels to each of their graphic representations, but they used disks to represent the amounts. C2 graphic models exhibited more clarity as to what amounts were represented and the value for each amount. The models also look more organized and cleaned.

It was found that both groups of participants started to build the mathematical concept of place value in first grade, and they recalled the use of manipulatives in that previous year as a fun, productive learning experience. Both classroom teachers reported using manipulatives in small-group settings to support students who were in the conceptconstruction process. Using manipulatives with specific tasks seemed to enhance engagement and learning, as well as collaboration. Figure 8 exhibits $\mathrm{C} 2$ participants using manipulatives to enhance the understanding of place value.

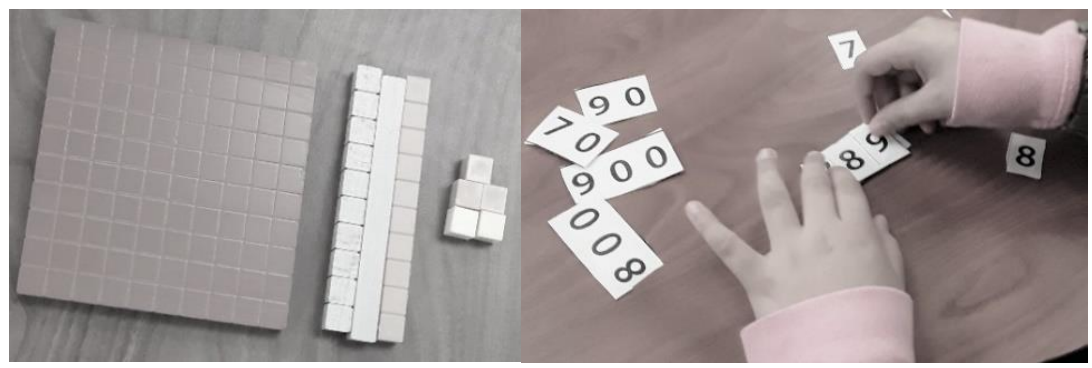

Figure 8. C2 participants use of manipulatives to support place value learning.

As shown in Figure 8, the use of manipulatives in early elementary grades appeared to enhance engagement and mathematics learning. However, the effect of using manipulatives in these classrooms was outside of the scope of this study. 
Similar sets of patterns of communication that were displayed in the third session for

$\mathrm{C} 1$ also emerged in this session in C2: Linguistic patterns and mathematics patterns.

Table 18 illustrates the use of these two patterns in C2.

Table 18

\begin{tabular}{|c|c|c|}
\hline Student & Linguistic Patterns & Mathematics Patterns \\
\hline S8 & $\begin{array}{l}\text { You can solve it by using either __ or } \\
\text { We can count like ___ } \\
\text { And then, we have these __ over here. }\end{array}$ & $\begin{array}{l}\text { hundreds, } \\
\text { tens } \\
\text { ten, twenty, thirty } \\
\text { tens }\end{array}$ \\
\hline S9 & $\begin{array}{l}\text { And __, right? } \\
\text { We have ___ and ___ over here. }\end{array}$ & $\begin{array}{l}\text { ones } \\
\text { one hundred, three tens }\end{array}$ \\
\hline S10 & $\begin{array}{l}\text { That would be like having ____ } \\
\text { is the answer. }\end{array}$ & $\begin{array}{l}\text { ten tens } \\
\text { one hundred and fifty-nine }\end{array}$ \\
\hline S11 & 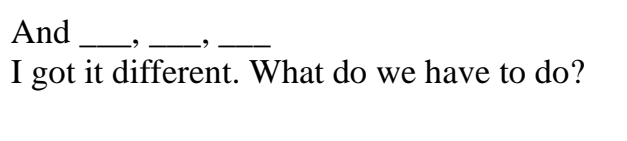 & $\begin{array}{l}\text { nine, ten, twenty } \\
\text { thirty-five plus twenty-four }\end{array}$ \\
\hline S12 & $\begin{array}{l}\text { Can we draw a line on top of the } \\
\text { We can do this! }\end{array}$ & $\begin{array}{l}\text { hundreds } \\
\text { one hundred and thirty-five plus twenty- } \\
\text { four equal one hundred and fifty-nine. }\end{array}$ \\
\hline $\mathrm{S} 13$ & $\begin{array}{l}\text { Can we draw the __ over here? } \\
\text { Then we can use ___, then, } \\
\end{array}$ & $\begin{array}{l}\text { ten } \\
\text { one hundred, one hundred ten, one hundred } \\
\text { twenty, one hundred thirty }\end{array}$ \\
\hline S14 & $\begin{array}{l}\text { There is only __ _ and __ } \_ \text {, exactly. } \\
\text { Yes, take only __ Only one of this _ }\end{array}$ & $\begin{array}{l}\text { one hundred, three tens } \\
\text { one hundred, } \\
\text { hundreds }\end{array}$ \\
\hline
\end{tabular}

As exhibited in Table 18, both patterns of communication complement each other in this context. The mathematical patterns complete the linguistic patterns to make sense of mathematics learning. These patterns appeared to be more elaborate than the ones described in the second session.

In summary, the qualitative analysis of the communication patterns used by participants in three small-group collaborative sessions revealed differences across the two classrooms. In C1, where the language of instruction was Spanish, participants 
reported difficulties in performing well in mathematics that were more related to the conceptual understanding of the concept of place value. They also exhibited inconsistencies in the use of the place value terms to refer to hundreds in their native language. Besides, they demonstrated less elaborate sentence frames that were used as referents for linguistic patterns. Participants in $\mathrm{C} 1$ chose to represent two- and three-digit numbers using paper and pencil first and manipulatives after, just to confirm their arrangements made in the paper.

In contrast, participants in $\mathrm{C} 2$ were more explicit when describing the topics they found difficult to learn in mathematics. It was also found that five students out of seven reported difficulties related to understanding the language of instruction (English), especially when the task was about writing. Two of the five students who expressed difficulties with the language of instruction demonstrated a fair grasp of the mathematical content related to place value. Interestingly, participants in $\mathrm{C} 2$ chose to use manipulatives first to represent two and three-digit numbers and then represented these amounts graphically.

Comparative Analysis: Teachers' Questionnaire. Comparative analysis was used to interpret teachers' responses to the questionnaire. When analyzing the teachers' responses to the questionnaire, it was found that both teachers have a similar number of years of experience in teaching in bilingual or dual language settings (T1: 20; T2: 22). They also coincided in their belief that students should be taught mathematics in their native language to ensure higher levels of understanding mathematical concepts. One additional aspect in which both teachers expressed commonalities was in the use of the 
CA CCSS-M as a resource to plan their lessons, or as reference for the already-planned lessons from the adapted curriculum. Table 19 shows the commonalities in the teachers' responses to each of the items in the questionnaire (Appendix D: Teacher Questionnaire).

Table 19

Summary of Similarities in Teacher Responses to the Questionnaire

\begin{tabular}{lcc}
\hline Questions/Themes & T1 & T2 \\
\hline $\begin{array}{l}\text { Ethnicity/race } \\
\text { Years of teaching experience } \\
\text { overall }\end{array}$ & Born and raised in Mexico & Born and raised in Mexico \\
$\begin{array}{l}\text { Years of teaching experiences } \\
\text { in bilingual settings }\end{array}$ & 28 years & 25 years \\
$\begin{array}{l}\text { Believes that language of } \\
\text { instruction impact mathematics } \\
\text { learning }\end{array}$ & 20 years & 22 years \\
$\begin{array}{l}\text { Uses mathematics CA CCSS-M } \\
\text { in planning lessons }\end{array}$ & Yes & Yes \\
\hline
\end{tabular}

As Table 19 displays, these two classroom teachers also had similar demographic information.

Some differences were observed in the following themes: Mathematics class structure, topics they considered difficult to teach and learn, the use of either language during planning time, and the additional resources and strategies they use to teach mathematics in their classrooms. T1 included the problem of the day as part of her daily mathematics routines, whereas $\mathrm{T} 2$ did not have her students work on the problem of the day but did present the objective for each lesson as an essential piece of her mathematics class structure. Another difference was found regarding the mathematical content that they considered difficult to teach. For T1, "regrouping" is a very difficult concept to teach and for her students to learn. This concept happens to be a key idea in learning 
place value. In T2's opinion, a difficult concept to teach is "time." Their responses did not provide any specifics as to what reasons they had to find these two concepts difficult to teach. They also expressed different ideas about the use of either first or second language to plan their lessons. While T1 only uses Spanish during mathematics planning time, T2 explained that even though she teaches mathematics in English, she uses Spanish and English during planning time as she thinks she might need to use Spanish to respond to specific students' needs.

Where most notable differences were found, however, was in the detailed list that T2 provided to answer the item related to resources or additional strategies used to enhance mathematics learning. The exhaustive list of resources and strategies provided by $\mathrm{T} 2$ in her mathematics instruction included, but was not limited to, skip counting chants, teacher created and internet-based place value games, revision, and bubble maps to work on number bonding. These strategies called for a lot more interaction and engagement in learning. They might have made the difference in $\mathrm{C} 1$ and $\mathrm{C} 2$ more elaborate mathematical language in the three small-group collaborative sessions reported above. Table 20 exhibits $\mathrm{T} 1$ and $\mathrm{T} 2$ differences in responses to the questionnaire. 
Table 20

\begin{tabular}{|c|c|c|}
\hline $\begin{array}{l}\text { Questions/ } \\
\text { Themes }\end{array}$ & T1 & T2 \\
\hline $\begin{array}{l}\text { Language for } \\
\text { planning time }\end{array}$ & Spanish & Spanish/English \\
\hline $\begin{array}{l}\text { Mathematics } \\
\text { class structure }\end{array}$ & $\begin{array}{l}\text { - The whole group worked to solve } \\
\text { the problem of the day } \\
\text { - Independent practice } \\
\text { - Small group with the teacher }\end{array}$ & $\begin{array}{l}\text { - Whole group instruction } \\
\text { - The teacher presents the objective } \\
\text { - Teach lessons according to curriculum } \\
\text { - Students practice with teacher support } \\
\text { - Independent practice and small group work }\end{array}$ \\
\hline $\begin{array}{l}\text { Resources/ } \\
\text { additional } \\
\text { strategies }\end{array}$ & $\begin{array}{l}\text { - Unifix cubes } \\
\text { - Anchor charts } \\
\text { - Visual stimuli }\end{array}$ & $\begin{array}{l}\text { - Realia/manipulatives (sticks/straws/bundles) } \\
\text { - Teams or collaborative groups } \\
\text { - Place-value charts } \\
\text { - Skip counting chants } \\
\text { - Variety of activities to differentiate } \\
\text { - Think-Pair-Share } \\
\text { - Teacher created place-value games } \\
\text { - Internet games } \\
\text { - Use of prior knowledge (comparative } \\
\text { symbols) when introducing new concepts } \\
\text { - Bubble map to work on number bonding } \\
\text { - Review work before the end-of-unit } \\
\text { assessment }\end{array}$ \\
\hline
\end{tabular}

As shown in Table 20, the teachers' responses to the questionnaire provided important details on each of the two classroom environments, which helped to explain the participants' engagement in math learning within each classroom. This engagement was highly linked to the process of building mathematics identities that sociocultural researchers have mentioned. The researcher of the current study believed that young Latinx EBs might start building their mathematics identities in early elementary grades and could continue to develop them throughout their schooling years.

The resources and strategies that each teacher used during mathematics instruction seemed to be linked to the communication patterns that emerged in both classrooms. The classroom environment might be a reflection of the teachers' beliefs and preferred methods to teach mathematics. It was found that mathematics instruction in $\mathrm{C} 2$ included 
but was not limited to the exploratory and guided use of manipulatives, the layout of the classroom, the structure of the lesson in which small-group collaborative tasks are present in everyday mathematics class. All of these other elements were derived from teachers' beliefs about the classroom environment. The language of instruction, in conjunction with these other elements, support the selected groups' long-term learning of the mathematical concept of place value in particular.

Support provided as needed in the participants' native language was another important aspect that made a difference in the students' communication patterns. Although no interaction in Spanish was found in the small-group collaborative session transcripts, T2 ensured that her students got engaged in learning mathematics and she planned and provided adequate support in their native language when needed.

\section{Analysis of Quantitative and Qualitative Data}

Evidence from both quantitative and qualitative findings suggest that the several aspects of the mathematics classroom impacted participants' understanding of the mathematical concept of place value. Using the participants' native language as the language of instruction for mathematics does not necessarily guarantee immediate success in learning. The language of instruction — either participants' native or another language - is an important aspect of the classroom practice. The language of instruction needs to be supported by other classroom practices such as collaborative conversations

around tasks that involved the target concept, as well as the use of manipulatives or other types of number representations or models. Going deep in these areas was outside the scope of this investigation, but they could be excellent targets for future research. 


\section{Chapter 5. Discussion and Conclusion}

This convergent parallel mixed-method study examined the impact of the language of instruction on Latinx EBs' understanding of the mathematical concept of place value. A pre- and post-test was the instrument to measure participants' understanding of the placevalue concept. The participants' communication patterns in small-group collaborative tasks and the two classroom teachers' responses to a questionnaire were also instruments the researcher used in the study. The research was guided by two research questions, which subsequently led the data collection process and analysis. The first question asked whether and how the language of instruction, either Spanish or English, had an impact on the selected population's comprehension of the concept of place value. The second question queried the participants' communication patterns in collaborative tasks when solving place value problems in second-grade Spanish-English transitional bilingual classrooms. The study's findings have implications for school administrators and elementary teachers when making decisions on the language of instruction for teaching mathematics. It also provides researchers with important considerations for future studies.

\section{Summary of RQ1: Implications}

The first research question inquired if the language of instruction, either Spanish or English, had an impact on the selected population's understanding of the concept of place value as measured by a pre-designed assessment instrument used as a pre- and post-test.

The instrument was originally used as a formative assessment of all students' understanding of the concept of place value. The researcher used this instrument to examine participants' increase in the understanding of the concept of place value in two 
bilingual classrooms that had chosen either Spanish or English for mathematics instruction. Research reviewed in the study stated that using the participants' native language in mathematics class may facilitate their understanding of key mathematical concepts such as place value. Nonetheless, the language of instruction, either Spanish or English, did not seem to significantly impact participants' understanding, at least for this small sample size. The language of instruction did not have a statistically significant impact on participants' overall understanding.

At first sight, the participants who received instruction in English during the placevalue unit seemed to slightly outperform their peers in the classroom where mathematics instruction was presented in Spanish. Still, it was found that there was not a significant difference in the pre- and post-test scores across $\mathrm{C} 1$ and $\mathrm{C} 2$ populations, according to the quantitative data analysis. This result suggested that the language of instruction did not play a significant role in the participants' understanding of place value in this small sample size of second-grade Latinx EBs in Spanish-English transitional bilingual classrooms. The participants' understanding of the place-value concept was measured by the participants' increase percentage points in performance from pre- to post-test. A study with a larger sample size would lead to more generalizable results. This finding has some implications for practice and research.

RQ1: Implications for teachers and school administrators. Teachers and schooladministrators may consider having courageous conversations about what language to use for mathematics instruction and their beliefs for teaching and learning mathematics. These conversations support the mathematics classroom environment set up. 
The decisions over what language of instruction to use for mathematics instruction need to be evidence and research-based, knowing that whatever language is chosen to teach and learn mathematics, some other aspects would contribute to enhancing students' understanding of the concepts being taught.

RQ1: Implications for the districts. This study's findings suggest that the districts need to provide high-quality professional development to bilingual teachers (and even non-bilingual teachers) to refine teachers' classrooms and strategies for teaching mathematics, including collaboration and engagement in mathematics classrooms. Making the relationship between language (native or non-native) and mathematics cognition more visible might be a long-term goal for a professional development series.

RQ1: Implications for future research. As for implications for future research projects, it is important to consider collecting data on all the students in each of the two classrooms. Collecting data on the entire classroom might provide a larger sample size for the study and ensure more generalizable results. Future researchers might also do an exhaustive analysis of the instrument to collect quantitative data or design their own instrument with the same purpose in mind.

\section{Summary of RQ2: Implications}

Some recent studies have pointed out that some other aspects of the classroom might also affect Latinx EBs' understanding of mathematical concepts (Boaler, 2002; Borgioli, 2008; Zavala, 2012). Focusing on multiple aspects of the learning environment and connecting them with the language of instruction is one way to ensure that bilingual students in any bilingual program get the quality of instruction they deserve. 
The second question investigated participants' communication patterns in small-group collaborative sessions solving place-value tasks in second-grade Spanish-English transitional bilingual classrooms. Both groups of participants showed evident progress in the understanding of the target concept from the beginning to the end of the place value unit. The qualitative analysis results revealed that participants who received instruction in English (C2) exhibited more consistent use of precise mathematical language from session to session. These participants were able to refer to place value key concepts such as units or ones, tens, hundreds, bundles, groups of ten, groups of hundreds, and so on. They also showed more consistent progress in the use of linguistic patterns to collaborate and discuss solving place value in collaborative groups. The students who were taught in Spanish did present some inconsistencies in the use of precise vocabulary and expressions in their native language to refer to place value key concepts and exhibited fewer details when describing challenging mathematical concepts.

It was also found that the classroom practices such as small-group collaborative work with engaging tasks captured second-grade Latinx EBs' interest in learning mathematics. Collaboration following classroom norms previously discussed and agreed upon with students appeared to happen consistently in the day to day mathematics learning environment. Classroom teachers in early elementary classrooms need sufficient time to plan the tasks, tools, and classroom norms that promote collaboration, respect for other's opinions and knowledge stages, and a safe place to make mistakes from which they can grow cognitively. These aspects should be consistently in place during mathematics instruction. 
Additionally, the qualitative datasets were analyzed in alignment with research findings related to the teachers' willingness to plan and provide support in the students' native language to those who need it, and whenever they need it. The sociocultural perspective of learning emphasizes the need for mathematics teachers to create safe, engaging, and supporting classroom environments in which Latinx EBs succeed at both learning mathematics and gaining higher levels of English proficiency, while simultaneously maintaining their native language. This study's findings from the qualitative data were aligned with the sociocultural learning perspective used as the study framework.

RQ2: Implications for teachers and school administrators. One key implication for teachers and school administrators was that the use of students' native language needs to be allowed in the mathematics classrooms. Examining teachers' and school administrators' beliefs about teaching and learning would help them set up expectations for classroom instruction and environment. Teachers could also be expected to intentionally integrate different aspects of the classroom environment (tasks, tools, and classroom norms) around the language of instruction. Honoring students' rights to use their native language in mathematics class and celebrating their bilingualism would support language development and increase their linguistic resources. As research states, linguistic knowledge stored can be accessed by the learner in either language, regardless of how it was acquired (Riches \& Genesee, 2006). This stored linguistic knowledge supports the development of English and mathematics academic knowledge in bilingual classrooms. 
When examining $\mathrm{C} 2$ participants' responses to the first task, it was found that five of them expressed difficulties related to writing in English. Special attention needs to be paid to the writing process in their first language. In English, the complexity of the writing domain makes it hard to develop, even for native English speakers. For Latinx EBs, writing in English is even harder since their listening and speaking skills are still in the process of developing. Nonetheless, as research has emphasized, by providing Latinx EBs with a nurturing learning environment that supports both English learning and mathematics learning, classroom teachers ensure that this population has fair access to mathematics knowledge (Borgioli, 2008; Major, 2012; Moschkovich, 2011, Zavala, 2012).

RQ2: Implications for districts. As for the districts, the main implication is related to providing teachers and school administrators with professional development that focuses on how to facilitate access of knowledge acquired in the first language to the second language. The districts can extend the focus of professional development series to refine mathematics teaching strategies that allow Latinx EBs to use their native language for collaboration while supporting them in their development of mathematics and English language proficiencies. Such professional development series can also focus on refining on the benefits of promoting more collaboration and making mathematics and language instruction connections visible.

RQ2: Implications for future research. Some implications for future research projects include modifications and improvement of the two qualitative instruments used in this study. For example, adding more specifications to the small-group collaborative 
tasks regarding a wider variety of tools participants might have available, as well as follow-ups in the process for participants to choose solutions to the tasks.

Conducting teachers' and students' interviews for more in-depth inferences from their responses is also an important implication for future research. The interviews might provide more valuable data on the students' and teachers' beliefs about learning mathematics and their own interest in engaging in its learning.

Another implication for researchers has to do with breaking out the items in the questionnaire regarding pedagogical practices and strategies to refine findings and more directly relate responses to RQ2.

In a broader sense, an important implication for researchers might be to focus on language and academic proficiency concepts, as suggested by MacSwan and Rolstad (2005). These research efforts can be applied to both the lens of school achievement, as well as the transfer of academic subject knowledge in bilingual settings.

\section{Limitations}

Although the study's findings might be useful for teachers, school and district administrators, and future researchers on the language of instruction for teaching mathematics in bilingual settings, it is recommended to take a closer look at its limitations.

One important limitation was the small sample size used in the study. Although the sample size of six participants in each classroom was the minimum number to conduct the study, it was expected to have at least ten participants per class, or better yet, complete the minimum sample size to run an inferential statistical analysis. The parent 
signature in the PCF determined the final number of participants. C1 (Language of Instruction: Spanish) ended up with only seven students who submitted the signed PCF in a timely fashion. C2 (Language of Instruction: English) ended up with nine participants, two of which missed two of the three small-group collaborative sessions and were excluded from the data analysis process. The small sample size also meant that the results from the quantitative analysis were not generalizable. Unfortunately, for this study, it was difficult to ensure a larger sample size. The planned meetings to informed parents in both schools had a very low attendance rate. It was learned that hosting several informative meetings before the study began would have helped increase the number of participants to ensure a larger sample size.

The instrument that was used to collect quantitative data needed, in the researcher's opinion, a much more in-depth analysis regarding each of the tasks and the relevant knowledge related to place value.

\section{Recommendations for Future Research}

It is recommended to design the study's own quantitative data collection instrument. If the intention is to have more possibilities for inferential statistical analysis, it would be better for the researcher to design the study's own instrument. Running a much more thorough instrumental analysis would also help to add more validity and generalizability.

Conducting similar studies with a much larger sample size might ensure more statistical power in the quantitative analysis.

A third recommendation has to do with conducting more educational research with bilingual teachers in the bilingual classrooms. 
Additionally, it is recommended to conduct similar studies that focus on how thirdand fourth-grade Latinx EBs deal with the concept of place value. At these grade levels, the CA CCSS-M 3.NBT and 4.NBT call for the use of the understanding of base-ten multidigit numbers and the four basic operations, and fractions of those numbers.

Research on evaluations and analyses of other potential influences on the participants' mathematics performance, such as parent involvement, parent's and students' perspectives toward mathematics, and out of school factors may provide further insights into the analysis of the impact of the language of instruction on these groups of Latinx EBs' understanding of mathematical concepts.

Finally, future research might benefit from narrowing focus on other classroom practices that appeared to have a greater influence on this population's mathematics learning, such as classroom norms for collaboration or teachers' beliefs about Latinx EBs learning mathematics, for instance.

\section{Conclusion}

This study examined the relationship between the language of instruction, either Spanish or English, and second-grade Latinx EBs' understanding of the concept of place value. Based on the quantitative data collected, analyzed, and interpreted in alignment with the first research question, this study's findings suggested that there was not a significant relationship between the language of instruction and the participants' understanding of the concept of place value. Both groups of second-grade Latinx EBs exhibited growth in percentage points in the understanding of the concept of place value, as measured by the increase in scores from pre- to post-test, regardless of the language of 
instruction. Thus, the language of instruction was not a barrier for Latinx EBs to reach higher levels of mathematics understanding of place value in this small sample size, as measured by the pre-and post-test used in the study.

In contrast, the qualitative data collected, analyzed, and interpreted in alignment with the second research question, revealed that the language of instruction might have indeed affected the communication patterns participants used in small-group collaborative conversations around place value tasks. It was also suggested that the mathematics classroom environment played an important role in second-grade Latinx EBs' understanding of the place value concept. Collaboration norms and ways to approach the tasks supported students' collaboration and impacted their learning. Classroom practices other than the language of instruction seemed to have more impact on this study's participants' understanding of the mathematical concept of place value.

This study's findings suggest that teachers, school administrators, and district leaders need to plan professional development series focused on the enhancement of mathematics classroom environments. Bilingual teachers need to attend consistent and high-quality professional development to refine their strategies to teach mathematics that involves more collaboration time around the language of instruction. The language of instruction integrated with other classroom practices supports students' meaning-making process in mathematics classes. More attention needs to be paid to tasks, tools, and classroom norms - the critical dimensions of classroom practice suggested by Carpenter and Lehrer (1999) - to promote understanding of mathematical concepts. 


\section{References}

Abedi, J. and Lord, C. (2001) The language factor in mathematics tests. Applied Measurement in Education, 14(3), 219-234. doi:10.1207/S15324818AME1403_2

Ackerman, D.J. \& Tazi, Z. (2015). Enhancing young hispanic dual language learner's achievement: Exploring strategies and addressing challenges. Wiley Online Library. Retrieved 4/8/2020. doi:10.1002/ets 2.12045

AERA (American Educational Research Association), APA (American Psychological Association), and NCME (National Council on Measurement in Education). (2014). Standards for educational and psychological testing. Washington, DC.

Anyon, J. (1981). Social class and school knowledge. Curriculum Inquiry, 11(1), 3-42.

Barbour, R. S. (1998). Mixing qualitative methods: Quality assurance or qualitative quagmire? Qualitative Health Research, 8(3), 352-61.

Barbour, R. S. (2008). Introducing qualitative research. London: Sage.

Berliner, D. C. (2009). Poverty and potential: Out-of-school factors and school success. Boulder, CO and Tempe, AZ: Education and the Public Interest Center \& Education Policy, Research Unit.

Bernardo, A.B.I. \& Calleja, M.O. (2005). The effects of stating problems in bilingual students' first and second languages on solving mathematics word problems. Journal of Genetic Psychology,166(1), 117-129. doi: 10.3200/GNTP.166.1.117-129

Borgioli, G.M. (2008). Equity for English language learners in mathematics classrooms. Teaching Children Mathematics, 15(3), 185-191.

Boaler, J. (2002). The development of disciplinary relationships: Knowledge, practice, and identity in mathematics classrooms. For the Learning of Mathematics, 22(1), 4247.

Boejie, H. (2010). Analysis in qualitative research. London: Sage.

Bowles, S. \& Gintis, H. (1976). Schooling in capitalist America revisited. Sociology of Education, 75(1); 1.

Brophy, J. (2004). Motivating students to learn (2nd ed.). Michigan State University: Routledge.

CAASPP (California Assessment of Student Performance and Progress). (2018). SBAC test results for English language arts/literacy and mathematics. 
CDE (California Department of Education). (2013-2014). California Common Core State Standards: Mathematics [electronic version].

CDE (California Department of Education). (2018). Facts about English Learners in California [electronic version].

CDE (California Department of Education). (2019). Language Acquisition Programs [electronic version].

Castellano, K.E., Duckor, B., Wihardini, D., Tellez, K. \& Wilson, M. (2016). Assessing academic language in an elementary mathematics teacher licensure exam. Teacher Education Quarterly, 43(1), 3-27.

Carpenter, T.P., \& Lehrer, R. (1999). Teaching and learning mathematics with understanding. In E. Fennema \& T.A. Romberg (Eds.), Mathematics classrooms that promote understanding (pp. 19-32). Routledge.

Clements, D. H., and Battista, M.T. (1990). Constructivist learning and teaching. The Arithmetic Teacher, 38(1), 34.

Clements, D. H., Sarama, J., \& Wolfe, C. B. (2010). TEAM-Tools for early assessment in mathematics. McGraw-Hill Education.

Cobb, P. (1998). Learning from distributed theories of intelligence. Mind, Culture, and Activity, 5(3), 187-204, Routledge. doi.org:10.1207/s15327884mca0503_4

Creswell, J. \& Plano Clark, V. (2011). Designing and conducting mixed methods research (2nd ed.). Thousand Oaks, CA: Sage Publications.

Cummins, J. (1976). The influence of bilingualism on cognitive growth: A synthesis of research findings and explanatory hypotheses. Working Papers on Bilingualism, (9).

Cummins, J. (1979). Linguistic interdependence and the educational development of bilingual children, Sage Journals, 49(2), 222-251. doi:10.3102/00346543049002222

Cummins, J. (2008). BICS and CALP: Empirical and theoretical status of the distinction. In B. Street \& N.H. Hornberger (Eds.), Encyclopedia of Language and Education (2nd ed.), (pp. 71-83). New York, NY: Springer Science + Business Media LLC.

Davis, B. (1995). Why teaching mathematics? Mathematics education and enactivist theory. For the Learning of Mathematics, 15(2), 2-9.

Dawson, C. (2009). Introduction to research methods. Oxford: How-To Books. 
EngageNY.org. (2015). NYS common core mathematics curriculum: End-of-module assessment task 2-3 [Online assessment]. Washington, D.C.: EurekaMath ${ }^{\mathrm{TM}}$ and Great Minds.

Fuson, K. C. (1990). Issues in place-value and multidigit addition and subtraction learning and teaching. Journal for Research in Mathematics Education, 21(4), 273280. doi: $10.2307 / 749525$

Fuson, K. C. \& Beckman, S. (2012). Standard algorithms in the common core state standards. NCSM Journal, 14(2) 14-30.

Fuson, K. C. \& Briars, D. J. (1990). Using a base-ten blocks learning/teaching approach for first-and second-grade place value and multidigit addition and subtraction. Journal for Research in Mathematics Education, 2(3), 180-206.

Fuson, K. C. \& Li, Y. (2009). Cross-cultural issues in linguistic, visual-quantitative, and written-numeric supports for mathematical thinking. ZDM Mathematics Education, $41,793-808$.

Fuson, K. C., Wearne, D., Hiebert, J. C., Murray, H. G., Human, P. G., Olivier, A. I., Carpenter, T. P., \& Fennema, E. (1997). Children's conceptual structures for multidigit numbers and methods of multidigit addition and subtraction. Journal for Research in Mathematics Education, 28(2) 130-162.

Garcia, O., Kleifgen, J. A., and Falchi, L. (2008). From English language learners to emergent bilinguals: A research initiative of the campaign for educational equity. [Equity Matters: Research Review No.1] New York, NY: Teachers College, Columbia University.

Glaser, B.G. \& Strauss, A.L. (1965). Discovery of substantive theory: A basic strategy underlying qualitative research. American Behavioral Scientist, 8(6), 5-12. doi: $10.1177 / 000276426500800602$

Golafshani, N. (2003). Understanding reliability and validity in qualitative research. The Qualitative Report, 8(4) 597-606.

Greeno, J.G., \& Boaler, J. (2000). Identity, agency, and knowing in mathematics worlds. In J.G. Greeno \& J. Boaler (Eds.), Multiple Perspectives on Mathematics Teaching and Learning. International Perspectives on Mathematics Education. Leone Burton, Series Editor. Westport, CT: Ablex Publishing.

Harding, J. (2019). Qualitative data analysis from start to finish (2nd ed.). Thousand Oaks, CA: Sage Publications Inc. 
Hopkinson, A. (2017, January 6). A new era for bilingual education: Explaining California's Proposition 58. EdSource.

Kempert, S., Saalbach, H. \& Hardy, I. (2011). Cognitive benefits and costs of bilingualism in elementary school students: The case of mathematical word problems. Journal of Educational Psychology, 103(3), 547-561. doi: 10.1037/a0023619

Khisty, L.L. (2002). Mathematics learning and the Latino student: Suggestions from research for classroom practice. Teaching Children Mathematics, 9(1), 32-35.

Kozulin, A. (2002). Socio-cultural theory and the mediated learning experience. School Psychology International, 23(1), 7-35. doi: 10.1177/0143034302023001729

Lincoln, Y.S., \& Guba, E.G. (1985). Naturalistic inquiry. Beverly Hills, CA: Sage Publications.

MacDonald, B.L., Westenskow, A., Moyer-Packenman, P.S., \& Child, B. (2018). Components of Place Value Understanding: Targeting Mathematical Difficulties When Providing Intervention. School Science and Mathematics, 118(1-2), 17-29.

MacSwan, J. (2000). The threshold hypothesis, semilingualism, and other contributions to a deficit view of linguistic minorities. Hispanic Journal of Behavioral Sciences, 22(1), 3-45. doi: 10.1177/0739986300221001

MacSwan, J. \& Pray, L. (2005). Learning English bilingually: Age of onset of exposure and rate of acquisition among English Language Learners in a bilingual education program. Bilingual Research Journal, 29(3) 653-678. doi: 10.1080/15235882.2005.10162857

MacSwan, J. \& Rolstad, K. (2005). Modularity and the facilitation effect: Psychological mechanisms of transfer in bilingual students. Hispanic Journal of Behavioral Sciences, 27(2), 224-243. doi: 10.1177/0739986305275173

MacSwan, J. \& Rolstad, K. (2014). The Facilitation effect and language thresholds. Frontiers in Psychology, 5. doi: 10.3389/fpsyg.2014.01197

Major, K. (2012). The development of an assessment tool: Student knowledge of the concept of place value. Paper presented at the Annual Meeting of the Mathematics Education Research Group of Australasia (MERGA). Singapore.

Merriam, S.D., \& Tisdell, E.J. (2016). Qualitative research: A guide to design and implementation (4th ed.), San Francisco: Jossey-Bass.

Moschkovich, J. (2007). Using two languages when learning mathematics. Educational Studies in Mathematics, 64, 121-144. doi: 10.1007/s10649-005-9005-1 
Moschkovich, J. (2011). Mathematics, the common core, and language:

Recommendations for mathematics instruction for ELs aligned with the common core, in K. Hakuta \& M. Santos (Eds.), Understanding Language: Language, Literacy, and Learning in the Content Areas (p. 17). Palo Alto, CA: Stanford University.

Murata, A. (2004). Path to learning understanding of teens sums: Addition solution methods of Japanese grade 1 students. Cognition and Instruction, 22(2), 185-218. doi: 10. 1207/s1532690xci2202_2

NRC (National Research Council) (2001a). Adding it up: Helping children learn mathematics. Washington, DC: National Academy Press.

NRC (National Research Council) (2001b). Knowing what students know. The science and design of education assessment. Washington, DC: National Academy Press.

Patton, M. Q. (2002). Qualitative evaluation and research methods $\left(3^{\text {rd }}\right.$ ed.). Thousand Oaks, CA: Sage Publications, Inc.

Razfar, A. \& Leavitt, D. R. (2011). Developing metadiscourse: Building mathematical discussions in an urban elementary classroom. Canadian Journal of Science, Mathematics, and Technology, 11(16), 180-197. doi: 10.1080/14926156.2011.570474

Riches, C. \& Genesee, F. (2006). Literacy: Crosslinguistic and crossmodal issues. In F. Genesee, K. Lindholm-Leary, W. M. Saunders, \& D. Christian (Eds.), Educating English language learners: A synthesis of research evidence (pp. 64-108). Cambridge, UK: Cambridge University Press.

Van Rinsveld, A., Schiltz, C., Brunner, M., Landerl, K., \& Ugen, S. (2016). Solving arithmetic problems in first and second language: Does the language context matter? Learning and Instruction,42, 72-82. doi: 10.1016/j.learninstruc.2016.01.003

Valeras, M. \& Becker, J. (1997). Children's developing understanding of place value semiotic aspects. Cognition and Instruction, 15(2), 265-286. http://www.jstor.org/stable/3233767

Vygotsky, L. (1978). Interaction between learning and development. In M. Ganvain \& M. Cole, Readings on the Development of Children (pp. 34-40). New York, NY: Scientific American Books.

Young-Loveridge, J. (2008). Analysis of 2007 data from the Numeracy Development Projects: What does the picture show? In Findings from the New Zealand Numeracy Development Projects 2007. (pp. 18-28, 191, 211). Wellington, New Zealand: Ministry of Education. 
Yushau, B. \& Bokhari, M. A. (2015). Language and mathematics: A mediational approach to bilingual Arabs. Dhahran, Saudi Arabia: Department of Mathematical Sciences, King Fahd University of Petroleum \& Minerals.

Zavala, M.R. (2012). Race, language, and opportunities to learn: Mathematics identity negotiation of Latino/a youth (Doctoral dissertation). ProQuest LLC, University of Washington. 


\section{Appendices}

\section{Appendix A: Email to the Assistant Superintendent}

$\mathrm{XX}-\mathrm{XX}-\mathrm{XXXX}$

Mr. (Name)

Assistant Superintendent of Educational Services Department,

I started the process of writing my doctoral dissertation and will begin to collect data for that purpose. As we have previously discussed, I am requesting your permission to conduct my research study in two schools within the district. I attached the parent consent letter in which I get committed to respecting the teachers, students, and families' privacy. The data collected will be used for this research purpose only. Personal information will not be shared or disclosed to any individual or organization following California's Laws (Children's Online Privacy Protection Act-COPPA and The Student Online Personal Information Protection Act-SOPIPA) regarding students and online privacy. Federal law (The Family Educational Rights and Privacy Act -FERPA) also protects the privacy of student education records After reading the attached document, please consider writing and signing a letter of support as evidence of your approval.

Thank you very much for your support and encouragement to continue my research study,

Angela M. Rengifo 


\section{Appendix B: Recruitment Teacher Email}

$\mathrm{XX}-\mathrm{XX}-\mathrm{XXXX}$

Dear (Name)

Second Grade Bilingual Teacher at (School Name),

I have completed the second year of course work to obtain my doctoral degree in Educational Leadership from the San Jose State University School of Education. I started the process of writing my dissertation study. This message is to request your voluntary participation in the research study that will be conducted in second-grade bilingual classroom settings. The title of the study is "The impact of the language of instruction on second grade Latinx Emergent Bilinguals' understanding of place value (CA Common Core Standard 2NBT 1-4) and the communication patterns these students use during collaboration time when solving mathematical tasks related to place value." Your participation involves your willingness to:

- Meet with the researcher once to get informed about the study, answer a questionnaire, and plan an informational meeting for parents in which the researcher will explain the details of the study and obtain parental consent.

- have the researcher in your classroom to audio recording a small group of students in three 20-minute sessions, in the beginning, middle, and end of the place value module (6-8 weeks)

- Share with the researcher team original pre-and-post assessments given to the students in the beginning and at the end of the place value module, as well as the scores and the rubric used.

It is my commitment to sharing with the district administrators and staff the study findings.

If you have any questions or concerns, please reach out to me via email or stop by Room 24.

Sincerely,

Angela M. Rengifo

SJSU

Student Researcher 


\section{Appendix C: Teacher Consent Form}

\section{REQUEST FOR YOUR PARTICIPATION IN RESEARCH}

\section{TITLE OF THE STUDY:}

The impact of the Language of Instruction on Second Grade Latinx Emergent Bilinguals' Understanding of Place Value and the Communication Patterns around This Mathematical Concept in Two Spanish-English Bilingual Classrooms in a District in Northern California

\section{NAME OF THE RESEARCHERS:}

Ms. Angela M. Rengifo, San Jose State University- Doctoral Candidate

\section{PURPOSE}

The purpose of this study is to examine whether and how the language of instruction have an impact on second-grade Latinx Emergent Bilingual students' understanding of place value. It also intends to verify to what extent this impact (if any) affects the communication patterns used in small-group collaborative sessions, in two SpanishEnglish bilingual classrooms in your district. The study results and findings will be shared and discussed with the dissertation committee in the first instance. General findings will also be shared with the school and district as part of the agreement to support the research. Non-identifying participant responses will be included in the results and findings report to share with the district. This consent form seeks your approval to share the results and findings from the study.

\section{PROCEDURES:}

Upon your participation consent signature, you will be requested to:

- Meet with the researcher once to get informed about the study, answer a questionnaire, and plan an informational meeting for parents in which the researcher will explain the details of the study and obtain parental consent.

- Have the researcher in your classroom to audio recording a small group of students in three 20-minute sessions, in the beginning, middle, and end of the place value module (6-8 weeks). This small group session will be audio-recorded upon parents' consent signature. We will be sure that students whose parents do not sign the parent consent form will work in other groups within the classroom. Only the students with signed parent consent will be audio-recorded since they will be arranged in a group together. After the data analysis, these audiorecordings will be destroyed.

- Share with the researcher team, original pre-and-post assessments given to the students in the beginning and at the end of the place value module, as well as the scores and the rubric used. 
Voluntary Nature of the Study: Teacher participation in this study is voluntary. Their decision to participate or not will not affect their current or future relationship with the school, district, or the researchers' organization. After deciding to participate, teachers are still free to withdraw.

\section{POTENTIAL RISKS:}

There are only minimal risks associated with this study. The small group activity planning may cause anxiety. To minimize this potential risk, the researchers get committed to providing specific details on the study to the participants. The participation is voluntary, and confidentiality is ensured by assigning identification codes instead of names and other identifiable information in every document used for the research.

\section{POTENTIAL BENEFITS:}

By participating in the study, the teacher may become more aware of his/her beliefs concerning teaching mathematics, more specifically place value. The participant may also become more intentional when planning small group activities for students to collaborate during mathematics instruction. Most importantly, the teachers who participate in this study may learn about the relationship between the language of instruction and the students' comprehension of key mathematical concepts such as place value and modify decisions accordingly.

COMPENSATION: The teachers who participate in the study will get a \$25 Amazon gift certificate and a U\$50 Lakeshore gift certificate to purchase materials that support mathematical learning.

\section{CONFIDENTIALITY:}

The researcher will not include any information that will make it possible to identify the teachers, the students, the classroom, the school, and the district. All research records will be kept in a locked file to be accessed only by the researcher and the Chair advisor. As aforementioned, confidentiality is ensured by assigning identification codes in place of names and other identifiable information in every document used for the research.

\section{PARTICIPANT RIGHTS:}

Your participation in this study is completely voluntary. You can refuse to participate in the entire study or any part of the study without any negative effect on your relations with San Jose State University or your institution. You also have the right to skip any question you do not wish to answer. This consent form is a written explanation of what will happen during the study if you decide to participate. You will not waive any rights if you choose not to participate, and there is no penalty for stopping your participation in the study. Even if you have decided to participate, you may withdraw at any time. 
QUESTIONS OR PROBLEMS: You are encouraged to ask questions at any time during this study.

- For further information about the study, please contact the researcher:

Angela M. Rengifo via phone (408) 6797438 or email

angela.schlindwein@sjsu.edu.

- Complaints about the research may be presented to Dr. Bradley Porfilio, Director of Doctoral Program, San Jose State University at (408) 9244098

- For questions about participants' rights or if you feel you have been harmed in any way by your participation in this study, please contact Dr. Pamela Stacks, Associate Vice President of the Office of Research, San Jose State University, at 408-924-2479.

\section{SIGNATURES:}

Your signature indicates that you voluntarily agree to participate in the study, that you understand the details of the study as they have been explained to you, that you have been given time to read this document, and that your questions have been answered. You will receive a copy of this consent form, signed and dated by the researcher, for your records.

\section{Participant Signature}

Participant's Name (printed) Participant's Signature Date

\section{Researcher Statement}

I certify that the participant has been given adequate time to learn about the study and ask questions. It is my opinion that the participant understands his/her rights and the purpose, risks, benefits, and procedures of the research and has voluntarily agreed to participate. 


\section{Appendix D: Teacher Questionnaire}

Name:

Site:

Grade Level:

1. How many years of teaching experience do you have?

2. How many years of teaching experience in bilingual settings?

3. What does mathematics class look like in your classroom?

4. Do you think the language of instruction has an impact on bilingual students' mathematics learning? Explain

5. What are some of the more difficult mathematical concepts to teach and/or your students to learn in this grade level?

6. How do you plan your mathematics lessons?

7. How do you use mathematics CCSS in your planning?

8. What language do you use when planning your lessons? 
9. When teaching place value units, what teaching practices and instructional strategies do you use to help your students learn CA Common Core State Standards: Number and Operation in Base Ten 2.NBT 1 through 4 as follows:

Understand place value

1. Understand that the three digits of a three-digit number represent amounts of hundreds, tens, and ones; e.g., 706 equals 7 hundreds, 0 tens, and 6 ones. Understand the following as special cases:

a. 100 can be thought of as a bundle of ten tens-called a "hundred."

b. The numbers 100, 200, 300, 400, 500, 600, 700, 800, 900 refer to one, two, three, four, five, six, seven, eight, or nine hundred (and 0 tens, and 0 ones).

2. Count within 1000 skip count by $2 \mathrm{~s}, 5 \mathrm{~s}, 10 \mathrm{~s}$, and 100s (CA)

3. Read and write numbers using base-ten numerals, number names, and expanded form

4. Compare two three-digit numbers based on meanings of the hundreds, tens, and ones digits, using >, =, and < symbols record the results of comparisons. 


\section{Appendix E: Parent Consent Form (English)}

\section{REQUEST FOR YOUR CHILD'S OR WARD'S PARTICIPATION IN RESEARCH}

TITLE OF THE STUDY: The Impact of the Language of Instruction on Second Grade Latinx Emergent Bilinguals' Understanding of Place Value and the Communication Patterns around This Mathematical Concept in Two Spanish-English Bilingual Classrooms in a District in Northern California

\section{NAME OF THE RESEARCHER}

Angela M. Rengifo, Educational Leadership Doctoral Candidate at San Jose State University Ed.D Program

\section{PURPOSE}

The purpose of the study is to find out if using Spanish or English to teach mathematics makes a difference in Bilingual second graders' understanding of concepts such as place value and the way they communicate this knowledge.

\section{PROCEDURES}

Your child will take a test in the beginning and at the end of the place value unit. The consent is only for the use of these test scores and to allow the researcher audio-record three small group sessions in which the students collaborate to solve place value tasks. The study is not expected to change or disrupt any of the daily learning experiences your child has in the classroom.

\section{POTENTIAL RISKS}

This study does not represent any risk.

\section{POTENTIAL BENEFITS}

Although there are no direct benefits to the children participating in this study, it might benefit many young mathematics learners in the future.

\section{COMPENSATION}

There is no direct compensation for the participants. However, if 10 out of 25 children participate in the study, the participating class will receive a $\$ 50$ Lakeshore gift certificate for purchasing class materials

\section{CONFIDENTIALITY}

The study will be completed at school. All information from the study will only be seen by the research staff and will be kept confidential. The study will use pseudonyms when processing this information to ensure that the reports of this research study will not include any information that could identify your child, your family, or you. You should know, however, that we are required by law to report any situations related to child abuse to the appropriate authority. 


\section{PARTICIPANT RIGHTS}

Your child's participation in this study is completely voluntary. You may refuse to allow your child to participate in the entire study or any part of the study without negative effects on your relations with San Jose State University or the school district. This consent form is not a contract. It is a written explanation of what will happen during the study.

\section{QUESTIONS OR PROBLEMS}

You are encouraged to ask questions and to have your child ask questions at any time during this study.

- For further information about the study, please contact the researcher: Angela Rengifo Schlindwein at angela.schlindwein @ sjsu.edu or 408-679-7438

- Complaints about the research may be presented to Dr. Bradley Porfilio, Director of Doctoral Program, San Jose State University at 408-924-4098

- For questions about participants' rights or if you feel you have been harmed in any way by participating in this study, please contact Dr. Pamela Stacks, Associate Vice President of the Office of Research, San Jose State University, at 408-924-2479.

\section{SIGNATURES}

\section{Parent/Guardian Signature}

Your signature indicates that you voluntarily agree to allow your child to be part of the study, that the details of the study have been explained to you and your child, that you have been given time to read this document, and that your questions have been answered. You will be given a copy of this consent form, signed and dated by the researcher, to keep in your records.

Name of Child or Minor

Parent or Guardian Name (Printed)

Relationship to Child or Minor

Parent or Guardian Signature Date




\section{Researcher Statement}

I certify that the minor's parent/guardian has been given adequate time to learn about the study and ask questions. It is my opinion that the parent/guardian understands his/her child's rights and the purpose, risks, benefits, and procedures of the research and has voluntarily agreed to allow his/her child to participate. I have also explained the study to the minor in language appropriate to his/her age and have received assent from the minor. 


\section{Appendix F: Parent Consent Form (Spanish)}

\section{SOLICITUD PARA LA PARTICIPACION DE SU HIJO(A) MENOR EN UN ESTUDIO}

TITULO DE LA INVESTIGACION: El impacto del lenguaje de instrucción en la comprensión de conceptos matemáticos relacionados con el valor de posición, y los patrones de comunicación alrededor de este concepto en estudiantes bilingüies de Segundo grado en dos salones bilingües español-ingles en un distrito en California.

INVESTIGADOR RESPONSABLE: Angela Rengifo Schlindwein, estudiante-aspirante al Doctorado en el programa de Liderazgo en educación de la Universidad Estatal de San Jose, California.

PROPÓSITO-OBJETIVO: El propósito del estudio es encontrar si enseñar un concepto matemático como el valor de posición, ya sea español o inglés, hace una diferencia en la comprensión y en las formas como los estudiantes bilingües de segundo grado comunican este conocimiento.

PROCEDIMIENTOS: Al inicio de la unidad titulada: Valor de posición, todos los niños de la clase toman un examen para indagar que saben sobre el tema. Al final de la unidad, toman un examen para determinar el crecimiento en el manejo del tema. El consentimiento es solamente para autorizar el uso de los resultados de los dos exámenes en la investigación y para grabar las conversaciones de los niños cuando trabajan en grupos pequeños. El estudio se completará en la escuela.

RIESGOS POTENCIALES: Este estudio no representa ningún riesgo.

BENEFICIOS POTENCIALES: Aunque no hay beneficio directo ni compensación para su hijo (a), este estudio podría beneficiar a muchos niños en su aprendizaje de las matemáticas en el futuro.

COMPENSACIÓN: No hay compensación directa para los participantes. Sin embargo, si 10 de 25 niños de la clase participan del estudio, la clase ganara una tarjeta \$50 dólares de Lakeshore para comprar materiales para la clase

CONFIDENCIALIDAD: El estudio se completará en la escuela. Toda la información obtenida por el estudio solo será vista por el equipo de investigadores y se mantendrá confidencial. El estudio usara seudónimos al procesar la información. Esto significa que la información presentada en el estudio no permitirá identificar a su hijo (a) ni a la familia en ningún reporte de la investigación. Sin embargo, usted debe saber que estoy obligada por ley a reportar cualquier situación de abuso infantil a las autoridades asignadas.

DERECHOS DE LOS PARTICIPANTES: La participación es voluntaria, Usted puede rehusar la participación de su hijo (a), en toda la investigación o en partes de ella, sin que haya efectos negativos en su relación con la universidad estatal de San Jose o con el 
distrito. Si usted decide permitir que su hijo (a) participe, y él o ella no quiere participar, se respeta la decisión del infante. También, si usted o su hijo (a) se quiere retirar del estudio, puede hacerlo en cualquier momento. No hay penalidad si decide no participar. Este consentimiento no es un contrato. Es una explicación por escrito de lo que pasara en el estudio.

PREGUNTAS O PROBLEMAS: Si tiene preguntas sobre este estudio, estaremos muy complacidos de hablar con usted personalmente. También puede llamar al teléfono (408) 6797438 o por correo electrónico: angela.schlindwein@sjsu.edu

- Para mayor información acerca de esta investigación, por favor contacte a la investigadora: angela.schlindwein@sjsu.edu, 408-679-7438 o al correo electrónico: angela.schlindwein@sjsu.edu

- Quejas o reclamos relacionados con esta investigación pueden presentarse al doctor Bradley Porfilio, Director del programa de Doctorado en educación y liderazgo en la universidad estatal de San Jose al 408-924-4098 o correo electrónico: bradley.porfirio@sjsu.edu

- Para preguntas acerca de los derechos de los participantes o si siente que ha sido afectado en alguna forma por su participación en este estudio, por favor contacte a la doctora Pamela Stacks, Vicepresidente asociada de la oficina de investigación, de la universidad estatal de San Jose al teléfono 408-924-2479.

Si usted permite la participación de su niño (a) en el estudio, por favor complete, firme y devuelva esta página a la maestra de su niño (a). Se le entregara una copia de esta forma, firmada y fechada por los investigadores para su comodidad.

\section{FIRMA DEL PADRE, MADRE O TUTOR LEGAL:}

Su firma indica que usted acepta voluntariamente que su hijo (a) participe de este estudio, que los detalles del estudio han sido explicados a usted y a su niño (a), que ha tenido tiempo suficiente para leer esta información, y que sus preguntas han sido contestadas. Usted recibirá una copia de este consentimiento firmado y fechado por los investigadores para su registro.

Nombre del menor

Padre, madre o tutor (letra de molde)

Relación con el menor

Firma del padre, madre o tutor

Fecha 
Declaración del investigador:

Declaro que los padres del menor han tenido tiempo adecuado para aprender sobre el estudio y hacer las preguntas. Es nuestra opinión que el padre, madre o tutor del estudiante menor ha entendido los derechos del menor, el propósito, riesgos, beneficios y procedimientos de esta investigación y que voluntariamente han permitido que su hijo (a) participe. Hemos explicado el estudio al menor en un lenguaje apropiado para su edad y hemos recibido aprobación del menor.

Angela M. Rengifo Fecha 


\section{Appendix G: Assent Script for Getting Verbal Assent from Children (English)}

STUDY TITLE: Impact of the Language of Instruction on Second Grade Latinx Emergent Bilinguals' Understanding of Mathematical Concepts Related to Place Value and the communication patterns around this topic in bilingual classrooms.

WHY AM I MEETING WITH YOU? I want to tell you about something I'm doing called a research study. A research study is when a person or a group of people collect information to learn more about something. I am doing a study because I'm also a student who wants to learn if when your teacher chooses Spanish or English to teach mathematics that helps you better understand and communicate your ideas about mathematics. After I tell you about the study, I will ask if you would like to be in the study or not.

WHY AM I DOING THIS STUDY? I want to find out if presenting mathematics ideas to you in either Spanish or English will help you to understand better and communicate what you learn. The study will begin as soon as I get your permission and your parents' permission to let you participate. The study will go on every school day for about six weeks. Your teacher has chosen Spanish or English to teach you mathematics since the beginning of the school year, and this will not change.

WHAT WILL HAPPEN TO YOU IF YOU ARE IN THIS STUDY? If you agree to be in this study, you will see me in the classroom, audio recording your conversations when working in small groups. Your teacher will continue teaching mathematics as she always does. Your name will remain secret when I share the results of this study. Nobody will be able to tell whether you participated in the study or not. At the end of the study, your class will receive a $\$ 50$ Gift Certificate for purchasing class materials.

WHAT HAPPENS IF YOU DO NOT WANT TO PARTICIPATE? You don't have to be in the study if you don't want to. If you are not in the study, you will still be in the classroom, but I will not use your test scores, nor will I audio record your group discussions. Whether or not you are in the study is completely your choice. If you decide that you want to be in the study, your participation may help teachers to make decisions on choosing the language to teach mathematics.

DO YOU HAVE ANY QUESTIONS? You can ask me questions at any time. You can ask now. You can ask later. You can talk to me, or you can talk to your teacher. They know all about the study. You can also talk about the study with your parents.

Do you want to be in the study?
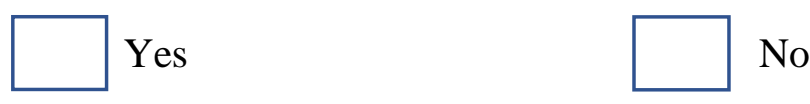
Signature of the Person Conducting the Assent Discussion

I have explained the study to (print name of child) in language he/she can understand, and the child has agreed to be in the study. Consent from the parent or guardian has also already been sought and obtained.

Printed Name of Person Conducting Assent Discussion

Signature of Person Conducting Assent Discussion

Date 


\section{Appendix H: Assent Script for Getting Verbal Assent from Children (Spanish)}

TITULO DEL ESTUDIO: El impacto del lenguaje de instrucción en la comprensión de conceptos matemáticos relacionados con el valor de posición, en estudiantes bilingües de Segundo grado en los salones de clase bilingüe Español-Inglés.

¿POR QUE ME ESTOY REUNIENDO CONTIGO? Yo quiero contarte sobre un estudio o investigación que estoy realizando. Un estudio o investigación es cuando una persona o un grupo de personas recoge información para aprender más sobre un problema y a veces para ofrecer una posible solución. Estoy haciendo esta investigación porque soy una estudiante de liderazgo y quiero aprender si cuando tu maestra escoge ensenar matemáticas en español o en inglés, eso te ayuda a entender y comunicar tus ideas de matemáticas. Cuando termine de contarte esto, te preguntare si quieres participar en el estudio o no.

¿POR QUE ESTOY HACIENDO ESTE ESTUDIO? Quiero saber si presentar las ideas de matemáticas en español o en ingles te ayudará a entender mejor lo que debes aprender. El estudio comenzará tan pronto como consigamos el permiso de tus padres para dejarte participar. El estudio se llevará a cabo en los días de escuela durante seis a ocho semanas. Tu maestra ya escogió el idioma, español o inglés, para ensenar las lecciones de matemáticas desde el comienzo del año. Esto no cambiará con el estudio.

¿QUE PASARA CONTIGO SI DECIDES PARTICIPAR EN EL ESTUDIO? Si decides participar del estudio, me veras grabando las conversaciones con tus compañeros en la clase de matemáticas. Tu maestra continuará ensenando matemáticas como siempre lo hace. Tu tomarás un examen al comienzo y al final de la unidad de matemáticas que tu maestra ha planeado Tu nombre permanecerá en secreto. Nadie podrá saber si tu participaste o no, solo tus padres y tú sabrán. Al final del estudio, tu clase recibirá una tarjeta de \$50 para comprar materiales para la clase.

¿QUE PASA SI TU DECIDES NO PARTICIPAR? Tú no tienes que participar del estudio si no quieres. No afectará tu calificación en la clase. Si tú no estás en el estudio, todavía estarás en tu clase, solo que no podré usar tus exámenes ni grabar las discusiones sobre matemáticas con tu grupo. Si quieres o no estar en el estudio es tu decisión. Tu participación puede ayudar a los maestros y maestras en el futuro para decidir qué idioma usar para ensenar matemáticas y esto puede ayudar también a otros estudiantes.

¿TIENES ALGUNA PREGUNTA? Tú puedes hacer preguntas en cualquier momento. Puede ser ahora o más adelante. Puedes hablar con tu maestra o con tus padres sobre el estudio. Ellos pueden también responder tus preguntas.

¿Quieres participar del estudio? 
Firma de la persona que condujo la discusión

He explicado el estudio a

$$
\text { Nombre del niño/niña en imprenta }
$$

en un lenguaje sencillo que el/ella puede entender, y el niño/niña ha decidido participar en el estudio. Consentimiento del padre, madre o tutor ha sido buscado y obtenido

Nombre en letra imprenta de la persona que condujo la discusión

Firma de la persona que condujo la discusión Fecha 


\section{Appendix I: Pre-Post-Test (English)}

Name

Date

1. a. Represent 403 using place value disks.

403

b. Write 403 in expanded form

c. Write 403 in word form.

2. Write each number in standard form.
a. 2 hundreds 3 tens 5 ones $=$
b. $\quad 6$ tens 1 hundred 8 ones $=$
c. $600+4+30=$
d. $80+400=$
e. Two hundred thirteen $=$
f. Seven hundred thirty $=$

3. Complete each statement.
a. 10 tens $=$ hundred
b. $\quad 10$ ones $=$ ten
c. tens $=1$ hundred
d. $\quad 160=$ tens 
4. Write the total amount of money shown in each group in the space below.

a.

\begin{tabular}{|l|l|}
\hline$\$ 100$ & $\$ 100$ \\
\hline$\$ 100$ & $\$ 100$ \\
\hline$\$ 100$ & $\$ 10$ \\
\hline$\$ 100$ & $\$ 10$ \\
\hline$\$ 100$ & $\$ 10$ \\
\hline
\end{tabular}

a.

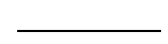

b.

\begin{tabular}{|l|l|}
\hline$\$ 10$ & $\$ 1$ \\
\hline$\$ 10$ & $\$ 1$ \\
\hline$\$ 10$ & $\$ 1$ \\
\hline$\$ 10$ & $\$ 1$ \\
\hline$\$ 10$ & $\$ 1$ \\
\hline
\end{tabular}

c.

\begin{tabular}{|l|l|}
\hline$\$ 1$ & $\$ 100$ \\
\hline$\$ 1$ & $\$ 100$ \\
\hline$\$ 1$ & $\$ 100$ \\
\hline$\$ 1$ & $\$ 100$ \\
\hline$\$ 1$ & $\$ 100$ \\
\hline
\end{tabular}

b.

c.

d. Write one way you can skip-count by tens and hundreds from 150 to 410 .

5. Compare.
a. 456 465
b. 10 tens<smiles>[AsH3]C1CCCCC1</smiles>
c. $60+800$<smiles>c1ccccc1</smiles> Eight hundred sixteen
d. 23 tens 7 ones<smiles>[123In]c1ccccc1</smiles>
e. $50+9+600$ 9 ones 65 tens

\section{EUREKA}

This work is derived from Eureka Math ${ }^{\text {th }}$ and This file derived from G2-M3-TE-1.3.0-06.2015

Module 3:

Place Value, Counting, and Comparison of Numbers to 1,000 


\section{Appendix J: Pre-Post-Test (Spanish)}

Fecha

1. a. Represente 403 usando discos de valor posicional.

403

b. Escriba 403 en forma expandida.

c. Escriba 403 en forma verbal.

2. Escriba cada número en forma estándar.
a. 2 centenares 3 decenas 5 unidades $=$
b. 6 decenas 1 centenar 8 unidades $=$
c. $600+4+30=$
d. $\quad 80+400=$
e. Doscientos trece $=$
f. Setecientos treinta $=$

3. Complete cada declaración.
a. 10 decenas $=$ centenar
b. $\quad 10$ unidades $=$ decena

c. decenas $=1$ centenar d. $\quad 160=$ decenas 
4. Anote la cantidad total de dinero que se muestra en cada grupo en el espacio a continuación.

a.

\begin{tabular}{|l|l|}
\hline$\$ 100$ & $\$ 100$ \\
\hline$\$ 100$ & $\$ 100$ \\
\hline$\$ 100$ & $\$ 10$ \\
\hline$\$ 100$ & $\$ 10$ \\
\hline$\$ 100$ & $\$ 10$ \\
\hline
\end{tabular}

a.

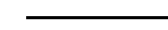

b.

\begin{tabular}{|l|}
\hline$\$ 10$ \\
\hline$\$ 10$ \\
\hline$\$ 10$ \\
\hline$\$ 10$ \\
\hline$\$ 10$ \\
\hline$\$ 1$ \\
\hline$\$ 1$ \\
\hline
\end{tabular}

b. c.

c.

\begin{tabular}{|l|l|}
\hline$\$ 1$ & $\$ 100$ \\
\hline$\$ 1$ & $\$ 100$ \\
\hline$\$ 1$ & $\$ 100$ \\
\hline$\$ 1$ & $\$ 100$ \\
\hline$\$ 1$ & $\$ 100$ \\
\hline
\end{tabular}

d. Anote una forma en que usted puede saltar-contando por decenas y centenares de 150 hasta 410.

5. Compare.
a. $456 \bigcirc 465$
b. 10 decenas $\bigcirc 99$
c. $60+800 \bigcirc$ Ochocientos dieciséis
d. 23 decenas 7 unidades $\bigcirc 237$
e. $50+9+600 \bigcirc 9$ unidades 65 decenas

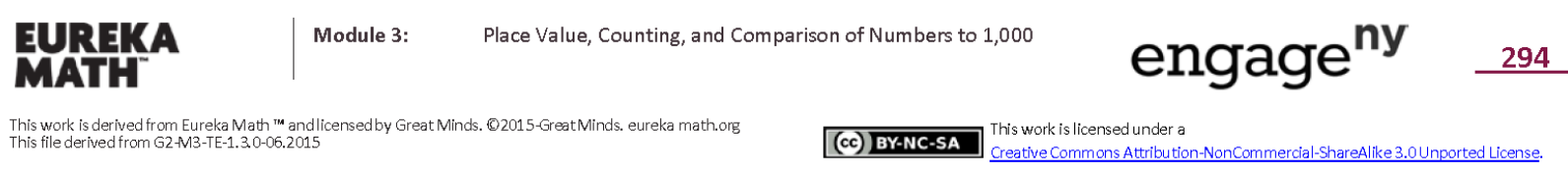




\section{Appendix K: IRB Protocol}

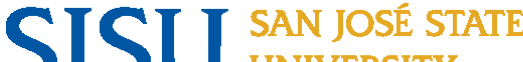 $\$ \cup$ UNIVERSITY}

Office of Research
Division of
Academic Affairs
San José State University One Washington Square

San José, CA 95192-0025
TEL: 408-924-2272

officeofresearch@sjsu.edu sjsu.edu/research

SAN JOSE STATE UNIVERSITY

HUMAN SUBJECTS INSTITUTIONAL REVIEW BOARD

IRB Notice of Approval

Date of Approval: 10/28/2019

Study Title: The Impact of the Language of Instruction on Second Grade Latinx Emergent Bilingual Students' Understanding of Place Value and the Patterns of Communication around This Topic in Transitional Spanish-English Bilingual Classrooms

Primary Investigator(s): Dr. Cheryl Roddick

Student(s): Angela Rengifo Schlindwein

Other SJSU Team Members:

Funding Source: None

IRB Protocol Tracking Number: S19120

Type of Review

$\square$ Exempt Registration: Category of approval §46.104(d)(1)

$\square$ Expedited Review: Category of approval $\$ 46.110(a) 0$

Full Review

Modifications

$\square$ Continuing Review

\section{Special Conditions}

$\square$ Waiver of signed consent approved

Waiver of some or all elements of informed consent approved

Risk determination for device:

Other:

\section{Continuing Review}

$\square$ Is not required. Principal Investigator must file a status report with the Office of Research one year from the approval date on this notice to communicate whether the research activity is ongoing. Failure to file a status report will result in closure of the protocol and destruction of the protocol file after three years. 
Is required. An annual continuing review renewal application must be submitted to the Office of Research one year from the approval date on this notice. No human subjects research can occur after this date without continuing review and approval.

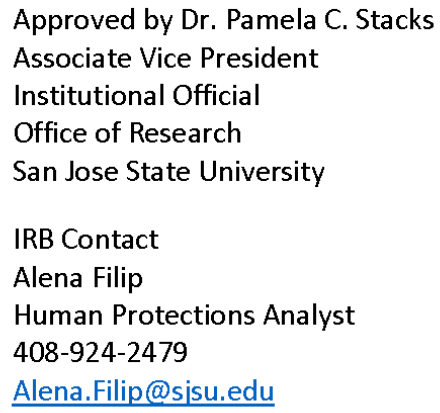

\section{Primary Investigator Responsibilities}

- Any significant changes to the research must be submitted for review and approval prior to the implementation of the changes.

- Reports of unanticipated problems, injuries, or adverse events involving risks to participants must be submitted to the IRB within seven calendar days of the primary investigator's knowledge of the event.

- If the continuing review section of this notice indicates that continuing review is required, a request for continuing review must be submitted prior to the date the provided. 


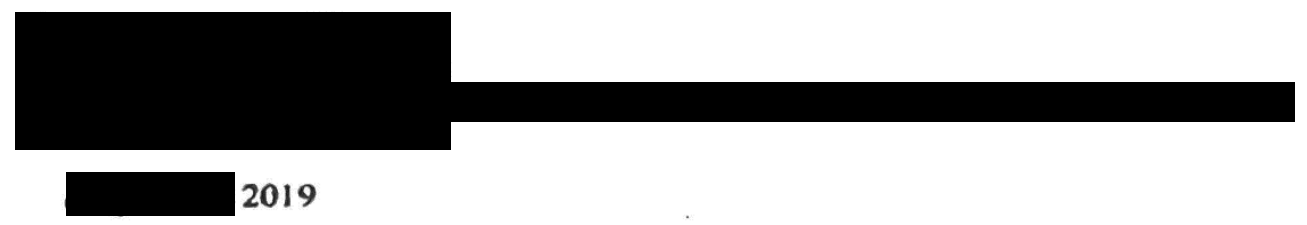

Dear Mrs. Schlindwein:

I am writing to support your research on the impact of the language of instruction in second grade Latinx Emergent Bilinguals' understanding of place value and the communication patterns they use for mathematics collaboration in Spanish-English bilingual classrooms in two bilingual schools in our district.

You have explained to me the details of your research, and according to that, you plan to interview our second-grade bilingual teacher and students in two different bilingual schools. The interviews with students will not affect instruction times as they will be conducted after school hours on an appointment basis. You also plan to videotape small group conversations around mathematical concepts related to place value. I have reviewed the parents' consent, and after talking to the principals of the schools involved in the study, I approve the conditions of the study.

I believe the conclusions of the study will provide teachers and administrators with valuable research-based information to guide decisions regarding the language of instruction to teach mathematics in Spanish-English bilingual classrooms. I am hopeful that after your study concludes, you would be willing to share your findings with our school and district for the benefit of all our bilingual students.

Should you need any further support or advice through this process, please do not hesitate to contact me via email or phone at extension Thank you!

\section{Sincerely,}

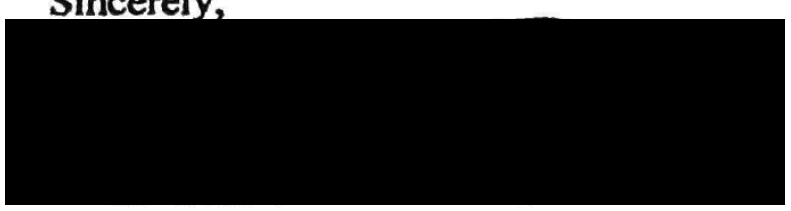

\section{Educational Services Division}

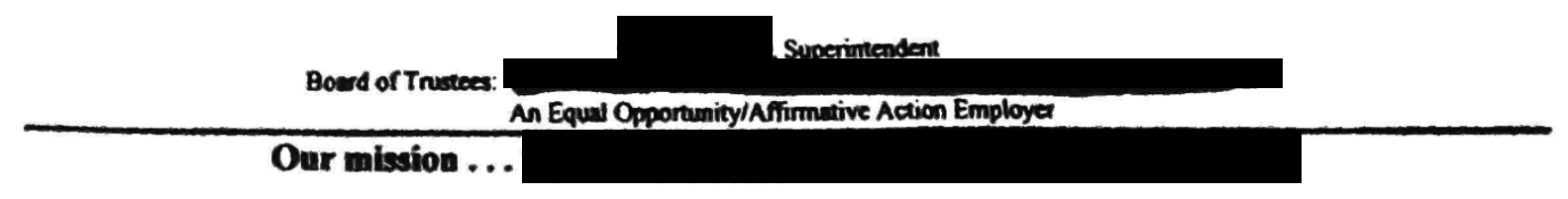




\title{
Appendix M: Verification of Translation Form
}

\section{San lose State University Human Subjects-Institutional Review Board VEAIFICATION OF TRANSLATION ACCURACY FORM}

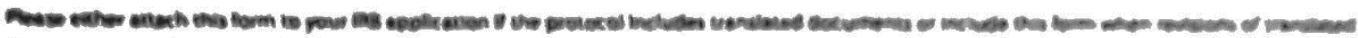

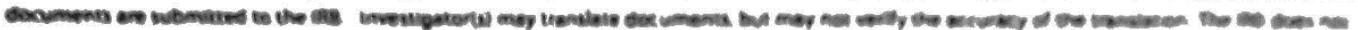

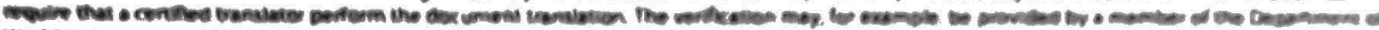

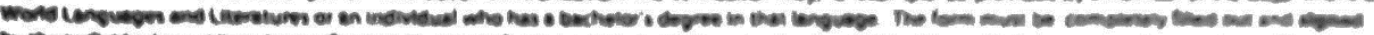

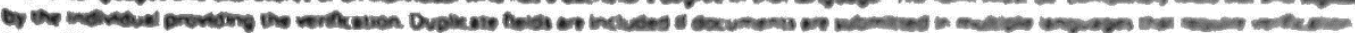

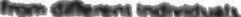

\begin{abstract}
Name of unvestigator(a)
Angela Rengifo Schindwein

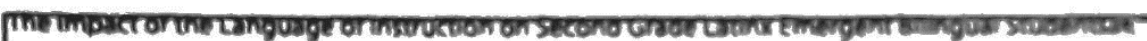

Thte of Proposed Project: Understanding of Place Value and The Communication Patteuns Around This Concept in Two Soansh-inglish Balinoual Classooms in a District in Northern Callornta

RB Tracking Number of already assigned by (RB):
\end{abstract}

Name of Vertying individuat

Language: Spanish and English

Phone Number.

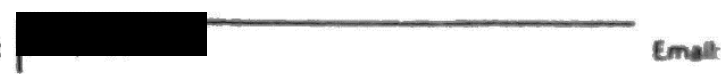

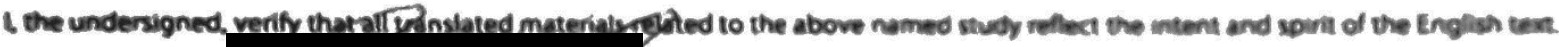

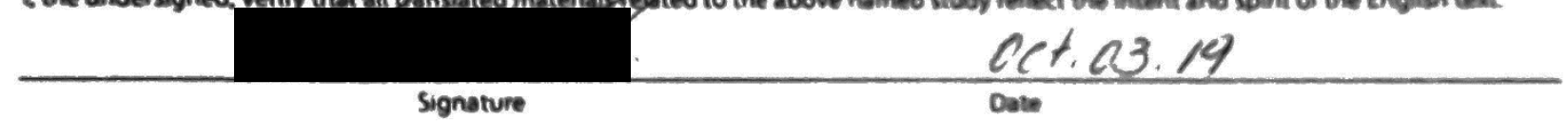

Name of Veribying individual:

Language Spanish and English

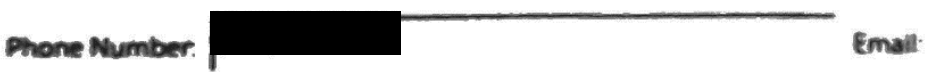

L the undersigned, verify that all translated materials related to the above named study reflect the intent and spirit of the English tex.

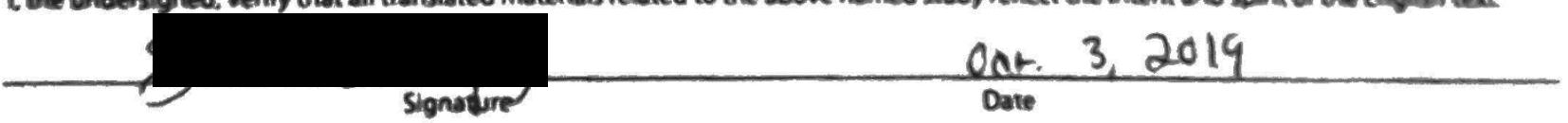

Name of Verbyng individuat:

unguage Fanish and English

Thane Kumber. Emat

1. the undenioned, venh that all tanslated materials retated to the cbove named study reflect the intent and spita of the Engish tera.

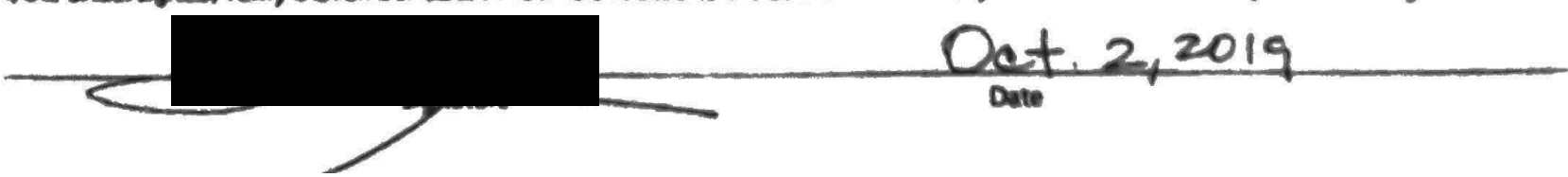

